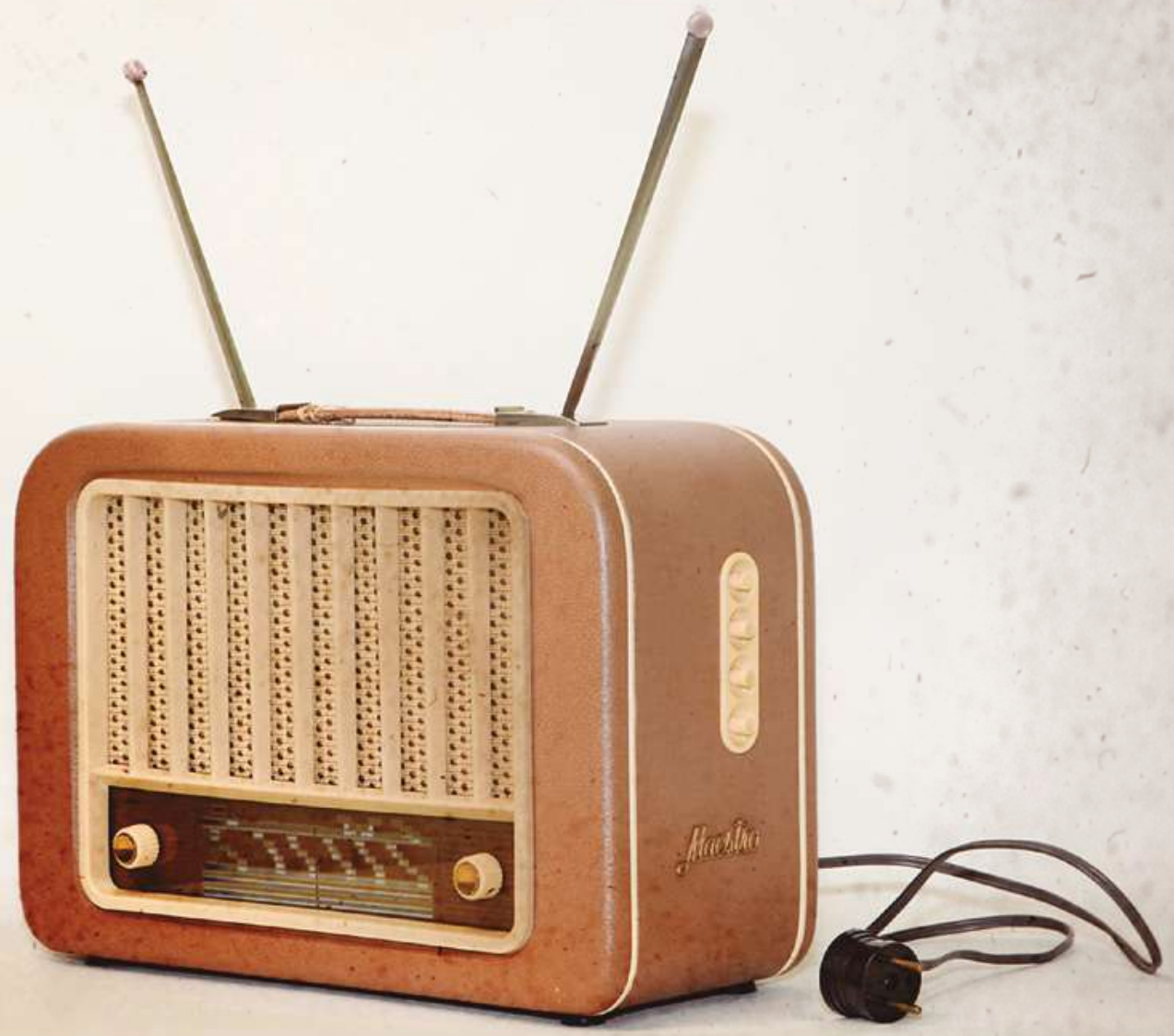

José Arturo Rojas Martínez

\title{
RADIO SUTATENZA Y ACCIÓN CULTURAL POPULAR (ACPO)
}

Los medios de comunicación para la educación del campesino colombiano 


\section{RADIO SUTATENZA Y ACCIÓN CULTURAL POPULAR (ACPO)}

Los medios de comunicación para

la educación del campesino colombiano

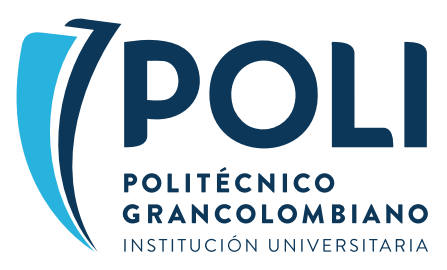




\section{POLI \\ POLITÉCNICO \\ GRANCOLOMBIANO \\ INSTITUCIÓN UNIVERSITARIA}

() Institución Universitaria Politécnico Grancolombiano

\section{RADIO SUTATENZA Y ACCIÓN CULTURAL POPULAR}

Los medios de comunicación para la educación

del campesino colombiano

ISBN: 978-958-5544-44-4

E-ISBN: 978-958-5544-45-1

Digital ISBN: 978-958-5544-46-8

Editorial Politécnico Grancolombiano

Calle 61 No. 7 - 66

Tel: 7455555, Ext. 1516

Bogotá, Colombia

Autor:

José Arturo Rojas Martínez

\section{Líder de publicaciones:}

Eduardo Norman Acevedo

\section{Analista de producción editorial}

Carlos Eduardo Daza Orozco

\section{Corrección de estilo:}

Hernán Dario Cadena

\section{Diseño y Producción Gráfica:}

Nelson Rocha Sánchez

\section{Foto Portada:}

Museokeskus Vapriikki

Tomada de Flickr y modificada

\section{Impresión:}

Xpress Estudio Gráfico y Digital S.A.

\section{¿Cómo citar este libro?}

Rojas Martínez, JA. (2019). Radio sutatenza y acción cultural popular: Los medios de comunicación para la educación del campesino colombiano. Bogotá: Institución Universitaria Politécnico Grancolombiano.

Creado en Colombia

Todos los derechos reservados

No se permite la reproducción total o parcial de esta obra, ni su incorporación a un sistema informático, ni su tratamiento en cualquier forma o medio existentes o por existir, sin el permiso previo y por escrito de la Editorial de la Institución Universitaria Politécnico Grancolombiano.

Para usos académicos y científicos, la Institución Universitaria Politécnico Grancolombiano accede al licenciamiento Creative Commons del contenido de la obra con: Atribución - No comercial - Sin derivar - Compartir igual.

El contenido de esta publicación se puede citar o reproducir con propósitos académicos siempre y cuando se indique la fuente o procedencia.

Las opiniones expresadas son responsabilidad exclusiva del autor(es) y no constituye una postura institucional al respecto.

Este libro es resultado de un proceso de investigación y ha sido evaluado por pares ciegos cumpliendo con los criterios de selectividad, temporalidad, normalidad y disponibilidad propuestos por Ministerio de Ciencia, Tecnología e Innovación.

La Editorial del Politécnico Grancolombiano pertenece a la Asociación de Editoriales Universitarias de Colombia (ASEUC). 
José Arturo Rojas Martínez

\title{
RADIO SUTATENZA Y ACCIÓN CULTURAL POPULAR (ACPO)
}

\author{
Los medios de comunicación para \\ la educación del campesino colombiano
}


Este trabajo está dedicado a mi familia, sin duda son el apoyo incondicional para alcanzar los éxitos y superar los obstáculos.

Un agradecimiento a todos los amigos que fueron cómplices para sacar adelante esta investigación, algunos con aportes y otros con voces de aliento y esperanza.

Y una mención especial para las familias campesinas de Colombia, que han sufrido como nadie la violencia, pero siguen de pie protegiendo y cultivando la tierra. Ellos son inspiración. 



\section{Tabla de Contenido}

I. ORIGEN DE RADIO SUTATENZA Y ACCIÓN CULTURAL POPULAR .....................14

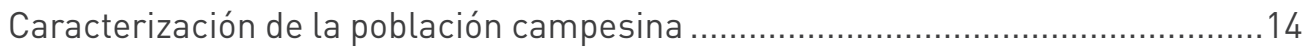

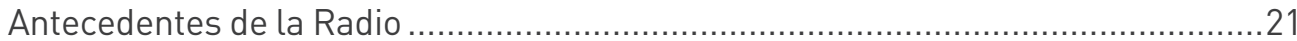

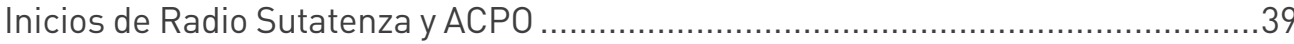

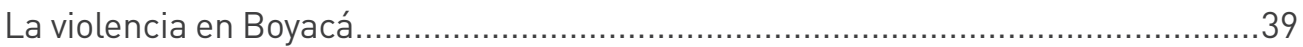

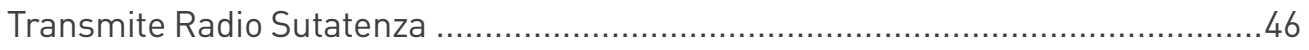

\section{ACCIÓN CULTURAL POPULAR Y LA EDUCACIÓN}

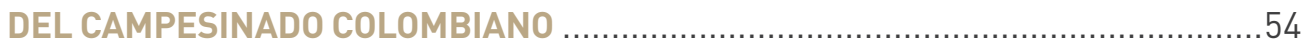

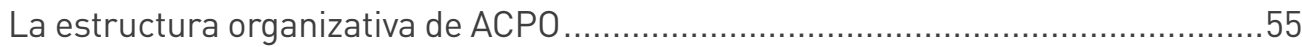

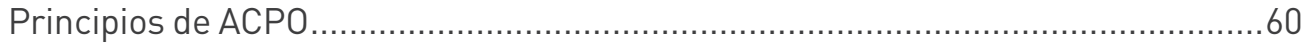

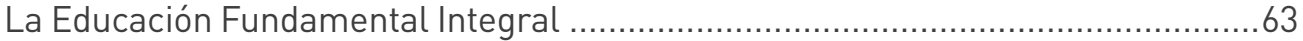

Las nociones de la Educación Fundamental Integral ........................................... 71

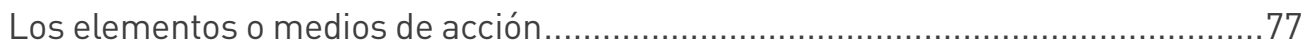

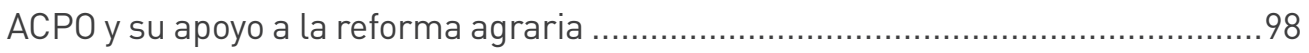

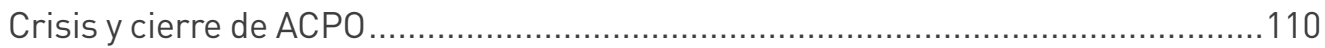

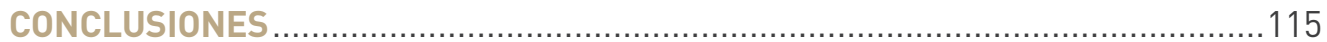

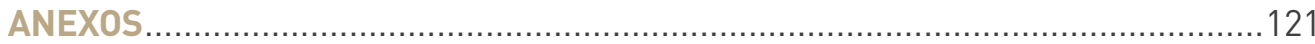

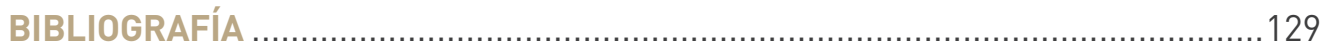





\section{INTRODUCCIÓN}

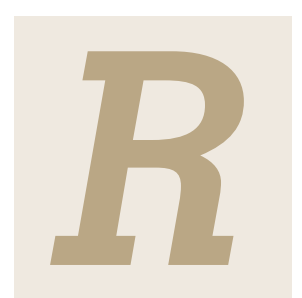

adio Sutatenza, la emisora creada en 1947 por el padre José Joaquín Salcedo, se convirtió a través de los años en la más importante experiencia radial de la Iglesia Católica. Los primeros campesinos que recibieron los beneficios de la educación radial fueron aquellos que habitaban la región del Valle de Tenza en el departamento de Boyacá. Por medio de la radio, Salcedo inició un proceso de alfabetización del campesinado con el objetivo de que aquellos hombres y mujeres mayores, que habitaban las zonas alejadas de los centros de estudios, pudieran acceder a diferentes conocimientos y lograran tener mayores oportunidades para mejorar sus condiciones de vida y para buscar el desarrollo de sus comunidades.

Aunque los primeros años de funcionamiento de Radio Sutatenza estuvieron enmarcados dentro de un proceso fundamentalmente empírico, con el tiempo se fueron creando unas estrategias y mecanismos que permitieron educar, con sentido cristiano, a un buen número de campesinos en Colombia. Con esa primera emisora, que era básicamente artesanal y desde el pequeño municipio de Sutatenza, se empezó una obra educativa que en pocos años se organizó mediante una institución que recibió el nombre de Acción Cultural Popular, más conocida como ACPO.

Acción Cultural Popular fue la organización que integró otros medios de comunicación en una estrategia educativa denominada Educación Fundamental Integral. Este fue el modelo que determinó la enseñanza de los diferentes conocimientos impartidos a través de la radio. 
Las Escuelas Radiofónicas, -conformadas por personas que se encontraban para escuchar las clases por la radio-, la Radio Sutatenza, y la Educación Fundamental Integral, llevaron a las comunidades campesinas a que se involucraran en un sistema cotidiano de educación no formal. La filosofía que inspiró esta estrategia educativa fue la del desarrollo integral, entendido este como la necesidad de vincular a grupos marginados en procesos de participación popular y de diálogo, lo que les permitiría ser protagonistas en instancias económicas, sociales y políticas, y así ser generadores de condiciones propicias para mejorar su calidad de vida.

La educación radial, por medio de las Escuelas Radiofónicas, consistió en la conformación de grupos de personas en las veredas a las que llegaba la señal de radio, para que escucharan clases emitidas por este medio. Estos grupos contaban con la colaboración de un auxiliar que les ayudaba en las explicaciones y en las tareas. La figura de auxiliar se fue convirtiendo en una de vital importancia, pues se entendió que cumplía un papel de liderazgo en la comunidad, razón por la cual los campesinos que participaron en el proceso accedieron a una formación de líderes en institutos creados especialmente para ello.

De esta manera, Radio Sutatenza no solo se transformó en un medio importante para la formación del campesinado en materias como el alfabeto, los números, la salud o la agricultura, entre otras, sino que llevó a cabo una formación que invitaba al hombre, a la mujer, a los niños y en general al campesinado, a trabajar tanto colectiva como individualmente por su propio desarrollo y a tomar las decisiones pertinentes para la vida diaria. Radio Sutatenza instruyó al campesinado para que pudiera superar la marginalidad y la pasividad, convirtiéndolo en sujeto social activo en su comunidad.

Acción Cultural Popular se creó en momentos en que el comunismo estaba en auge y que para muchos se convirtió en una amenaza que podía llegar a América Latina. Por tal motivo, la Iglesia venía trabajando para evitar que el comunismo se instaurara en el continente y llenara espacios que tradicionalmente la Iglesia Católica había ocupado y reivindicado como suyos, especialmente aquellos relacionados con el tema social, con la situación de la clase obrera y con las condiciones de vida del campesinado, entre otros. La Iglesia, desde finales del siglo XIX, ya venía trabajando en el tema y mediante la encíclica Rerum Novarum y la Acción Católica, empezó a desarrollar obras que beneficiaran a las comunidades más desprotegidas. En Colombia, Crisanto Luque, director de la Diócesis de Tunja, realizó trabajos en ese sentido y apoyó constantemente la labor de José Joaquín Salcedo en el municipio de Sutatenza. 
Es importante aclarar que para el año de la puesta en funcionamiento de Radio Sutatenza, la Iglesia ya había apoyado otras obras relacionadas con el tema social. Por ejemplo, se habían promovido sindicatos de obreros y grupos católicos que prestaban servicios asistencialistas y de apoyo a las comunidades menos favorecidas o de escasos recursos. Sin embargo, a excepción de algunos sindicatos campesinos que se intentaron constituir en torno al tema de la tierra, hasta ese momento los proyectos de la Iglesia no vincularon al campesino. La relación de párrocos con el campesinado había consistido en intentar mantener en este una conducta moral "católicamente correcta".

De acuerdo con lo mencionado anteriormente, el periodo de análisis en el segundo capítulo inicia en 1958, fundamentalmente con la fundación del periódico $E l$ Campesino, hasta 1968, año donde se evidencian las últimas acciones desarrolladas por ACPO a favor de la reforma agraria. Este periodo está considerado como la etapa de crecimiento y consolidación de ACPO.

El punto de partida de esta monografía está determinado principalmente desde la puesta en funcionamiento de la primera emisora de Radio Sutatenza hasta la constitución legal de Acción Cultural Popular como una institución con personería jurídica y reconocimiento eclesiástico, es decir, entre los años de 1947 y 1952. Sin embargo, el primer capítulo aborda algunas etapas relacionadas con la infancia y formación de Salcedo que incidieron en la idea de fundar una emisora con la cual educar al campesinado. De la misma manera, este capítulo hace una mirada de la situación de violencia vivida por los campesinos de Colombia, y en especial de Boyacá, y el papel del clero católico en un momento tan convulsionado del país.

Debido a que Acción Cultural Popular fundamentalmente inicia como un proyecto radial, en el primer capítulo se hace un recorrido de los primeros años de la radio en Colombia y su importancia en aspectos bélicos, como el conflicto entre Colombia y Perú, o en aspectos culturales como la idea de generar un proyecto de consolidación de identidad del colombiano mediante la emisión de programas radiales.

El segundo capítulo explica cómo se fundó Acción Cultural Popular, cuál fue su estructura organizativa y cómo empezaron a aparecer otros medios que fortalecieron la educación de los campesinos. La primera parte de este capítulo muestra la lógica administrativa de ACPO y la relación, en este sentido, con la Iglesia Católica. La organización de la institución, a pesar de algunos cambios 
generales por el crecimiento de la misma, conservó una estructura vertical y dependiente de un Consejo Superior conformado por miembros de la Iglesia.

Una segunda parte de este capítulo hace el análisis de la Educación Fundamental Integral, que fue el modelo utilizado por Acción Cultural Popular para la búsqueda del desarrollo del pueblo campesino. Este modelo abordó varias áreas de conocimiento que ACPO consideró necesarias e indispensables para que los campesinos tuvieran una formación integral, es decir, una educación que abarcara todos los espacios de su vida pública y privada. Además, explica cuáles fueron esas áreas trabajadas, llamadas en el modelo de la Educación Fundamental Integral como nociones. También muestra la capacidad de ACPO para integrar varios medios de comunicación para la enseñanza. Así se fue consolidando una institución y un modelo que utilizó la radio, la prensa, los afiches, los libros y las cartillas, entre otros medios, como instrumentos compartidos e integrados para el aprendizaje.

Una tercera y última parte de este capítulo tiene relación con el papel que desempeñó Acción Cultural Popular para impulsar y apoyar una reforma agraria que beneficiara al campesinado colombiano, especialmente la reforma que fue aprobada bajo el gobierno de Alberto Lleras Camargo en el año de 1961. Para este año, el semanario El Campesino, uno de los medios de ACPO, ya llevaba tres años de circulación y durante ese tiempo realizó una constante campaña de apoyo a la reforma agraria y de presión a la clase política para que la aprobara y para que se tuviera en cuenta que esa reforma no implicaba única y exclusivamente la entrega de tierras. El periódico El Campesino cumplió una importante labor y fue un componente sobresaliente en la Educación Fundamental Integral. El semanario fue complemento del trabajo de las Escuelas Radiofónicas, pues por medio de él se les llevaba a los campesinos los horarios de las clases, las actividades a desarrollar y se publicaban las inquietudes de los estudiantes.

Esta última parte del capítulo permite observar y analizar el papel que desempeñó Radio Sutatenza y Acción Cultural Popular en la conformación de grupos y liderazgos mediante la Educación Fundamental Integral. Es claro que la reforma agraria no fue ejecutada cabalmente y solo se hicieron unos tímidos intentos por aplicar la ley, sin embargo, ACPO, con este y otros procesos, consiguió cambiar la vida del campesino y permitió que se insertara a proyectos colectivos y participativos. 
El problema que esta monografía aborda está enmarcado en la apuesta que hizo la Iglesia para alfabetizar a un campesinado que había estado aislado de los sectores de poder, ignorante por su falta de acceso a la educación y con carencias en diferentes ámbitos, que no le permitían ser un sujeto social con capacidad de decisión de su propio futuro. La intención de la Iglesia Católica era trabajar con el campesino para mantener dentro de ella a una población que podía ser afectada por nuevas ideologías como el comunismo.

La Iglesia Católica abordó activamente, por medio del Proyecto de Acción Cultural Popular, un nuevo escenario para la educación. Si bien la Iglesia ya tenía una amplia experiencia en la administración y manejo de colegios, los estudiantes de Radio Sutatenza eran diferentes a aquellos que ingresaban en los colegios tradicionales. Entonces, el proyecto educativo de Acción Cultural Popular fue una iniciativa que se constituyó con una población educativamente inexplorada, pero vinculada con la Iglesia por medio de los párrocos de los diferentes municipios del país. Incluye este problema de investigación entender cómo se construyó el sistema de medios que permitió transmitir conceptos a los campesinos con instrumentos diferentes a los tradicionales.

A partir del problema, se plantea en esta monografía la hipótesis de que Radio Sutatenza y Acción Cultural Popular fueron unas iniciativas que lograron formar académicamente en diferentes áreas a una gran cantidad de campesinos colombianos y permitieron que se consolidara una cultura diferente, donde el campesino pasó de ser un sujeto pasivo a un sujeto que participaba en acciones para el mejoramiento de su calidad de vida. Un ejemplo de ello fue la participación de la población campesina, a través de los medios de comunicación de ACPO, en la búsqueda de una reforma agraria justa y equitativa. ACPO fue una iniciativa de Acción Social que, a pesar de tener un origen en los valores tradicionales de la Iglesia Católica, utilizó nuevos medios de comunicación para el desarrollo de los pobres y de los más necesitados.

Para entender la situación del campesinado en Colombia y en Boyacá, se abordó las investigaciones de Orlando Fals Borda, El Hombre y la Tierra en Boyacá y a Gustavo Pérez, con El Campesinado Colombiano, un problema de estructura. La primera es una investigación sociológica de Boyacá. Es una radiografía de cómo era la sociedad rural del departamento de Boyacá. El autor hace un estudio de la primera mitad del siglo $X X$, tomando como muestra algunos municipios del departamento. El segundo trabajo apunta, en general, a la situación de las estructuras económicas agrarias y el papel 
desempeñado por el campesino en ellas; igualmente, muestra un análisis de las condiciones económicas, geográficas, demográficas y de movilidad del campesino colombiano.

Sobre el papel de los medios de comunicación en la Iglesia, una buena parte de las investigaciones están enfocadas en los aspectos políticos e institucionales de la relación entre la Iglesia y el Estado. Del mismo modo, hay unos acercamientos hacia el análisis de proyectos sociales de la Acción Social, sin embargo, específicamente sobre los medios de comunicación aún queda bastante camino por explorar.

Frente al tema de la Iglesia Católica y los medios de comunicación, Ricardo Arias elaboró dos trabajos que en algunos de sus capítulos abordaron la temática de la prensa católica. De una parte, en Los Leopardo, una historia intelectual de los años 1920, analiza cómo los intelectuales católicos del momento utilizaron el diario El Debate como un medio para fortalecer su identidad. Un periódico que mantenía en sus líneas una posición antiliberal y una férrea defensa de las ideas conservadoras y católicas. Según Arias, este periódico fue considerado como católico por su organización, por el equipo que hacía parte del medio de comunicación y por la publicación de noticias relacionadas con diferentes asuntos religiosos. El Debate mostró el interés del clero para hacer parte de una empresa periodística "creando un diario, financiándolo y brindándole su apoyo"1

Por otra parte, en Episcopado Colombiano: Intransigencia y laicidad 11850 2000), Ricardo Arias, trabaja con el periódico El Catolicismo para analizar el papel que este medio tuvo en la promoción de las orientaciones conciliares. Aunque el autor utiliza este medio como una fuente de su trabajo histórico, profundiza en él a partir de la década de 1960, cuando la Iglesia Católica latinoamericana da muestras de tener un interés mayor por la cuestión social, interés que -como lo menciona el autor- "constituye un claro cuestionamiento a las posiciones de catolicismo integral e intransigentes" 2 . Es claro que dentro de los objetivos del trabajo de Ricardo Arias no está el de hacer un examen riguroso de los medios de comunicación de la Iglesia Católica, sin embargo, muestra algunas etapas donde la prensa católica tuvo protagonismo especial en la divulgación de diferentes posiciones de la Iglesia.

1. ARIAS, Ricardo. Los Leopardos, una historia intelectual de los años 1920, Bogotá, Uniandes, 2007, p. 232.

2. ARIAS, Ricardo. Episcopado Colombiano: Intransigencia y laicidad (1850 - 2000), Bogotá, Uniandes, 2003 p. 191. 
Una lectura sobre las relaciones de la Iglesia, especialmente entre los párrocos y los fieles, fue el estudio que realizó Gustavo Jiménez, titulado Sacerdote y cambio social. Este trabajo permitió ver mediante encuestas y entrevistas realizadas a párrocos, laicos y fieles, cómo se concibe la labor del sacerdote en sectores agrarios del país. Para Jiménez, el sacerdote es un actor fundamental en la vida política, social y económica del campesino. Además, aunque reconoce el papel desarrollado por instituciones como ACPO, también determina que por lo general el sacerdote orienta su acción hacia la consolidación y mantenimiento del statu quo.

También el investigador y profesor Fernán González ha trabajado el tema de la Iglesia Católica y su influencia en el ámbito político y social. Poderes Enfrentados, Iglesia y Estado en Colombia, es uno de los textos de este investigador, donde refleja el papel de la Iglesia en diferentes momentos históricos, partiendo desde la conquista, y recorriendo la historia política del país desde el siglo XV hasta finales del siglo XX. Este trabajo muestra la presencia activa de la institución eclesiástica en el desarrollo del país. Fernán González estudia los vínculos entre la Iglesia Católica y los partidos políticos. De igual manera, analiza la preocupación de la Iglesia por los problemas del desarrollo y la Acción Social. Este texto deja ver cómo la institución eclesiástica, ante los sucesos de la modernización, idealizó la vida campesina con la intención de que precisamente el habitante del campo no migrara hacia la ciudad ${ }^{3}$.

Otro de los textos escritos por Fernán González, Partidos Políticos y Poder Eclesiástico, estudia el protagonismo social y político de la Iglesia Católica en el siglo XIX, caracterizado por la continua confrontación de los partidos políticos. Este trabajo, aunque no profundiza en el tema de los medios de comunicación de la Iglesia, hace mención de la fundación de los periódicos La Sociedad y La Unidad4. Estos periódicos, que salieron a la luz a principios del siglo XX, estuvieron patrocinados por la Iglesia; el primero, editado con la gestión de la Conferencia Episcopal y el segundo, patrocinado por los padres jesuitas.

Los ensayos de historia política colombiana, en el libro Para leer la política ${ }^{5}$, son otros de los escritos de Fernán González. Allí trabaja diferentes etapas de la vida política del país y la forma como se fue formando una sociedad en torno al bipartidismo existente hasta hace pocos años en el Colombia. Este texto, si bien no está dedicado al papel de la Iglesia Católica en Colombia, como

3. GONZÁLEZ, Fernán. Poderes Enfrentados, Iglesia y Estado en Colombia, Bogotá, Cinep, 1997, p. 390.

4. GONZÁLEZ, Fernán. Partidos políticos y poder eclesiástico, Bogotá, Cinep, 1977, p. 199.

5. GONZÁLEZ, Fernán. Para leer la política, Bogotá, Cinep, 1997, tomo 1, p. 390. 
los mencionados anteriormente, sí deja entrever la relación existente entre la institución eclesiástica y algunos de los sucesos que hacen parte de la vida política del país.

En particular sobre el tema del periodo de la violencia en Colombia, tomamos Los años del olvido, de Javier Guerrero. Este texto muestra el origen de la violencia colombiana de los años treinta, particularmente en las regiones de Boyacá, Santander y Norte de Santander. Guerrero relaciona la participación del Estado, de la Iglesia y de los partidos en esta época, que llevó a la muerte a más de 200 mil personas.

Para contextualizar el tema de la radio, abordamos a Renán Silva y a Hernando Téllez. El primero trabaja en un texto del libro República Liberal, intelectuales y cultura popular, un análisis de cómo la radio llegó a Colombia y se utilizó como instrumento para desarrollar una política cultural en el país. Entre tanto, Téllez, en Cincuenta años de la Radiodifusión en Colombia, hace un recorrido descriptivo del funcionamiento de la radio en el país, de la creación de nuevas emisoras y de la conformación de las cadenas radiales comerciales existentes hasta hoy.

Específicamente, sobre Radio Sutatenza se han desarrollado algunos trabajos que fueron financiados por organizaciones interesadas en el tema comunitario y participativo. Entre estos hay un ejemplo conocido ampliamente: el de la Fundación Rockefeller, que financió el texto Haciendo Olas. Este trabajo realiza un análisis de diferentes experiencias de comunicación desde un enfoque participativo con interés en el cambio social. Esta investigación muestra que América Latina es el continente con mayor número de experiencias de comunicación participativa, donde la radio sirve para el desarrollo de las comunidades. El trabajo describe la primera etapa de Radio Sutatenza como la inspiradora de nuevos procesos comunicativos en diferentes partes del mundo. El texto es un relato de un buen número de experiencias de radio comunitaria y participativa.

Sobre Acción Cultural Popular, hace poco tiempo se publicó un estudio documental que da indicios importantes sobre las causas que determinaron la desaparición de Acción Cultural Popular. Este texto se titula De la realidad a la utopía, y es la descripción de una experiencia colombiana en el área de la educación de adultos campesinos, mediante la radiodifusión. Es un trabajo de Hernando Bernal Alarcón, donde analiza la organización de ACPO desde la perspectiva de Peter Drucker, quien hace una distinción entre las instituciones 
sociales y las organizaciones, destacando que las primeras tienen una mayor estabilidad, pues responden a necesidades que son propias de la sociedad humana, y las segundas son creadas para cumplir unos fines concretos y pueden desaparecer y ser limitadas en el tiempo. El autor de este trabajo da una explicación de las razones por las cuales se dio el ocaso y el fin de Acción Cultural Popular.

Revisando el estado del arte sobre el tema tratado en esta monografía, se puede concluir que aún falta mucho por hacer a la hora de analizar el papel que cumplió Radio Sutatenza como medio para la educación y como medio de la Iglesia para la difusión de los principios católicos. No hay trabajos históricos conocidos que hayan abordado específicamente el tema de los medios de comunicación de la Iglesia Católica. Si bien hay algunas menciones sobre la prensa católica, aún está inexplorado el tema de la radio y, por supuesto, el estudio de otros medios de comunicación utilizados por el clero. Esta monografía se convierte así en una invitación para profundizar en el estudio de Radio Sutatenza y ACPO como problemas históricos fundamentales en la generación de nuevas culturas en el sector rural colombiano.

La mayoría de las fuentes escritas sobre ACPO se encontraron en el municipio de Sutatenza (Boyacá), en unas instalaciones que aún tiene la institución allí; sin embargo, posteriormente los archivos fueron entregados a la Biblioteca Luis Ángel Arango, donde están a disposición del público. Si bien los archivos no estaban catalogados y organizados sistemáticamente en el municipio de Sutatenza, se realizó una revisión de la colección completa del semanario El Campesino, se trabajó con algunos de los informes que ACPO debía enviar a la Conferencia Episcopal y se hizo una selección de cartas enviadas por los estudiantes de las Escuelas Radiofónicas, especialmente aquellas que correspondían a los años de consolidación y auge de Acción Cultural Popular. Por otra parte, se tuvo acceso a varias publicaciones impresas por la Editorial Andes, empresa de Acción Cultural Popular. Estas publicaciones están relacionadas con trabajos desarrollados por la institución en diferentes momentos, especialmente desde finales de la década de 1950. Algunas de estas publicaciones fueron las cartillas que se utilizaban para la enseñanza y los informes de trabajo desarrollados por algunos directivos de ACPO, pero el más importante fue el texto que se imprimió en 1960, titulado Acción Cultural Popular. Sus principios y medios de acción, consideraciones teológicas y sociológicas, de Francisco Houtart y Gustavo Pérez, dos sacerdotes católicos vinculados a ACPO. 
Para explicar lo relacionado con los primeros años de Radio Sutatenza, se revisaron el diario El Tiempo, periódico liberal y de circulación nacional; la Revista Javeriana, editada por la Pontificia Universidad Javeriana, que publicaba información de diversos temas, entre ellos políticos, religiosos, económicos e internacionales; y por último, El Catolicismo, periódico católico colombiano que publicaba, y aún publica, información relacionada con los hechos, acontecimientos y acciones de la Iglesia Católica. 
CAPÍTULO I ORIGEN DE RADIO SUTATENZA Y ACCIÓN CULTURAL POPULAR

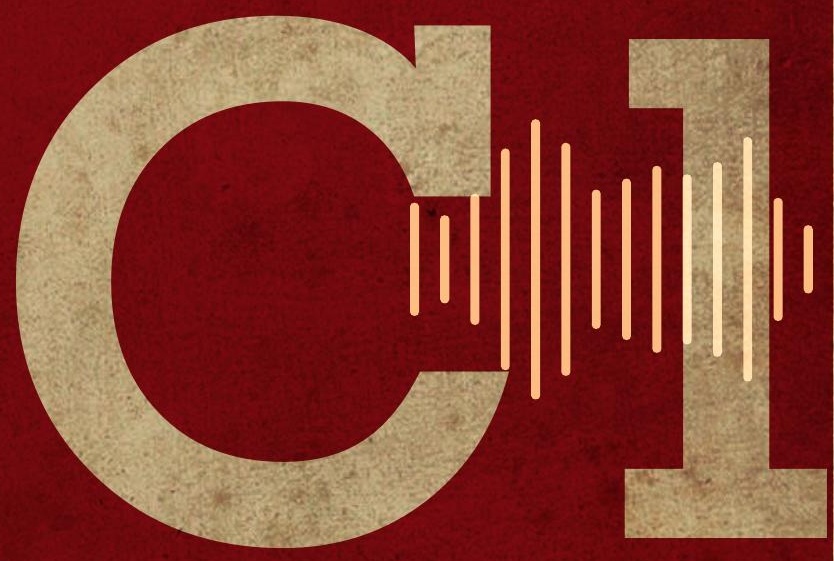




\begin{tabular}{|c|c|c|c|c|c|}
\hline 700 & 300 & 1000 & $200 \quad 14$ & $20 \quad 1600$ & $\mathrm{k}: \mathrm{L}$ \\
\hline 94 & 97 & 100 & 103 & $106 \quad 108$ & yhe \\
\hline 152 & 156 & $161 \%$ & 167 & $171 \quad 174$ & Wali \\
\hline 35 & 38 & 42 & 46 & 50 & thes \\
\hline 470 & 480 & & 500 & 512 & 182 \\
\hline 6 & & & 28 & 29136 & 14: \\
\hline
\end{tabular}
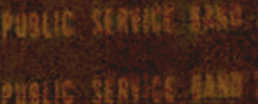

C / BATTERY - SQUELCH CIRCUIT

\section{SQUELCH}

VoLUMA:

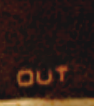

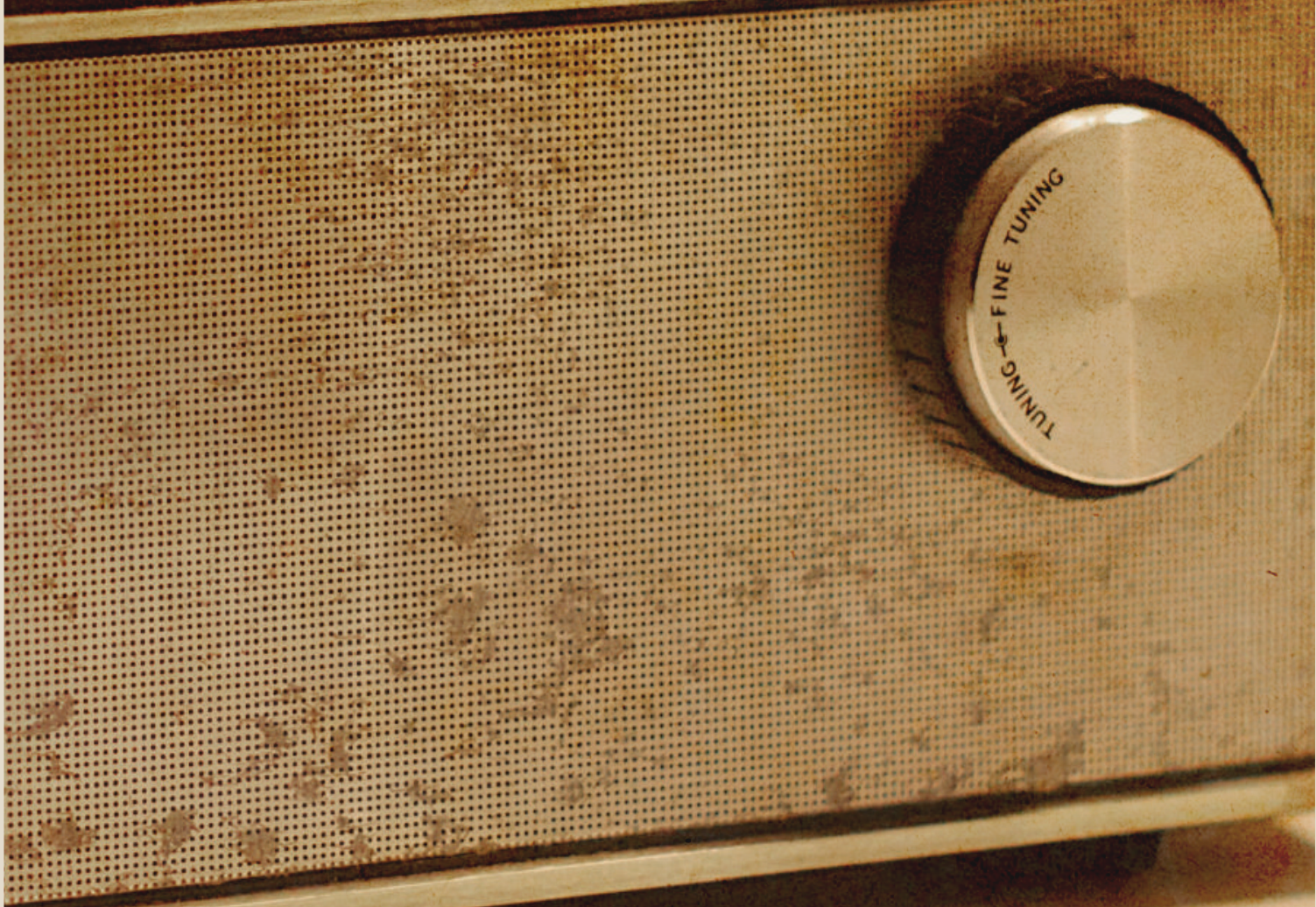

Levine. Fotografía modificad 


\section{ORIGEN DE RADIO SUTATENZA Y ACCIÓN CULTURAL POPULAR}

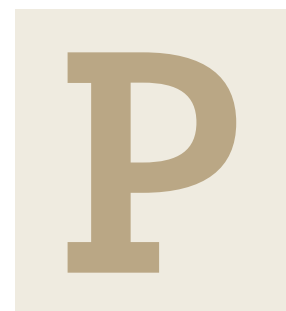
Popular y el trabajo que desarrolló en la institución. Además, deja entrever las relaciones de Salcedo con los políticos del país, con organizaciones internacionales y con la misma Iglesia, en el marco de creación y consolidación de Acción Cultural Popular.

Radio Sutatenza empieza a funcionar bajo un contexto particular que permitió llevar a cabo la novedosa propuesta educativa a través de medios de educación. Las características de ese contexto se enmarcaban en una fuerte presencia de la religión católica en el país, una situación de violencia permanente y el desarrollo de un medio de comunicación como la radio, que había empezado a hacer presencia en Colombia en 1930.

Este capítulo muestra cuál es el origen del proyecto del padre José Joaquín Salcedo, quien utilizó la radio como un medio para la educación campesina en Colombia. Este proyecto se inició en el municipio de Sutatenza, en el departamento de Boyacá, y precisamente de allí adquirió su nombre la emisora que cubrió con su señal buena parte del país. Esta fue un componente de la institución que se creó dos años más tarde, denominada Acción Cultural Popular. 


\section{Caracterización de la población campesina}

Radio Sutatenza empieza a funcionar en 1947, en momentos en que la violencia partidista se presentaba en el país, la pobreza del campesinado era evidente y la clase obrera trabajadora venía creciendo en las ciudades, manifestando su inconformismo por la situación laboral. A partir de los trabajos realizados por sociólogos como Gustavo Pérez y Orlando Fals Borda se hará a continuación una caracterización del campesino colombiano y, en particular, en algunos casos, de los habitantes de las zonas rurales de Boyacá y de la región del Valle de Tenza, precisamente donde se encuentra el municipio de Sutatenza. Allí fue donde inició labores Radio Sutatenza con sus Escuelas Radiofónicas.

El Valle de Tenza es una inmensa depresión formada por los ríos Súnuba y Garagoa, y se subdivide en veredas, como la mayoría de las regiones del país. Dentro de los municipios, estas veredas eran confiadas a un comisario o a un inspector que velaba por el orden en ese territorio. En esta región se encuentra el municipio de Sutatenza, que está ubicado a cinco minutos de Guateque, la capital de la provincia de Oriente Boyacense, que a principios de la década de los años de 1950 contaba con no más de 3.000 habitantes y basaba su economía en la agricultura, las explotaciones pecuarias y la minería.

En los primeros años de Radio Sutatenza, la población colombiana se caracterizaba por habitar mayoritariamente en las zonas rurales y ejercía actividades agrícolas. Para 1951, según el estudio realizado por Gustavo Pérez, el 55,6\% de la población colombiana vivía en caseríos o sitios distantes a las cabeceras municipales. Es decir, más de la mitad de la población colombiana se dedicaba a labores agrícolas.

Debido a la dispersión de las zonas habitacionales, en Boyacá se concentraba sólo el 13,64\% de la población del país. ${ }^{6}$ La falta de medios y vías de comunicación llevó a que las diferentes zonas del país estuvieran aisladas. A pesar de que gran parte de los colombianos habitaba la región Andina (78,4\%), las posibilidades de relación e integración eran muy difíciles. Estas cifras coinciden con la densidad poblacional observada en poblados pertenecientes al Valle de Tenza como Guayatá, que tenía 171 habitantes por kilómetro cuadrado, Guateque 244, Tenza 256 y Sutatenza 98,5 habitantes, siendo el Valle de Tenza el sector de Boyacá con mayor densidad poblacional? .

6. PÉREZ, Gustavo. El Campesinado Colombiano, un problema de estructura. Bogotá, Editorial Iqueima, 1959. p. 39

7. FALS, Orlando. El Hombre y la Tierra en Boyacá, 4ta ed., Tunja, UPTC, 2006, p.244 
El crecimiento de la densidad poblacional se encontraba para el año de 1954 en un $2,2 \%$. A pesar de no ser demasiado alto, este comprometía el nivel de empleos e ingresos de la población, empeorando las condiciones de vida de los colombianos. Para la década de los años de 1950, en el país las familias estaban compuestas por 5,7\% miembros. En Boyacá, de acuerdo con el estudio Estructuras demográficas y sociales de Colombia, las familias eran de aproximadamente cuatro personas ${ }^{8}$. En esta cifra coincide Orlando Fals Borda en la investigación desarrollada sobre los Campesinos de los Andes?. El número de miembros por familia era alto, de acuerdo con los niveles de ingresos obtenidos por los habitantes del departamento, especialmente en el sector rural.

Gustavo Pérez afirma: "la sobreoferta de la mano de obra provoca un estado de subempleo, de empleo simulado, que entraña un despilfarro de las fuerzas de trabajo y un empleo abusivo de la mano de obra", que por supuesto implicaba una disminución en los salarios de los campesinos.

Específicamente en Boyacá, los ingresos entre 1950 y 1954, según el Anuario General de Estadística, fueron para los hombres de 2,41 pesos y para las mujeres de 1,74 pesos. Estos salarios eran unos de los más bajos del país, estando solo por debajo los del departamento del Atlántico y de Nariño. El más alto correspondía al departamento del Tolima, con 4,03 pesos para los hombres y 2,43 pesos para las mujeres. Pérez evidencia que en aquellas zonas donde los salarios eran menores, también era donde se presentaba mayor presencia de la mujer trabajadora. Sin embargo, el porcentaje nacional fue realmente bajo, alcanzando solo el 4,5\%. Las condiciones laborales de las mujeres eran aún más precarias que la de los hombres.

Esta situación se vio agravada por la falta de formación de la población campesina. Pérez evidencia que los niños y niñas del campo escasamente alcanzaban a cursar entre el primer y segundo grado de primaria, para posteriormente retirarse de las aulas y dedicarse a las labores agrícolas junto con sus padres.

Como se comentó inicialmente, las familias campesinas, por lo general, vivían aisladas y desconfiaban de toda organización. Las condiciones sociológicas del campesino colombiano, según Pérez, llevaron a que se caracterizara por ser un individuo fundamentalmente individualista. Esta situación permitió que

8. DE LANNOY, Juan y PÉREZ, Gustavo. Estructuras demográficas y sociales en Colombia. Bogotá, Centro de Investigaciones Sociales, p. 158

9. FALS, Orlando. Campesinos de los Andes. Bogotá, Universidad Nacional, 1961. p. 242. 
se mantuvieran las discriminaciones y los bajos salarios. El aislamiento del campesinado, escasamente se veía interrumpido cuando acudía, como comenta Fals Borda, a la iglesia, al mercado o a las tiendas, que eran los puntos de encuentro de las comunidades. ${ }^{10}$

Se puede observar que las zonas del país donde se cultivaban productos como el café ofrecían un mayor ingreso a los campesinos. Igualmente, esas zonas tenían unas migraciones constantes, mientras que las zonas dedicadas más al cultivo de productos de autoconsumo no recibían mayor cantidad de población de otros departamentos. Boyacá fue, en este sentido, una de las zonas que mantenía gran población autóctona, el 96,7\% de los habitantes eran agricultores de la misma región"1. Al respecto, Orlando Fals Borda menciona que "esta tremenda exclusividad

del boyacense ha sido tradicional. Es un hecho al cual se le debe brindar gran significado sociológico: al cerrar sus puertas a los que llevan culturas foráneas, Boyacá, así como hasta cierto punto Colombia toda, ha mantenido una civilización provinciana que en muchos aspectos ha quedado rezagada"12.

Las precarias condiciones económicas del campesino y el pobre poder adquisitivo producían deficiencias en la alimentación, en las condiciones de la salud, de la cultura y del trabajo. Las carencias en diferentes aspectos condicionaban los rendimientos en el trabajo; entre menor era la calidad de vida, también eran menores las posibilidades de hacer un buen trabajo. Era un círculo que mantenía al campesino con pocas posibilidades de mejorar su situación.

Gustavo Pérez, en su investigación caracterizó también las condiciones de las casas rurales; en este sentido determinó que las estructuras habitacionales contaban, en general, con una sola alcoba de una superficie de 4 metros cuadrados. Las casas tenían unos 20 metros cuadrados y eran construidas en adobe, tierra pisada, guadua o bahareque. Los techos eran de paja o de madera. “En general, la casa campesina carece de muebles. No hay armarios, sino baúles o cajas que sirven al mismo tiempo de asientos"13. Pérez agrega que es notoria la falta de iluminación y además que se duerme con la ropa

10. FALS, Orlando. El Hombre y la Tierra ... p. 201.

11. La fuente utilizada por Pérez fue el Censo de 1951, donde discrimina la población por lugar de nacimiento, actividad económica y sexo.

12. FALS, Orlando. El Hombre y la Tierra... p.44

13. PÉREZ, Gustavo. El Campesinado Colombiano... p. 110 
de trabajo, ya sea en hamacas o bancos que sirven de cama. Adicionalmente, carecían de servicios higiénicos, agua potable y electricidad. ${ }^{14}$

En cuanto a la alimentación, el estudio determinó que el campesino colombiano consumía suficientes calorías, pero era deficiente en proteínas, grasas, calcio, fósforo y vitamina A. En zonas frías como las de Boyacá, el consumo generalmente era de papa, habas, maíz y trigo. El consumo de carne a nivel nacional era significativamente bajo, llegando a entre 20 y $25 \mathrm{~kg}$. por persona. Según el análisis desarrollado por Gustavo Pérez, la falta de vías de acceso y de transporte adecuado fue una de las causas de la baja producción nacional de alimentos: "No es exagerado ver en este estado de subalimentación y de mala nutrición del pueblo un factor poderoso que contribuye a la deficiencia de la agricultura y especialmente al bajo nivel de rendimiento del trabajador"15.

Una de las características del departamento de Boyacá es que la forma predominante de la tenencia de la tierra era la de propietario con un $77 \%$. Sin embargo, esas extensiones territoriales no eran sino pequeñas propiedades. Específicamente en el municipio de Sutatenza, de un total de 1.588 viviendas, el $86 \%$ estaban habitadas por sus propietarios, mientras que el $10,1 \%$ por arrendatarios. El restante $3,8 \%$ correspondía a otras formas u otros usos. Aunque los minifundios se encuentran en casi todo el departamento de Boyacá, sobresale el Valle de Tenza. "Sutatenza, con una densidad de 98,5 habitantes, es un buen ejemplo de un área de minifundios... Es difícil comprender cómo sobreviven estos agricultores: solo parece que la tierra diera cosechas suficientes como para compensar la falta de espacio. Pero en cambio queda en evidencia por qué los tenzanos son pobres desde varios puntos de vista"16.

Una de las áreas trabajadas por Acción Cultural Popular era la educación, pues consideraba que la situación del campesinado era uno de los grandes problemas nacionales. El porcentaje de analfabetos, de acuerdo con lo mencionado por Pérez, llegaba a 42,4\%. El autor afirma que el analfabetismo en las zonas rurales obedecía a causas socioeconómicas e históricas. En general, los niños campesinos colaboraban en las labores de la cosecha y las niñas en los quehaceres del hogar, por lo que su asistencia a clase no era continua. Fals Borda resalta que en Boyacá

14. En relaciones con las condiciones habitacionales, Orlando Fals Borda, en el libro El hombre y la Tierra en Boyacá, confirma las características descritas por Gustavo Pérez en cuanto a los materiales usados para su construcción, y los implementos adquiridos y utilizados dentro de las casas.

15. PÉREZ, Gustavo. El Campesinado Colombiano... p. 118.

16. FALS, Orlando. El Hombre y la Tierra... p. 162 
los niveles de analfabetismo son más altos y alcanzan una cifra del $54,4 \%$, uno de los porcentajes más altos del país ${ }^{17}$.

El estudio de Pérez hace mención de la labor cumplida por Acción Cultural Popular. En lo referente a la educación rural colombiana, destaca el papel de las Escuelas Radiofónicas de Sutatenza. "Con muy buena organización y técnica y un sentido patriótico descollante, estas Escuelas buscan llegar al campesino en su aislamiento. No solo tratan de alfabetizarlo, sino de darle cultura general con pautas para el laboreo de la tierra, el mejoramiento del hogar y la elevación de su estándar de vida"18.

Tres años después de la publicación del trabajo El Campesino Colombiano, un problema de estructura, Gustavo Pérez, junto con Juan Luis de Lannoy, publicó la investigación sociológica titulada Estructuras demográficas y sociales de Colombia, donde analiza la población colombiana desde diferentes aspectos como su movilidad, su distribución étnica, el aumento en las tasas de crecimiento y la composición de la población. De igual manera, hace un balance y análisis de la evolución, situación y localización de los diferentes grupos sociales del país.

Tal y como se evidenció en la investigación sobre el campesinado colombiano, el crecimiento de la población siguió siendo una preocupación, pues alcanzaba porcentajes hasta del 2,9\%, lo que preveía que en 23 años se duplicara la población del país. Estos niveles de crecimiento poblacional debían ir de la mano de un aumento proporcional en la producción agrícola e industrial que garantizara elevar la calidad de vida.

Del mismo modo, en lo relacionado con la distribución demográfica percibió una dispersión geográfica que tenía como consecuencia desigualdades entre diferentes zonas del país. Desigualdades que se veían reflejadas en los índices de mortalidad infantil, en la natalidad, en el nivel de vida y en la producción económica. Desde esta mirada, el planteamiento de la implementación de una reforma agraria era urgente para los autores. Orlando Fals Borda, en su trabajo El hombre y la Tierra en Boyacá, también señala que la meta principal de la reforma agraria debía ser "el bienestar socio económico que viene con el aumento parsimonioso de la producción, y la superación física y cultural del hombre del campo como elemento indispensable para la prosperidad nacional"19.

17. Ibid., p.48.

18. PÉREZ, Gustavo. El Campesinado Colombiano...pp. 124 y 125.

19. FALS, Orlando. El Hombre y la Tierra... p.235. 
Otra preocupación tenía que ver con las migraciones del campo a la ciudad: el desplazamiento de mujeres, jóvenes y niños a las ciudades ocasionaría nuevos problemas, pues la población económicamente activa de los sectores primarios disminuiría mientras los sectores secundarios y terciarios contarían con mayor mano de obra.

El papel que jugó la Iglesia Católica en ese contexto abarcó el ámbito político, el educativo y el social. De una parte, la lucha política no le era ajena, la Iglesia siempre se mantuvo en relación con el poder y en ese sentido había tomado partido a favor o en contra en muchas ocasiones. Generalmente tuvo coincidencias ideológicas con el partido conservador y contradicciones con el partido liberal. Con este último mantuvo una confrontación mayor cuando el presidente López Pumarejo intentó impulsar un Estado laico, donde existiera separación entre el Estado y la Iglesia, pero con espacios de colaboración entre los dos poderes. Por ejemplo, la Iglesia seguía dirigiendo varios colegios católicos y seguía manteniendo el control sobre el estado civil y la soberanía sobre los territorios donde la Iglesia llevaba a cabo misiones. López, en este sentido, buscó la colaboración del clero con el Estado "ayudándolo a elevar el nivel intelectual y material del pueblo"20. Si bien se quería tener un Estado laico, también se quería mantener la cooperación entre el Estado y la Iglesia.

La educación fue otro escenario donde tuvo presencia la Iglesia Católica. Administraba los centros de educación, donde las enseñanzas incluían una fuerte formación católica. También, mediante proyectos de carácter social, la Iglesia evangelizó e intentó realizar labores que mejoraran las condiciones de vida de los colombianos. Las acciones en este sentido constituyeron, entre otras, la organización de la Juventud Obrera Católica (JOC), en 1933, la organización de sindicatos católicos, las cooperativas locales y el apoyo a asociaciones de caridad.

Durante este periodo, el país se caracterizó por la creciente confrontación partidista que llevó a que los enfrentamientos entre liberales y conservadores se intensificaran. Una de las regiones donde era evidente dicha situación fue precisamente en el departamento de Boyacá, donde José Joaquín Salcedo nació, creció y se formó como sacerdote. El fundador de Radio Sutatenza nació en la población de Corrales, un municipio agrícola de estirpe conservadora donde habitaban sus padres, José Joaquín Salcedo Cujar y Eva María Perry de Salcedo.

20. ARIAS, Ricardo. Episcopado Colombiano: Intransigencia y laicidad (1850 - 2000), Bogotá, Uniandes, 2003 p. 128 
En 1920, un año antes del nacimiento de Salcedo, los cables del telégrafo se empezaron a levantar en este municipio, mejorando así la comunicación entre los habitantes de Boyacá y el sur del país. La administración de los telégrafos en el municipio de Corrales estuvo a cargo de José Joaquín Salcedo Cujar, lo que permitió que su hijo tuviera un constante acercamiento a dicha tecnología y en general a las telecomunicaciones. Al lado de su padre, Salcedo aprendió telegrafía trabajando en la oficina repetidora entre Bogotá, Sogamoso y los Llanos del Casanare.

Sin embargo, este no fue el único adelanto tecnológico que conoció Salcedo en Corrales: hacia 1930 la radio llegó al municipio. Quienes instalaron los equipos se alojaron en la casa de los Salcedo y tenían la misión de ubicar la enorme antena en la Casa Consistorial, e instalar el mueble receptor y los altoparlantes en diferentes lugares de la plaza para que el público escuchara lo que se transmitía ${ }^{21}$.

\section{Antecedentes de la radio}

Los antecedentes de la radio en Colombia datan de los primeros años del siglo XX, especialmente lo que tiene que ver con la puesta en marcha de la Radiodifusora Nacional de Colombia, que oficialmente se inauguró durante el gobierno de Eduardo Santos. ${ }^{22}$ Sin embargo, es importante precisar que la radio como tecnología de información ya había empezado a operar en 1929, cuando el país estaba en el conflicto limítrofe con el Perú. Para ese momento, Miguel Abadía Méndez inauguró la estación de radio HJN que sirvió para “comunicar órdenes militares y para informar a la opinión nacional acerca del desarrollo del conflicto" ${ }^{23}$.

Renán Silva, en el texto República Liberal, Intelectuales y Cultura Popular, plantea que en la primera etapa de la radio en Colombia, es decir, desde la creación de HJN hasta 1946, esta se utilizó como un medio donde estaba presente una idea de "nación de identidad colectiva, de interés general y público" ${ }^{24}$, dentro de una concepción de libertad de información y de creación intelectual. De esta manera,

21. ZALAMEA, Luis. El Quijote Visionario, Bogotá, Jorge Plazas Editor, 1994

22. GÓMEZ, Gabriel y QUINTERO, Juan. Diagnóstico del servicio de radiodifusión de interés público, Bogotá, Ministerio de Comunicaciones, 2003, p. 12

23. SILVA, Renán. Ondas nacionales. La política cultural de la república liberal y la radiodifusora nacional de Colombia. Revista Análisis Político, No. 41, p. 13

24. SILVA, Renán. República Liberal, Intelectuales y Cultura Popular, Medellín, La Carreta Editores, 2005, p. 64. 
la idea planteada hacía parte de la formación de un concepto de cultura que estaba constituida por la construcción de una identidad como nación.

Entonces, la radio no solamente se constituyó como un medio de información, sino como un proyecto cultural al que se le dio un carácter "social" a partir de la reforma constitucional de 1936. Esta identificación con lo social permitió caracterizar la radio como cercana a las políticas populares y a favor del pueblo que defendía el liberalismo, en contraposición a las políticas de élite que privilegiaban los conservadores según sus contradictores. Planteado de esta manera, "en el campo de la cultura, 'social' quería decir con toda precisión que se consideraba la cultura como una fuerza 'activa' y que en la educación popular se encontraba una condición de despegue económico" 25 . Renán Silva complementa que el término "social" también era entendido como el derecho que tenían los ciudadanos de participar y de disfrutar de los bienes culturales de la nación.

De esta manera, la cultura estaba asociada a un proceso educativo que tenía la posibilidad de ser extendido a través de los nuevos medios de comunicación como eran en su momento el cine y la radio. El ministro de educación encargado, Luis López de Mesa, planteó en 1931 que estos dos medios eran unos recursos educativos que podían desplazar los tradicionales métodos de la educación, y que por eso era urgente la necesidad de adaptarse y entender esas novedades e igualmente aprovechar las oportunidades que ofrecían. ${ }^{26}$ Es decir, estos medios podrían ser utilizados dentro de una política cultural como instrumentos que sirvieran para la alfabetización en diversas y remotas regiones.

Por medio del proyecto liberal de Cultura Aldeana, entre 1935 y 1936 se intentó divulgar expresiones de cultura intelectual en las sociedades campesinas. La intención fue mejorar los niveles de lectura y de vida, y aplicar conocimientos técnicos en actividades funcionales en su entorno, pero también favorecer la construcción de una forma coherente y homogénea de vida social, es decir que culturalmente hablando se conformara una comunidad y una nación. Este proyecto de Cultura Aldeana se convirtió así en una primera expresión de educación para los sectores rurales, a partir del uso de medios diferentes a los que habitualmente la Iglesia estaba acostumbrada a manejar en los diferentes centros de enseñanza que administraba.

25. Ibid., p. 67.

26. Ibid., p. 68. 
Posterior a la guerra con el Perú, el gobierno liberal intentó hacer de la radio un medio oficial de comunicación para la educación popular, "dotando a cada escuela pública de un radiorreceptor y un instrumento de integración nacional”27. Se pretendía que la radio se considerara como un servicio del Estado que tuviera como interés principal la divulgación de una programación cultural. Una radio que estuviera por encima de los intereses particulares y comerciales. Renán Silva señala que para Darío Echandía era de primer orden el uso de la radio y el cine como instrumentos para la creación de "una auténtica universidad popular a cuya enseñanza se acoja la totalidad de la población colombiana". Considera Silva que tanto Echandía como López de Mesa fueron dando las pautas para la creación del modelo de la radio cultural y educativa que se proponía el gobierno liberal. Lo que llamaba Echandía la universidad al aire era "el fomento del espíritu nacionalista, la vinculación entre las regiones, el servicio a la industria y a la agricultura, la información veraz sobre el movimiento de precios, y la educación de la mujer, del niño, el estudiante, del maestro y del campesino" 28 .

La HJN, que recibió posteriormente el nombre de Radio Nacional, trasmitía durante ocho horas diarias y su programación estaba conformada por música, noticias científicas, información general y un noticiero donde se daba específicamente información que tenía que ver con las medidas y decisiones tomadas por el gobierno ${ }^{29}$. Entre 1940 y 1948 la Radio Nacional tuvo su “Época de Oro”. Este periodo estuvo caracterizado por ser una fuerte organización radial que contaba con personal calificado, amplia nómina, y además tenía gran capacidad técnica.

El trabajo de Renán Silva muestra que la Radio Nacional fue una fuente de educación cívica al trasmitir información relacionada con las normas electorales y también al emitir programas radiales que daban a conocer la geografía del país con sus diferentes regiones. "La idea era la de favorecer el conocimiento entre las gentes de las distintas regiones respecto de su historia, de sus costumbres y su estado de progreso material" 30 .

Durante esta "etapa de oro", en general, se ampliaron y diversificaron las labores de divulgación oficial y educativa y del mismo modo se amplió el cubrimiento de la Radio Nacional en todo el territorio del país. Hacia 1944 se incorporaron nuevos 
estilos modernos de periodismo radial, como las entrevistas y las conferencias, que se habían convertido en nuevos géneros a partir de la Segunda Guerra Mundial. En general, el éxito durante estos años de la Radio Nacional se dio gracias a la participación decidida de personas que hacían parte del proyecto de la República Liberal y que además apoyaban la idea de extender y fortalecer la formación cultural. Algunos de los reconocidos hombres que participaron en esta etapa de la Radio Nacional fueron Eduardo Caballero Calderón, Hernando Téllez, Eduardo Carranza, Rafael Maya, Bernardo Romero y Jorge Zalamea, entre otros.

Para Renán Silva, existieron unos elementos que favorecieron el avance inicial de la Radio Nacional; ellos fueron, por una parte, las calidades del grupo de colaboradores y, por otra, la Segunda Guerra Mundial, puesto que "los Estados Unidos y la Gran Bretaña, potencias de la radio, intensificaron su trabajo diplomático y cultural sobre los países latinoamericanos" ${ }^{31}$, convirtiéndose en una fuente de constante apoyo en el campo técnico, en el intercambio cultural y en la implementación de nuevos géneros de producción periodística.

Sin embargo, la débil democracia colombiana, sumida en un escenario de constante violencia partidista, marcó el final del proyecto de extensión cultural con el que se fue borrando la memoria cultural del país y la posibilidad de construir una nación con identidad. Silva, en este sentido, afirma que la pérdida de esa memoria cultural no solo afectó “la memoria intelectual sino la memoria social popular, en cuanto a los elementos de nación que, muy primariamente se había tratado de construir y que buscaba un punto de enganche con la historia anterior del país"32.

A medida que perdía espacio e importancia cultural la Radio Nacional, se fueron fortaleciendo otras experiencias radiales, pero también se fue consolidando un amplio sector privado que empezó a trabajar comercialmente con este medio de comunicación. Hernando Téllez muestra en su libro Cincuenta años de la radiodifusión en Colombia ${ }^{33}$ cómo se fueron creando diferentes estaciones de radio y posteriormente grandes cadenas radiales que coparon el dial de los transistores que tenía la mayoría de las familias del país.

Para mediados de la década de 1940, la radio ya se había empezado a convertir en un instrumento indispensable en los hogares colombianos para estar informado

31. Ibid., p. 83.

32. Ibid., pp. 84 y 85

33. TÉLLEZ, Hernando. Cincuenta años de Radiodifusión en Colombia. Bogotá, Editorial Bedout S.A., 1974. 
y 'conectado' con los eventos del país: “la extensión de la cobertura y la posesión de un aparato receptor era ya un hecho en vía de generalización en el país"34, aunque el proyecto cultural de la Radio Nacional ya no fuera el objetivo principal, sino nuevas iniciativas de carácter comercial, pero también educativo, como sería el de Radio Sutatenza.

Para poner en marcha la idea de Radio Sutatenza, no solo influyó la cercanía a los medios de comunicación y la creación de nuevas iniciativas radiales en el país, sino que también fue importante la formación que tuvo Salcedo en el seminario y el apoyo constante que recibió por parte del obispo de Tunja.

La formación de Salcedo en el seminario se da en un momento de crisis social en el país y de reflexión de la Iglesia ante el avance del liberalismo y el socialismo. La preocupación de la Iglesia Católica, por una parte, se debe a la pérdida de fieles, por otra a la pérdida de influencia en diferentes esferas de la vida de los seres humanos. Durante las primeras tres décadas del siglo XX se empezaron a constituir en Latinoamérica los movimientos de acción social de la Iglesia, por medio de la Acción Católica. Esta última era un instrumento que permitía que se pusiera en marcha un sistema social para las clases más desposeídas, a partir de la colaboración y ayuda de las clases dirigentes; es decir, la Acción Católica fue el medio que pretendía despertar la conciencia social en aquellos que poseían mayores riquezas y comodidades.

La doctrina social católica tuvo sus orígenes al final del siglo XIX, cuando León XIII, quien ejerció como máximo jerarca de la Iglesia Católica entre 1878 y 1903, impulsó, con la encíclica Rerum Novarum, nuevas instituciones donde los laicos tuvieran un protagonismo activo en los temas concernientes a la educación cristiana. Rerum Novarum resalta los beneficios que dejan a la humanidad los servicios de instituciones, corporaciones, congregaciones y órdenes religiosas, pero también destaca que la Iglesia tiene plena potestad sobre ellas. Pío XI, el sucesor de León XIII, fue quien llamó a la conformación de la Acción Católica mediante la encíclica Il Fermo proposito; esta directriz del Papa reafirmaba que las obras sociales llevadas a cabo debían estar bajo la tutela del clero y de la jerarquía.

Es así como la encíclica Rerum Novarum y el surgimiento de la Acción Católica marcaron un periodo de transición de la Iglesia hacia la modernidad. Con este periodo se inicia una nueva relación con el laicado y su organización, y una concepción sobre el tema social, que no está limitado exclusivamente a la caridad,

34. SILVA, Renán. Op. cit., p. 85. 
sino también a la organización de movimientos y grupos sociales que trabajaran por el desarrollo y la mejora en las condiciones de vida de los más pobres y desposeídos. Esto a pesar de la resistencia que oponía Roma ante la amenaza de que se fortaleciera el liberalismo laicizante.

Tanto la encíclica Rerum Novarum como la conformación de la Acción Católica, empezó a ser impulsada a principios del siglo XX en Colombia; de esta manera, buena parte de jerarquía eclesiástica y párrocos empezaron a promover la organización de movimientos de laicos católicos que aportaran y colaboraran en las obras sociales que requería el país. La reivindicación de los obreros y campesinos, y el mejoramiento tanto de sus condiciones de vida como su situación laboral fue objetivo de esta empresa iniciada por la Iglesia, para así cerrarle el paso al liberalismo y al socialismo que habían acogido las necesidades de esos sectores como suyas. Lo que marcaba la diferencia es que la "lucha" del clero por esas reivindicaciones estaba acompañada por la formación cristiana. En este sentido, Ricardo Arias explica que las dos encíclicas mencionadas anteriormente “sientan las bases para el desarrollo de esa militancia católica que rápidamente se diversifica, pero que siempre pretenderá inculcar los valores cristianos en todos los niveles de la sociedad"35.

No era extraño, entonces, encontrar que en las primeras décadas del siglo XX, la Iglesia ya estuviera trabajando en la creación y consolidación de movimientos en el marco de la acción social católica. Para cumplir con lo trazado, el episcopado inició un proceso de sensibilización al clero en lo referente a los problemas sociales que aquejaron a la población colombiana, especialmente a los obreros, acompañada de lecturas de documentos papales como la encíclica Rerum Novarum. Además, se crean cátedras en los seminarios sobre acción social católica que le permitían a religiosos y estudiantes apropiarse de las "herramientas doctrinarias indispensables no solo para responder a las expectativas de las clases trabajadoras, sino también para hacer frente a los embates de la izquierda en el terreno social"36.

Junto con la instrucción necesaria para el clero, se incentiva la creación de instituciones de carácter popular que ayuden a mejorar o aliviar las dificultades de la vida de trabajadores y familiares. En este sentido, se crean cajas de ahorro, cooperativas de agricultores, bibliotecas, escuelas de arte y oficios, y bancos agrícolas, entre otros.

35. ARIAS, Ricardo. Op. cit., p. 60

36. Ibid., p. 101 


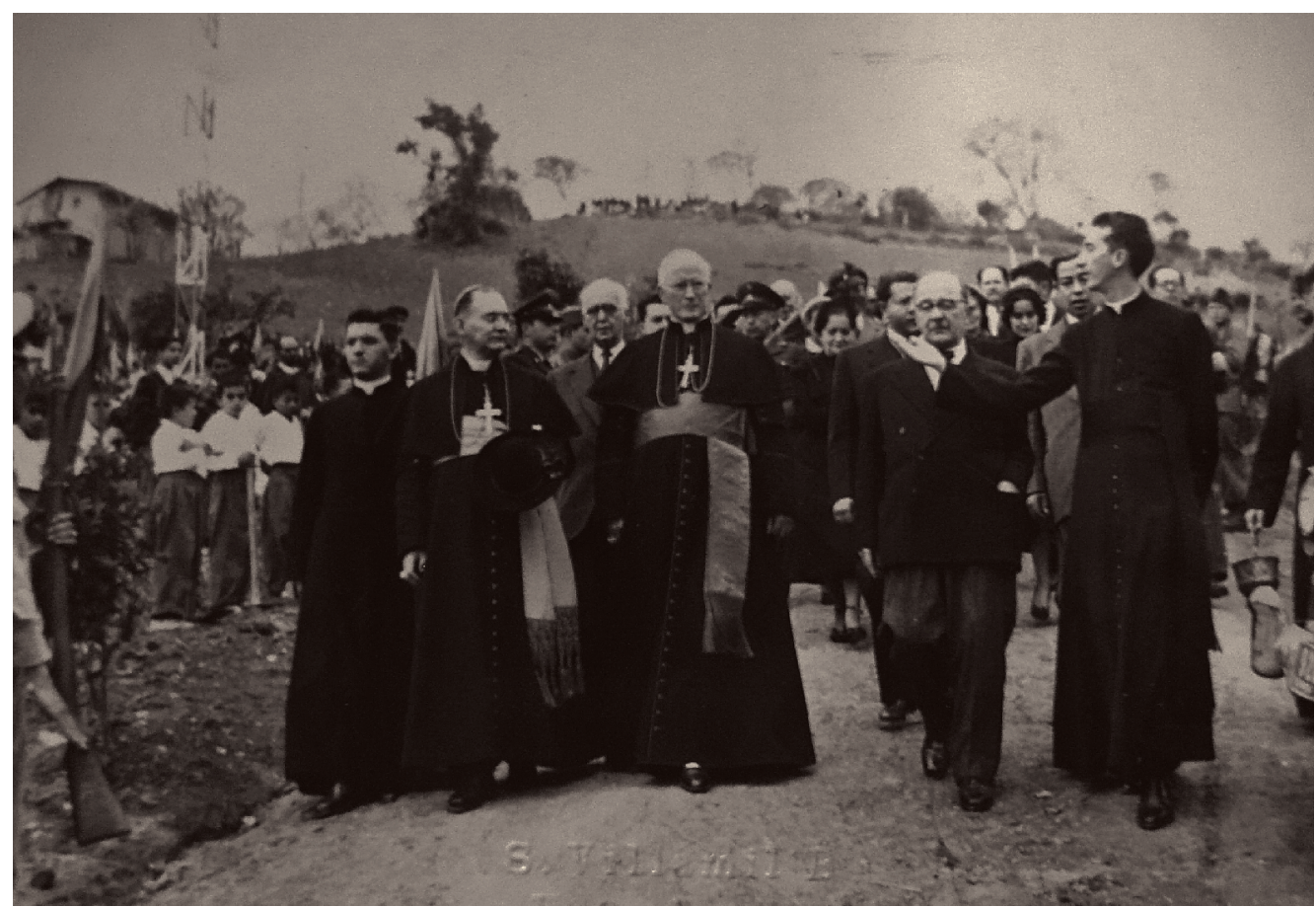

Monseñor Crisanto Luque y el Padre José Joaquín Salcedo.

Sin embargo, la transformación de la sociedad colombiana en estos primeros años necesitaba de una respuesta clara de la Iglesia, que se vio reflejada en la organización de la Acción Católica en Colombia a partir de 1933; su función consistió en lograr la colaboración de los laicos mediante organizaciones que trabajaran en la difusión de los principios cristianos y la relación de estos con la vida individual, familiar y social ${ }^{37}$.

Las acciones emprendidas por la acción social católica desde 1913 y los inicios de la Acción Católica en Colombia, con el establecimiento de sus estatutos en 1933, generaron y proyectaron el trabajo social desarrollado por la Iglesia con la participación del clero y del laicado. Por esa época surgieron varias opciones que pretendían ser una respuesta a los problemas sociales que enmarcaban la modernización. Tal fue el caso de la Juventud Obrera Católica, que organizó a obreros y campesinos en sindicatos, configurándose en una alternativa diferente a los partidos. 
El arzobispo de Tunja, monseñor Crisanto Luque Sánchez, apoyó y colaboró para que la Acción Católica en la región se extendiera y se consolidara. Durante los 18 años que ejerció la labor episcopal en la diócesis de Tunja, empezando en 1932, monseñor Luque organizó más de 150 sindicatos obreros y campesinos, y creó la Unión de Trabajadores de Boyacá (UTRABO). Además, apoyo la fundación de la Caja Popular Cooperativa, el Seminario de orientación vocacional de Tuta y participó en la creación de la Coordinación de Acción Social, donde se estableció un canal de comunicación entre la jerarquía y las clases trabajadoras ${ }^{38}$.

Es evidente que la Acción Católica no fue ajena para monseñor Luque; por el contrario, este desarrolló actividades tendientes a proyectarla en toda la región boyacense. No resulta extraña, entonces, la decisión de monseñor en apoyar proyectos que de una u otra manera estuvieran relacionados con el acercamiento a las comunidades obreras y campesinas en Boyacá. En relación con el apoyo a Salcedo, el padre jesuita Francisco Javier Mejía, en la revista Javeriana, exaltó la labor desarrollada por el Obispo de Tunja, monseñor Crisanto Luque: "Sin él esta obra no hubiera existido. Su clarividencia vio que lo que otro pudiera calificar de chifladuras de un amateur de radio, era una nueva ruta para llegar a las almas" ${ }^{39}$.

Si nos remitimos al texto del escritor y periodista colombiano Luis Zalamea, sobre la vida y obra de Salcedo ${ }^{40}$, podemos hallar referencias que muestran el constante apoyo que recibió Salcedo por parte de monseñor Luque, tanto para continuar sus estudios como para iniciar posteriormente su proyecto radial ${ }^{41}$.

La creación de nuevas instituciones en el marco de la acción social de la Iglesia incluía una serie de actividades relacionadas con la educación, como las escuelas de artes o la administración de instituciones escolares. De otra parte, no era ajeno el manejo de medios de comunicación como el periódico El Catolicismo o la Revista Javeriana como instrumentos para la divulgación del pensamiento del clero y para criticar y controvertir todo aquello que estaba en contra de los intereses de la Iglesia.

38. www.cec.org.co

39. Revista Javeriana, No. 160, noviembre de 1949.

40. ZALAMEA, Luis. El Quijote Visionario, Bogotá, Jorge Plazas Editor, 1994

41. Según el texto de Luis Zalamea, el mismo Salcedo le comenta que en varias ocasiones fue suspendido del seminario y así mismo, en varias ocasiones, monseñor Crisanto Luque abogó por él para que fuera reintegrado. Las suspensiones tenían que ver en muchos casos por obstinarse en llevar cine a los pueblos de Boyacá y proyectarlo en sus plazas, también por hacer lecturas prohibidas que tenían que ver con el comunismo. 
Desde el seminario, José Joaquín Salcedo empezó a trabajar con medios de comunicación. En las plazas de los pueblos de Boyacá proyectaba películas en $16 \mathrm{~mm}$ con un equipo sonoro de su propiedad. La acogida de la población permitió a Salcedo entender y confirmar la eficacia de los medios de comunicación para llegar a los campesinos ${ }^{42}$. La formación educativa fue el otro campo que exploró Salcedo en el seminario, una de esas experiencias se dio con la alfabetización de reclutas analfabetos en el batallón de Tunja, comandado por el entonces coronel Gustavo Rojas Pinilla. Allí Salcedo organizó y dirigió cursos para aquellos soldados que no sabían leer ni escribir.

La preocupación por los temas sociales y el conocimiento adquirido sobre el telégrafo y en general de los medios de comunicación, permitió que Salcedo fuera consolidando la idea de utilizar la tecnología como instrumento para el campesinado, especialmente aquel que no tenía acceso a las escuelas. Los recorridos de Salcedo por municipios y veredas le permitían reconocer ampliamente la precaria situación de los habitantes del departamento.

Tres años antes de la ordenación de Salcedo como sacerdote, en 1944, la Acción Católica creó una coordinación nacional encabezada por los jesuitas para controlar y coordinar todas las iniciativas enmarcadas en la misma. Sin embargo, la Acción Social seguía dependiendo de la Conferencia Episcopal. Los cambios que se dieron con la nueva coordinación se hicieron visibles en la crítica que se le hizo a la caridad tradicional y a la beneficencia, llevando a generar propuestas donde se buscara la participación de aquellas personas pobres, desposeídas y carentes de condiciones de vida digna.

Rodolfo Ramón de Roux considera que esta coordinación nacional fue importante, pues permitió que la jerarquía cambiara de mentalidad, formándose realmente en la doctrina social católica. A partir de este momento, se consideró primordial la formación del clero en los temas sociales y por ello los capacitó mediante cursos intensivos donde se enseñaba doctrina social, cooperativismo y sindicalismo. Estos cursos fueron el primer esfuerzo para que el clero saliera de un enfoque exclusivamente de beneficencia ${ }^{43}$.

42. ZALAMEA, Luis. Op. cit., p.72

43. DE ROUX, Rodolfo. "La Iglesia colombiana en el período 1930 - 1962". En: Historia general de la Iglesia Católica en América. T. VII, p. 531 
La relación de la Iglesia con sus creyentes y especialmente con comunidades como los obreros y el campesinado, se transformó debido a las circunstancias económicas, políticas y sociales del país. Los cambios en materia política, por ejemplo, llevaron a que la Iglesia tomara acciones que le permitieran adaptarse mejor a los nuevos retos; esas acciones determinaron transformaciones en los modelos del trabajo social. La Iglesia pasó a tener un sector del clero con una posición modernizante y reformista.

Juan Luis De Lannoy y Gustavo Pérez plantean un ejemplo de los cambios mencionados cuando proponen la necesidad de que la Iglesia instruya a la población para disminuir las altas tasas de natalidad. La idea era educar "la mente de los fieles con la doctrina católica, sobre la reglamentación de nacimientos, pues, se observa que el control de los nacimientos es uno de los problemas fundamentales en el alejamiento de la Iglesia" ${ }^{4}$. Existía una preocupación en este sentido, pues se consideró que la opinión de catedráticos universitarios y escritores sobre el tema estaba provocando polémicas, por eso era mejor "organizar la educación de las familias y de los médicos y enfermeras sobre los métodos lícitos de reglamentación de los nacimientos" 45 . Para la Iglesia, según los autores mencionados, era imperioso mostrar el problema del aumento demográfico como una cuestión de justicia social.

Estas acciones exigían un mayor número de sacerdotes y laicos, y nuevas formas y bases de apostolado, lo que implicaba cambios en las estructuras y en la mentalidad de los colombianos. La reconocida devoción católica de los habitantes de Sutatenza permitía que la participación del campesinado en los proyectos de la Iglesia fuera posiblemente mayor que en otras zonas del país. Fals Borda comentaba que "es de conocimiento general que el pueblo boyacense es casi en su totalidad católico romano. Esta homogeneidad religiosa es una de las principales y más influyentes características de Boyacá"46.

La religión en esta zona del país permitió que existiera un mecanismo de cohesión social, pues las creencias católicas de los habitantes permitían que se practicara la religión colectivamente en las diferentes celebraciones. Además, la percepción que se tenía de los párrocos era bastante positiva, según lo estableció la investigación Sacerdote y Cambio social ${ }^{47}$.

\footnotetext{
44. DE LANNOY, Juan y PÉREZ, Gustavo. Estructuras demográficas... p. 101.

45. Ibid.

46. FALS, Orlando. El Hombre y la Tierra... p.49.

47. JIMÉNEZ, Gustavo. Sacerdote y Cambio social, Bogotá, Tercer Mundo, 1967.
} 
Las necesidades apremiantes de la población, en una etapa donde se pedía mayor desarrollo, era también un llamado a la Iglesia para que se comprometiera

con el apoyo y favorecimiento de procesos o "factores de evolución social que conducen a una civilización técnica y urbana"48. El modelo de desarrollo propuesto hasta ese momento pasaba más por una formación técnica que vinculara al ciudadano al mundo laboral con unos conocimientos básicos que le permitieran mejorar la calidad de vida y los niveles de productividad. Es lo que posteriormente se llamó "desarrollismo". Desde esta perspectiva, la Iglesia apoyaría opciones relacionadas con reformas agrarias que le dieran valor al medio rural en aspectos como la higiene, la productividad y los niveles de vida del campesino. Igualmente, iniciaría acciones que permitieran agrupar los habitantes rurales en núcleos que facilitaran su educación y la asistencia, tanto técnica como social y religiosa.

Respecto al uso de tecnologías u otros medios tradicionales para el cultivo, Fals Borda afirma que aunque existen casos de "agricultura del fuego" 49 , en Boyacá los campesinos "ejercen su profesión todavía dentro del complejo del azadón y el arado rudimentario" 50 . En el Valle de Tenza los medios eran aún más "primitivos": el uso del azadón era escaso y primaba la utilización de la pala de cabo largo junto con el machete ${ }^{51}$.

Pérez y De Lannoy reconocieron que ACPO desarrollaba un trabajo pastoral a favor del pueblo campesino: "El fenómeno de la dispersión de la población en los campos obliga a la Iglesia a adoptar métodos nuevos de pastoral rural, como la Acción Cultural Popular y las misiones ambulantes" 52 . Si tenemos en cuenta el trabajo desarrollado por la Institución de José Joaquín Salcedo, su modelo coincidía plenamente con el planteamiento de Pérez, en cuanto a la necesidad de que la Iglesia apoyara a las instituciones que introdujeran procesos técnicos en la vida rural. En la población campesina se podría, de esta manera, practicar una “amplia pedagogía del aprendizaje técnico: preparando la formación mental para adquirir nuevas técnicas y motivaciones para el trabajo industrial" 53 .

48. DE LANNOY, Juan y PÉREZ, Gustavo. Estructuras demográficas.... 103.

49. Explica Orlando Fals Borda que la agricultura del fuego consistía en la práctica de los campesinos en la época de verano cuando cortaban el monte y dejaban que se secaran las ramas y hojas para posteriormente quemarlas. Tres días después, en el lugar de las quemas se sembraba maíz o papa. El objetivo principal de esta práctica consistía en evitar que la vegetación silvestre creciera.

50. FALS, Orlando. El Hombre y la Tierra... p.182.

51. Ibid., p.187.

52. DE LANNOY, Juan y PÉREZ, Gustavo. Estructuras demográficas... p. 103.

53. Ibid., p. 105. 
Gustavo Jiménez, en el trabajo Sacerdote y Cambio social muestra la influencia que tiene la religión en los aspectos seculares de la vida humana, en la vida local, y el papel del párroco como agente de mejoramiento económico y social, "que hace las funciones de un puente múltiple que conecta diferentes sectores del complejo social y cultural: sirve de puente entre las instituciones religiosas y seculares, entre la sociedad rural y la sociedad urbana, entre la unidad política local, formada por el municipio y el departamento o la nación, entre la parroquia y la diócesis o la iglesia universal"54. En definitiva, el objeto general de la investigación, según el mismo autor, es averiguar cuál es el papel del sacerdote como promotor del bienestar material para la comunidad campesina.

Como ya se mencionó, el sacerdote estaba en un puesto privilegiado frente al resto de la comunidad y eso le permitía tener una amplia influencia en los acontecimientos de los municipios donde estaba asignado. "Un estudio de recopilación de los padres Houtart y Pin reconoce que generalmente en América Latina el sacerdote rural ocupa un puesto de liderazgo en la comunidad; si bien se le critica su autoritarismo"55. Por tales razones, Jiménez afirma que los sacerdotes que se encuentran trabajando en áreas rurales o campesinas se constituyen en una fuerza importante para frenar o incentivar el desarrollo.

La investigación de Jiménez, al igual que la de Pérez, resalta la labor positiva que lleva a cabo Acción Cultural Popular en el desarrollo del campesinado colombiano, pero hace evidente la necesidad de la presencia del párroco como una condición para que pueda funcionar el proceso de educación rural. ${ }^{56}$ "Hay un consentimiento bastante unánime entre los especialistas de las ciencias sociales en reconocer el prestigio elevado de que goza la Iglesia y sus representantes dentro de las comunidades rurales, y en admitir la importancia potencial del sacerdote para impulsar u obstaculizar el desarrollo"57. Calcula Jiménez que para 1964 el porcentaje de católicos representaba el $98 \%$ de la población, lo que significaba en términos generales obediencia a la Iglesia y a su representante: el párroco.

Los obispos y párrocos tenían posiciones diversas frente a la vida social y política del país, pero sin duda por el papel que representaban en las comunidades rurales poseían un influjo importante en la vida pública. “En consecuencia,

\footnotetext{
54. JIMÉNEZ, Gustavo. Sacerdote y Cambio Social... p. 22

55. Ibid., p. 44

56. Ibid., p. 48

57. Ibid., p. 49
} 
la Iglesia constituye una fuerza potencial para canalizar la dinámica en marcha de las transformaciones sociales, en tal forma que tenga lugar una evolución en vez de una revolución destructiva y violenta" ${ }^{58}$. Era claro que esta posición proponía un cambio de actitud del clero para que se buscara mejorar las condiciones de vida de los colombianos, pero sobre todo para evitar la posibilidad de que se fraguara una revolución derivada de las carencias de campesinos y obreros, y alimentada con los discursos de algunos sectores liberales y de izquierda.

Este estudio cobra importancia en el marco de este documento, porque muestra cuál es la visión o imaginario que las comunidades tienen de los párrocos y porque además indaga con los mismos párrocos hasta dónde consideran ellos que debe llegar su papel con la comunidad. Para realizar la investigación, Jiménez se entrevistó con personas conocedoras del tema, visitó las sedes de las organizaciones de la Iglesia donde había programas de mejoramiento socioeconómico, se estudiaron los mecanismos de funcionamiento y se revisaron los archivos. Entre las sedes visitadas, estuvo la de Acción Cultural Popular.

La transformación sociocultural, según la mirada de Jiménez, ya estaba en marcha con las acciones que se habían desarrollado en esos últimos años. "La industrialización creciente, la mejora de carreteras y la construcción de caminos vecinales, la difusión del radio transistorizado entre los campesinos analfabetas, la labor de Acción Cultural Popular, los programas de acción comunal, etc., han sido fuerzas de gran poder para crear entre los campesinos una actitud de inconformidad con la situación presente y de anhelos de cambio"59. Con esta última afirmación, Jiménez, buscar establecer la relación entre los avances en diferentes áreas y el papel de la Iglesia para que estos se hicieran realidad.

El papel transformador de la Iglesia no siempre alcanzó progresos significativos y esto se debía, entre otras razones, a la misma organización de la Iglesia Católica y a su estructura de autoridad. Administrativamente, se dividía en diócesis gobernadas por obispos, y estas a su vez en parroquias que estaban dirigidas por el párroco. Afirma Jiménez que según esta estructura “cada obispo en su diócesis es independiente a la de los demás obispos" ${ }^{60}$, esto significa entonces que, dependiendo de los intereses del obispo y en sí, de la diócesis, el apoyo variaba de acuerdo con el tipo de obras que se realizaran.

58. Ibid., p. 96.
59. Ibid., p. 80
60. Ibid., p. 95. 
Las nuevas obras implementadas por la Iglesia dieron paso a una institución con un enfoque menos tradicional y asistencialista, pues la caridad y la beneficencia eran la característica de una actitud paternalista y conservadora, que en términos generales mantenía las condiciones de pobreza e ignorancia. Gustavo Jiménez explica que "la caridad, tal como ha sido entendida y practicada con frecuencia por gentes de la clase media y alta, es un patrón sociocultural que tiende a consolidar la rigidez de las estructuras sociales más bien que a levantar el nivel de vida de las clases pobres" ${ }^{61}$. Para el autor, una muestra del cambio de pensamiento en el clero tiene que ver con la conciencia tomada en torno a las injusticias estructurales del sistema tradicional sobre la tenencia y propiedad de la tierra. Las declaraciones emitidas por la Iglesia en torno a la necesidad de una reforma agraria hacia 1960 son muestra de que la Iglesia había entrado por la senda de la búsqueda del desarrollo y del cambio de algunas estructuras.

En Sacerdote y Cambio social, el autor describe y contextualiza el origen y el camino de Acción Cultural Popular, y trata de esta manera de demostrar cómo el cambio de la Iglesia y de sus párrocos se reflejaba en los procesos llevados a cabo por instituciones como ACPO. La formación educativa del campesino en diferentes áreas, la conformación de núcleos de estudio, la formación de líderes o la alusión y pedido constante de la reforma agraria eran pruebas de ese cambio.

Una respuesta positiva frente a los cambios sociales propuestos por los párrocos en sus comunidades se podía lograr en tanto las innovaciones que se llevaran a esas personas estuvieran en armonía con los valores y las experiencias de la comunidad. Ya había mencionado Gustavo Pérez que existían mayores posibilidades de que se acogieran nuevos aprendizajes si estos estaban relacionados con el entorno de los campesinos. Gustavo Jiménez, en relación con ACPO, reitera: “Con todo, la filial confianza que el campesino tiene en la Iglesia ha ayudado para que este incorpore en sus métodos de cultivo no pocos adelantos tecnológicos sugeridos por Acción Cultural Popular"62.

Seguramente, ACPO en su afán por dar una formación al campesinado, también aportó significativamente en el cambio del clero colombiano, moldeando el papel que el sacerdote debe cumplir en las zonas rurales. Acción Cultural Popular, mediante cursos y seminarios para sacerdotes, permitió que el clero tuviera mayor relación con los problemas del campesinado y buscara posibles soluciones.

61. Ibid., p. 99.

62. Ibid., p, 115. 
Es claro que donde han existido fuertes y estrechos lazos entre la Iglesia y la comunidad, las Escuelas Radiofónicas han funcionado mucho mejor. Pero también donde "predomina el minifundio" 63 . Sin embargo, dice Jiménez, el mérito de Acción Cultural Popular es que ha logrado introducir integrada y rápidamente cambios en las actitudes y valores de los campesinos.

De esta forma, aunque algunos sacerdotes siguieron aferrados al orden tradicional, a otros se les vio como decididos promotores del progreso material. De acuerdo con las entrevistas realizadas por Gustavo Jiménez, se determinó que existía unanimidad entre los laicos, pues el $97,3 \%$ considera que al sacerdote se le debía exigir un interés y una participación activa en las obras que contribuyeran al progreso material de la comunidad. Ese sentir manifestado entre los laicos también estaba presente entre los sacerdotes entrevistados con un $95 \%$. El resultado mayoritario de los 187 laicos y 22 párrocos entrevistados fue que los sacerdotes eran las personas potencialmente más importantes para el progreso del municipio.

Referente a las Escuelas Radiofónicas de ACPO, aunque la mayoría de los sacerdotes $(85 \%)$ mostraron un compromiso en la promoción y establecimiento de estas Escuelas, algunos párrocos afirmaron que no veían como obligatorio y fundamental apoyarlas. Sin embargo, tanto laicos como sacerdotes reconocen en estas un recurso válido para corregir las diferencias cuantitativas y cualitativas del sistema educativo del momento ${ }^{64}$.

En lo concerniente al caso de Acción Cultural Popular, según la investigación desarrollada por Jiménez, en general existe un acuerdo en que laicos y párrocos deben organizar el sistema de las escuelas radiofónicas en sus parroquias. Pero el objetivo principal sívaría, pues mientras los laicos creen que estas son un instrumento de educación general, los sacerdotes lo ven como una posibilidad para inculcar la vida religiosa y la moral en los campesinos. De acuerdo con el papel que deberían cumplir, los sacerdotes deberían ser protagonistas también en las reuniones que realizan las Escuelas Radiofónicas y en la promoción del periódico El Campesino.

El estudio de Jiménez muestra que los sacerdotes tienen posiciones más democráticas frente a la posibilidad de dar mayores responsabilidades al

63. Ibid., p, 117.

64. De acuerdo con las entrevistas realizadas, el autor analiza cuál es la posición de los diferentes actores sociales sobre las Escuelas Radiofónicas. Aunque reconoce que algunos no conocen de cerca la obra, también muestra que en general nadie está en desacuerdo con que se lleve a cabo. Por el contrario, una buena parte de los párrocos la aprecian y la apoyan. 
campesinado. Esto significaba que la formación que se les diera en aspectos diferentes a los agrícolas les permitía tomar autónomamente decisiones sobre el futuro de sus propias vidas.

Concluye Jiménez que, de acuerdo con las características y condiciones socioculturales existentes, se ve un sacerdote de la Iglesia Católica jugando un "papel importante como agente de cambio social y de desarrollo económico" 65 . En el caso de Acción Cultural Popular, esas condiciones, entre otras, tenían que ver con la voluntad del párroco por consagrar su tiempo y energías a esa obra, y el grado de vínculo de la comunidad con la Iglesia Católica. Afirma Jiménez que particularmente se pudo evidenciar que en las regiones donde existían los minifundios, como era la del Valle de Tenza, habían tenido mayor éxito los programas de ACPO. En relación con esta última idea, el autor dice que la propiedad de la tierra está relacionada con "actitudes mentales y emocionales que hacen al propietario más receptivo a la idea de que él es el dueño del progreso personal"66.

Un balance general de la investigación muestra que los roles de los sacerdotes con los fieles iban mucho más allá de la relación exclusivamente espiritual. El sacerdote debía estar más involucrado con la consecución de recursos, la realización de gestiones y la implementación de proyectos que beneficiaran a las comunidades. Sin embargo, las apremiantes necesidades llevaban a que en ocasiones las soluciones se proyectaran a corto plazo, evitando los cambios estructurales necesarios para mejorar la situación del campesinado colombiano.

El proyecto de Salcedo, que estaba a poco tiempo de empezar, estaría más enfocado hacia un trabajo realizado conjuntamente con el campesinado y no propiamente a un trabajo de beneficencia y de carácter asistencialista.

Las circunstancias que rodearon los años previos al origen de Radio Sutatenza fueron entonces importantes para que el proyecto radial contara con unas características muy propias de la Acción Católica. En este sentido, se debía formar núcleos de personas que estuvieran sometidos al cura en la parroquia y al obispo en la diócesis. La intención era que un grupo de apóstoles ayudaran a la jerarquía a "conquistar las almas, perfeccionarlas y hacerlas trabajar en la restauración cristiana de las familias y de la sociedad" 67 .

65. JIMÉNEZ, Gustavo. Sacerdote y Cambio social... p, 285

66. Ibid., p.264

67. BIDEGAIN, Ana. Op. cit., p.61 


\section{Inicios de Radio Sutatenza y ACPO}

Los primeros años de Sutatenza y de Acción Cultural Popular se reconstruyen a partir del relato escrito por el periodista Indalecio Rodríguez Sánchez, y publicado en el texto Educación Fundamental Integral: Teoría y aplicación en el caso ACPO ${ }^{68}$. La versión escrita por este periodista en 1978 se convirtió en la historia oficial de los orígenes de dicha obra. Esta historia oficial y la carencia de otros documentos que la verifiquen constituyen un problema para el autor de este documento, pues la verificación de la información no se puede realizar. En los archivos de Radio Sutatenza no se encuentran otros documentos que puedan evidenciar los primeros años de la obra de José Joaquín Salcedo.

Comenta Indalecio Rodríguez que el campesinado de Boyacá tenía ingresos que escasamente alcanzaban para la subsistencia, y que los habitantes de la zona del Valle de Tenza, lugar donde estaba ubicado el municipio de Sutatenza, no tenían fácil acceso a las escuelas. Sin embargo, no evidencia la situación de violencia y confrontación partidista que se vivía no solo en la región sino en buena parte del país.

\section{La violencia en Boyacá}

Los años precedentes a la creación de Radio Sutatenza estuvieron enmarcados en un contexto de violencia que recorrió todo el país. Boyacá fue, junto con el departamento de Santander y del Norte de Santander, escenario de continuas confrontaciones partidistas. Liberales y conservadores fueron actores de hechos violentos; el clero tuvo una participación importante al aliarse con el partido conservador que era la colectividad que representaba con mayor fidelidad sus intereses.

La violencia generada a partir de las guerras civiles que tuvieron lugar en el siglo XIX se mantuvo en los inicios del siglo XX. Mientras algunas regiones dentro de dichos procesos tuvieron cambios significativos y empezaron a dar pasos hacia la modernidad, otras se mantuvieron con niveles de atraso que no permitieron obtener mejores condiciones de vida. Ese fue el caso de Boyacá, que mantuvo una economía basada en la agricultura, pero con bajos niveles de tecnificación.

68. RODRÍGUEZ, Indalecio. “ACPO: origen y nacimiento”, En: BERNAL, Hernando. Educación Fundamental Integral, teoría y aplicación, Bogotá, ACPO, 1978. pp. 31- 52 
Las dificultades económicas estuvieron acompañadas de las confrontaciones partidistas y de fuertes controversias morales, que llevaron a que se mantuviera lo que Javier Guerrerollamóla “PrimeraViolencia"69, que comprendió desde la Guerra de los Mil Días hasta 1948. En este periodo se pasó de "una violencia de discurso, una violencia simbólica, imbuida de un carácter moral"70, a una violencia política en la que el clero y en general la religión católica tuvieron un fuerte protagonismo. En el caso específico de Boyacá, en sus zonas minifundistas la violencia se presentaba por la "identidad veredal y local, que se refleja en las venganzas de sangre, en los desquites de la localidad contra los desmanes cometidos por el adversario"71.

En el departamento de Boyacá, la Iglesia se constituía como un poder con amplia autonomía, que tenía una fuerte influencia en la población construida a la "luz del papel histórico de la Iglesia en la formación de la nacionalidad colombiana"72. La posición frente a la función que debía tener la Iglesia en el Estado marcó las diferencias de las doctrinas políticas, y por supuesto fue uno de los factores que determinaron la ya mencionada alianza entre el partido conservador y la Iglesia.

Esta alianza cobró un significado especial, puesto que la Iglesia con sus parroquias tuvo funciones que le daban la capacidad de controlar la actividad cultural, la educación y el accionar social e individual de la población. Esta institución, por medio de sus párrocos, tenía unos niveles de convocatoria más altos que los de cualquier otro organismo. Es decir, afirma Guerrero, "la parroquia ha sido un organismo político, administrativo..." ${ }^{73}$.

La filiación política de buena parte de la población del país estuvo enmarcada en la estrecha relación Iglesia - Estado, y por supuesto Boyacá no fue la excepción. Por el contrario, la fuerte presencia del clero en la región, sumada a las características de la tenencia de la tierra y al tradicionalismo del campesino boyacense, llevó a que este sector tuviera una filiación política mayoritariamente conservadora.

El papel de la Iglesia en las primeras décadas del siglo XX no detuvo la violencia, sino que en varios casos la propició o al menos fue fuente de agitación

69. GUERRERO, Javier. Los años del olvido, Bogotá, Tercer Mundo Editores, 1991. p. 53

70. Ibid., p. 53

71. GONZÁLEZ, Fernán. "Poblamiento y conflicto social en la historia colombiana", en Para leer la política. Bogotá, Cinep. 1997, p. 87 y 88.

72. Ibid., p. 63

73. Ibid., p. 62 
partidista que estuvo acompañada de conflictos agrarios, laborales y sociales, especialmente a partir de la crisis económica mundial de 1929. Por el escaso margen de maniobra institucional, estos conflictos fueron reprimidos con excesiva fuerza y de manera autoritaria, llevando a agudizar las confrontaciones políticas en el país.

La impopularidad del régimen conservador que llevaba en el poder 46 años, el desencanto por las secuelas del empobrecimiento del sector agrario, la corrupción y el desempleo, fueron para 1930 hechos que cobraron importancia en las campañas electorales, entre ellas la presidencial. Ese año el país presenció la caída del conservatismo y el triunfo del liberal Enrique Olaya Herrera, quien alcanzó la presidencia de la República. En este sentido afirma Javier Guerrero que realmente "el Partido Liberal no asciende por un proceso político en el que derrota al Partido Conservador, sino que más bien es el derrumbe paulatino de un régimen ahogado en sus propios problemas y debilitado en su interior por sus propias contradicciones, donde la consecuencia lógica no era otra que el relevo político"74.

Pero la transición hacia la República liberal no fue pacífica. Estuvo acompañada de fuertes tensiones a raíz de los constantes enfrentamientos con una clase política conservadora que se había enquistado en amplios sectores burocráticos del país, y que, además, aún mantenía el poder sobre varias instituciones del Estado. En Boyacá los conservadores mantuvieron el manejo de la educación, los telefonistas y la guardia departamental y municipal, lo que significa tener una "fuerza de choque partidista", que fue usada en no pocas ocasiones contra los liberales. A partir del ascenso al poder de los liberales, asegura Guerrero, la situación que se presentó en Boyacá, Santander y Norte de Santander fue calificada como "una guerra civil regional”75.

La defensa de parte del conservatismo estuvo enfocada en mantener a su favor los espacios de poder ganados durante la hegemonía conservadora, mientras que para los liberales fue imperioso conquistar esos espacios y buscar escenarios que les permitiera cambiar las tendencias electorales. Una de las medidas aplicadas fue el nombramiento de alcaldes liberales en poblaciones conservadoras; sin embargo, esa medida generó que en varias zonas se crearan fuerzas de policía cívica para que protegieran a los mandatarios locales contra los abusos de la policía departamental.

74. Ibid., p. 113

75. Ibid., p. 121 
Guerrero evidencia cómo de lado y lado fueron constantes las agresiones, las amenazas y las acusaciones sobre la participación en los hechos de violencia que repetidamente se presentaban en diferentes zonas del país. Los enfrentamientos se dieron en variados escenarios; el control que mantuvo el conservatismo en la rama judicial llevó a confrontaciones entre las instituciones encargadas de impartir justicia y la autoridad del alcalde y la policía. Es decir, lo que se presentó fue un fraccionamiento del poder del Estado, o como lo denomina Guerrero, una “desarticulación del sistema institucional"76.

Durante esta etapa, al igual que en buena parte de la vida republicana del país, el clero mantuvo una actitud de rechazo hacia las ideas liberales. Por eso, a través de los púlpitos incitó a la población creyente a que rechazara y desalojara a los liberales. Este tipo de actitudes de algunos párrocos de la Iglesia Católica, unido a otras causas generadoras de violencia mencionadas anteriormente, llevó a que el gobierno liberal intentara aplicar un proceso de pacificación que consistió en el desarme de la población, en la disolución de los cuerpos de la policía departamental y municipal, y por supuesto, en la limitación a la Iglesia en cuanto a su participación en política, además de evitar que el clero siguiera llevando a cabo actos de agitación y protección de grupos armados afines al conservatismo.

La guerra con el Perú logró frenar el clima de violencia que se presentaba en el país. Las preocupaciones delos colombianosinmersosenlaguerrasetrasladaronalafrontera con el vecino, apaciguando el debate político interno. Sin embargo, después de acabada la guerra en 1933, el partido conservador salió fortalecido "en la medida en que lo acercó más a una estrategia militar", ${ }^{77}$ hasta llegar al punto de crear escuadrones que tenían el nombre de sus más connotados líderes como Laureano Gómez. Con la finalización de la guerra, de nuevo arreciaron los enfrentamientos internos y el país se sumió una vez más en hechos violentos. En general, el proceso de pacificación llevado a cabo había fracasado.

La confrontación política se mantendría durante los años posteriores a la década de los 30 y se agudizaría el debate en torno a ambos partidos, por la llegada al poder del presidente Alfonso López Pumarejo, quien inició un proyecto político llamado la "Revolución en Marcha", que tuvo como fin crear un estado laico, en el que por medio de una reforma educativa y una reforma del concordato, la Iglesia tuviera una menor injerencia en aspectos políticos, educativos y culturales del país.

76. $\quad$ Ibid., p. 62

77. Ibid., p. 187 
Para el año de 1947, cuando Salcedo llega al municipio de Sutatenza, El Tiempo, periódico liberal, registraba constantemente los enfrentamientos entre conservadores y liberales. El presidente Mariano Ospina Pérez intentaba, con la política de Unidad Nacional, apaciguar la violencia y trabajar en colaboración con los líderes tanto del partido liberal como del partido conservador. Aún así, la violencia seguía muy presente en las zonas alejadas de la capital del país.

Los liberales se quejaban constantemente de los atropellos cometidos por los conservadores. Los dirigentes regionales del departamento de Boyacá recibían constantemente críticas por la actitud permisible ante los desmanes de los conservadores o porque ellos mismos se encargaban de ocasionarlos.

En agosto de 1947, El Tiempo denunciaba cómo en Chiquinquirá la situación de los liberales era grave, debido a la actitud agresiva de los policías:

Entre tanto, la situación en el departamento de Boyacá continúa siendo en extremo grave, como consecuencia de la actitud de algunos funcionarios del departamento y de la policía y los resguardos que, bajo la mirada indiferente del gobierno se han entregado a la empresa de sembrar el terror en la mayoría de los municipios del norte y del occidente del departamento...

Informaciones de fuente responsable en el día de ayer, indican que la formación actual de la policía de Boyacá obedece a un claro sentimiento sectario, pues del cuerpo han sido desplazados todos los agentes de filiación liberal, para ser reemplazados por conocidos y peligrosos elementos conservadores, dispuestos a todo con tal de ver afianzado a su partido en el poder... ${ }^{78}$

Las constantes alusiones a la situación del departamento de Boyacá en el periódico El Tiempo dejaban ver la difícil situación que se presentaba entre los partidarios de liberales y conservadores. Dos días más tarde, en primera página, el mismo periódico titulaba “El Directorio Liberal de Boyacá informa a los parlamentarios sobre el difícil momento actual"79, refiriéndose a las constantes muertes que se habían dado no solo en Chiquinquirá, sino también Tunja.

78. El Tiempo, 7 de agosto de 1947

79. El Tiempo, 9 de agosto de 1947 
Las ediciones de los días posteriores del mismo periódico continuaban mostrando una situación caótica de violencia en el departamento. Era el tema a tratar en las editoriales ${ }^{80}$, pues revestía gran importancia para la dirigencia liberal. Debido a las muertes sucedidas no solo en Boyacá, sino en otros departamentos como Santander y ante un eventual rompimiento de la política de Unidad Nacional del gobierno, este se ve en la obligación de llegar a un acuerdo para intentar controlar la situación en las regiones donde la violencia había hecho mayor presencia. Jorge Eliécer Gaitán, jefe del Partido Liberal para ese momento, Laureano Gómez, como jefe del conservatismo, y el ministro de gobierno, Roberto Urdaneta, acordaron entonces unas normas que permitieran mantener la unidad nacional. Entre ellas estaban el desarme, la condena de la violencia, y la caída de algunos gobernantes que habían patrocinado la violencia ${ }^{81}$. La Revista Javeriana también hizo alusión a los acuerdos, destacando la necesidad de alcanzar un "ambiente de serenidad y comprensión entre los diferentes grupos políticos del país, agitados en los últimos meses por el insano estímulo de las pasiones banderizas y el empeño contra una nueva concepción administrativa que tiende a la sana emulación entre los partidos para el mejor servicio de la república, como lo ha proclamado insistente y diáfanamente el actual mandatario" 82 .

En Boyacá siguieron presentándose hechos violentos con matices partidistas. Un ejemplo de ello, que tuvo cercana relación con el Padre José Joaquín Salcedo, fue el intento de agresión a la población de Sutatenza por parte de los pobladores liberales de Guateque, a raíz del asesinato del líder liberal Jorge Eliécer Gaitán en Bogotá, pues la Iglesia aún conservaba esa imagen de ser una institución aliada al partido conservador. Luis Zalamea, escritor, periodista colombiano y amigo de Salcedo, narra este capítulo de cómo la violencia también llegó hasta las puertas de Sutatenza:

La situación se tornó muy peligrosa para el Padre Salcedo. Llegaron a sus oídos rumores de que los liberales, que eran mayoría en Guateque, consideraban que había que eliminar a Radio Sutatenza por 'goda y gobiernista'. En efecto, organizaron una cabalgata para tomarse la emisora y aprehender a su director. Para ello lo primero que hicieron fue cortar la luz pública del pueblo, pero el padrecito reaccionó como veterano estratega. Primero prendió su propia planta eléctrica a la 1 a.m. e hizo sonar los altoparlantes a todo volumen mientras que sus ayudantes, según lo previamente acordado, soltaban una salva de voladores. ${ }^{83}$

\footnotetext{
80. El Tiempo, 10 de agosto de 1947

81. El Tiempo, 24 de agosto de 1947

82. Revista Javeriana, No. 139, octubre - noviembre de 1947

83. ZALAMEA, Luis. Un Quijote Visionario. Bogotá, Jorge Plazas S. Editor. 1994. p.111
} 
Según Zalamea, la idea era que creyeran que era fuego de armas y así evitar la entrada al pueblo de los habitantes de Guateque, único pueblo liberal alrededor del Valle de Tenza. Para Salcedo, este fue el único acto político de su vida, aunque arguye que se trató realmente de una defensa. ${ }^{84}$

Con la muerte de Jorge Eliécer Gaitán se inició otro periodo de la violencia en el país que está comprendido entre 1949 y 1953, según Jesús Antonio Bejarano. La violencia se trasladó al campo, lugar donde se encontraban posicionados los partidos. Esta etapa, dice Bejarano, tiene dos subfases, una que estaba determinada por una lucha por la hegemonía del poder político, y otra, que fue el ingreso del Partido Comunista al escenario político en diferentes regiones del país. ${ }^{85}$

\section{Transmite Radio Sutatenza}

Bajo las tensiones políticas mencionadas empezó labores en el municipio de Sutatenza el sacerdote, recién ordenado, José Joaquín Salcedo. Había llegado el 23 de agosto de 1947 a colaborar como párroco coadjutor del padre Eliécer Pinto, en una población que contaba con 8.000 habitantes en total, la mayor parte de ellos minifundistas y asentados en el sector rural. Los índices de analfabetismo superaban el 85 por ciento de la población. El trabajo de Indalecio Rodríguez comenta cómo Sutatenza se caracterizaba también por ser una población donde se consumía en exceso la chicha, ocasionando permanentes peleas y discusiones entre los habitantes, lo que ocasionaba por lo general muertos y lesionados ${ }^{86}$.

El difícil acceso a las escuelas y el bajo porcentaje de alfabetización se convirtió en el escenario propicio para desarrollar procesos educativos con la ayuda de medios tecnológicos como la radio. Salcedo realizó el montaje de la primera radio escuela a los pocos meses de su arribo a Sutatenza. Un equipo de radioaficionado y tres receptores sirvieron para dictar unas clases de catecismo. La primera obra que realizó de manera conjunta con la población fue la construcción de un teatro

84. A partir de la entrevista realizada por Zalamea para escribir el libro Un Quijote Visionario, José Joaquín Salcedo explica el papel que tuvo en el levantamiento de los habitantes de Guateque en contra de Sutatenza y, según él, en contra de Radio Sutatenza. Para Zalamea, a partir del 9 de abril de 1948 la violencia política se recrudeció en todo el país, y especialmente azotó los pueblos y las veredas.

85. BEJARANO, Jesús. “Campesinado, Luchas Agrarias e Historia Social”, en Anuario Colombiano de Historia Social y de la Cultura. Volumen 11. Bogotá, Colombia.

86. RODRÍGUEZ, Indalecio. “Acpo: Origen y nacimiento” Op cit. pp. 31- 52 
donde pudieran ver cómodamente las películas que ya se habían empezado a proyectar. Para realizar esta obra, los campesinos hicieron donaciones de huevos, gallinas y productos del campo, además de su trabajo ${ }^{87}$.

El padre Salcedo, desde los primeros días que llegó a Sutatenza, inició labores para conseguir un equipo de radioaficionado. Con la ayuda de su hermano Antonio, diseñaron el transmisor. De la misma manera, adelantó las gestiones para adquirir en Bogotá el radio-receptor. Como el abastecimiento de energía era muy esporádico, se consiguió una planta eléctrica que permitió mantener durante mayor tiempo el suministro de energía necesario para el adecuado funcionamiento, tanto de los equipos de radiodifusión como de los aparatos necesarios para la proyección de películas. Una sábana blanca y un proyector lograban que las plazas de los pueblos se convirtieran en un teatro.

La fecha oficial de la primera transmisión radial fue el 16 de noviembre de 1947, dirigida a una vereda cercana llamada Irzón. Allí los labriegos ya tenían un radio-receptor que operaba con pilas. La trasmisión inició con unas palabras de saludo y continuó con una pieza musical. De esta manera se inició el trabajo de una de las experiencias más importante de educación campesina en Colombia.

Mientras se iniciaba el proyecto de Radio Sutatenza, otras obras sociales se desarrollaban en diferentes lugares del país y con fines diversos. El periódico El Catolicismo promocionaba constantemente en sus páginas las labores desarrolladas por la Acción Católica, considerándola como:

...el elemento más dinámico y poderoso para el implantamiento de la vida cristiana de que dispone la Iglesia Católica. Son sus funciones tan diversificadas que en ellas se atienden a todos los sectores de la actividad espiritual y material humanas, e incluye y alcanza en su organización todas las esferas sociales, desde aquellas de más alto rango hasta las más sencillas y humildes, en un espíritu de unión y fraternidad que eliminan las barreras que distancian a los seres humanos... ${ }^{88}$

87. "El teatro contaba con 38 metros de largo y once de luz, planeado con todos los requisitos que hoy se estilan en el arte escénico. Sus cimientos de 2 metros de profundidad y 1,20 de ancho desafían la incuria e inclemencias del campo. Allí, los campesinos de Sutatenza han ofrendado, además de aportes en dinero (se llevan gastados unos veinte mil pesos), la reciedumbre de sus músculos y la habilidad práctica de sus mentes en un trabajo gratuito". En: Revista Javeriana, No. 160, noviembre de 1949.

88. El Catolicismo, 11 de diciembre de 1949. 
Igualmente, bajo estas mismas directrices, Salcedo hizo el llamado a los habitantes de Sutatenza, para que unidos y en fraternidad buscarán objetivos comunes que les ayudaran a superar las dificultades y carencias, tanto en lo material como en lo espiritual. De esta manera, Salcedo integraba a la población a las soluciones y la invitaba a participar activamente de ellas. "Yo no puedo hacerlo solo. El mejoramiento tenemos que hacerlo juntos" ${ }^{89}$, decía.

Todos los grupos, asociaciones y acciones sociales debían estar bajo la supervisión de las jerarquías. El Catolicismo, por medio de un artículo, hizo énfasis en ese sentido refiriéndose a los cuatro puntos expuestos como norma por el Papa Pío XII. El primero, tenía que ver con la estrecha relación que debía existir entre los obispos, la jerarquía y la Acción Católica; el segundo, el estudio del catecismo y la permanente oración; la tercera, la permanente unidad entre los miembros de la Acción Católica, y la cuarta, la armonía con las otras obras; así se hubieran creado antes de la Acción Católica, hacían parte de ella por orden del episcopado ${ }^{90}$.

Pero la Acción Católica también tocaba otros terrenos más allá de los exclusivamente evangelizadores. Durante el discurso del Papa a las mujeres de la Acción Católica italiana, hizo énfasis en la necesidad de conseguir avances en la justicia social, entendida como mejor acceso a la educación y la consecución de viviendas dignas ${ }^{91}$.

El Catolicismo hizo eco constante para que se continuara con asociaciones que llevaran al crecimiento y proyección de la Acción Católica en Colombia. En sus páginas difundió los grupos que venían trabajando en diferentes lugares y zonas del país, como en Cartagena.

Radio Sutatenza no fue entonces una obra aislada en un pequeño pueblo de Boyacá, sino que respondió a la actividad que venía desarrollando la Iglesia Católica en relación con los temas sociales y con la necesidad de acercar a las personas a las obras de la Iglesia para la búsqueda del bienestar individual y del prójimo.

En ese contexto se originó Radio Sutatenza, como una opción para la educación de los campesinos y como un medio para la evangelización. El uso de la radiodifusión ya había empezado años atrás (1930), pero aún eran muy pocas las emisoras que

89. RODRÍGUEZ, Indalecio. “Acpo: Origen y nacimiento” Op cit. p. 39

90. El Catolicismo, 25 de diciembre de 1949. p.10

91. El Catolicismo, 26 de febrero de 1950. p.9 
funcionaban en el país. Estaba en el dial la Radiodifusora Nacional, que era de carácter oficial, la HKF y la Voz de Antioquia, entre otras.

Si bien el proyecto de Radio Sutatenza inició labores con la construcción del primer transmisor y puesta en funcionamiento en 1947, se constituyó como organización el 18 de octubre de 1949, cuando obtuvo la personería jurídica civil mediante resolución 260 del Ministerio de Justicia, y bajo el nombre de Acción Cultural Popular. Un mes atrás, exactamente el 6 de septiembre de 1949, se inauguraron oficialmente las Escuelas Radiofónicas por parte del Gobierno Nacional. Ese día el presidente de la República, Mariano Ospina Pérez, dirigió una alocución a los campesinos de Colombia en la que destacaba la necesidad de que por medio de las Escuelas Radiofónicas se integraran los conocimientos en diversas áreas y la formación religiosa: "La instrucción moral y religiosa, la historia patria, los conocimientos de agricultura e higiene combinados con las lecciones para aprender a leer y a escribir, hacen que sobre los campos, en la penumbra de la tarde, empiece el amanecer de las inteligencias..." 92

Escasamente llevaba dos años de iniciada la labor de Radio Sutatenza y ya alcanzaba una notoriedad a nivel nacional, por una parte, como se mencionó, el presidente de la República asistió al acto de constitución de ACPO y, por otra, se hacía ya mención en los medios de comunicación como la Revista Javeriana y El Tiempo al trabajo realizado por las radio- escuelas a la cabeza del padre Salcedo.

Las Escuelas Radiofónicas se empezaron a presentar como la solución a los problemas del campesinado colombiano y como la fórmula que permitía el acceso del campesinado a la educación. El padre Francisco Javier Mejía, en un artículo titulado "Las Escuelas Radiofónicas”, mostraba las adversas condiciones del campesinado al que le negaban la posibilidad de educarse, pero destacaba la labor que venía desarrollando Salcedo como el método indicado para acabar con la ignorancia de esa población:

Pensar en la educación del campesino es una ciega quimera: las enormes distancias, los fatigantes senderos por los repechos y cañadas, el cavernario aislamiento de nuestros campesinos, su indolencia ingénita, el estrecho horizonte de sus aspiraciones, su racial desconfianza y mil causas más levantan una muralla china que

92. El Campesino, Bogotá, 27 de noviembre de 1988. p.9 
circunda de ignorancia a nuestro pueblo... pero ¿cómo realizarla? En el mismo campo, imposible... Una campaña entre campesinos hay que encuadrarla en la paradoja de un día con duración de una semana. Pero un joven y dinámico sacerdote del clero boyacense ha encontrado la fórmula... ${ }^{93}$

De esta manera, de una parte, Mejía mostraba cómo las clases dirigentes poco hacían por una población que era mayoritaria en el país, pero también que la misma clase campesina tenía unas características que no le permitían acceder fácilmente a la educación. Se daba por hecho que el campesino estaba resignado a su suerte $y$, por lo tanto, difícilmente deseaba mejorar sus condiciones de vida.

Sin embargo, el texto del padre jesuita, por ser uno de los pocos documentos que dejaron huella de los primeros años de Sutatenza, cobra importancia. Allí describe a las Escuelas Radiofónicas técnicamente como la Emisora Cultural del Valle de Tenza HJKI, de onda larga, con 1.580 kilociclos y con una potencia de 300 watios, lo suficiente para cubrir aproximadamente 60 kilómetros a la redonda. Para el año de 1949 ya se había ampliado el número de equipos. Se contaba con la emisora, los transmisores, los preamplificadores, micrófonos, antenas, tocadiscos, discoteca y planta eléctrica, infraestructura que tenía un valor aproximado de 15.000 pesos, alcanzados en su mayoría mediante las donaciones realizadas por los mismos campesinos. Del mismo modo, Mejía hace alusión a los receptores que tenían un costo de 121 pesos y funcionaban en cada una de las escuelas. Estos aparatos estaban previamente sincronizados para que funcionaran exclusivamente en la frecuencia de Radio Sutatenza.

Con solo dos años de funcionamiento de la emisora, y a pocos días de la inauguración oficial de las Escuelas Radiofónicas, ya se contaba con 90 escuelas y con 7.000 alumnos que habitaban las veredas de los municipios de Sutatenza, Guateque, Tenza, Pachavita, Macanal, Garagoa, Almeida, Somondoco, Guayatá y Manta94.

Durante los primeros años, los profesores fueron el padre José Joaquín Salcedo junto con el maestro Enrique Parra, quien recibía un pago del departamento de Boyacá. Sin embargo, ya se trabajaba con un maestro auxiliar, que era un campesino

93 Revista Javeriana, No. 160, noviembre de 1949 pp. 285 - 286

$94 \quad$ Ibid, pp. $285-286$ 
dotado de algunos conocimientos en escritura y lectura, para así colaborarles a los otros campesinos en la comprensión de las explicaciones dadas mediante la radio. Este trabajo estaba guiado en su totalidad desde la emisora por el maestro principal.

Fundamental, los objetivos iniciales del proyecto abarcaban la enseñanza de asignaturas básicas como la lectura y la escritura, con el ánimo de atacar el grave problema del analfabetismo entre el campesinado; y de algunas nociones en historia patria, agricultura, higiene, música, urbanidad, cívica y religión. Por medio de estas nociones se abarcaban otros ámbitos de la vida del campesinado que tenían que ver con la recreación, la familia y su trabajo en el campo.

La visita de Mariano Ospina Pérez, por supuesto, mostraba ya un apoyo por parte del gobierno nacional, que pasó del discurso del presidente a la notable colaboración del Ministerio de Educación Nacional, el cual donó las cartillas que servían de guía de estudio a los campesinos y eran distribuidas por Acción Cultural Popular en cada nueva escuela radiofónica. De la misma manera, el ministro de Higiene apoyó a ACPO en su objetivo de disminuir el consumo de chicha entre los pobladores de la zona.

La proyección de las primeras películas en la plaza de Sutatenza le dieron un carácter cultural al trabajo que empezó a desarrollar José Joaquín salcedo desde 1947; no obstante, la inclusión de la radio como un instrumento divulgador de conocimientos básicos permitió crear un modelo educativo que disminuyera el analfabetismo en la zona del Valle de Tenza, en el departamento de Boyacá y posteriormente en las diferentes regiones del país.

Este proyecto educativo, como ya se mencionó, estaba acompañado de otros aprendizajes que replicaban las asignaturas que se daban en las diferentes escuelas del país, aprendizajes que reforzaban imaginarios relacionados con la historia, el civismo y el Estado, además de las enseñanzas de los principios cristianos católicos. En fin, por medio de la enseñanza se encontraba el fin mismo del proyecto de Acción Cultural Popular.

En ese sentido, el objetivo específico de ACPO quedó establecido en el artículo 3 de los estatutos aprobados por la Resolución 260, y afirma que “Acción Cultural Popular tiene por fin la educación integral cristiana del pueblo, especialmente de los campesinos adultos, mediante las Escuelas Radiofónicas". 
Para ACPO, la educación integral se entendía como la formación y enseñanza en diferentes campos de la vida humana, campos que no solo estaban relacionados con el ser humano como individuo, sino también con la relación de este con la sociedad. La Iglesia, de esta manera, abarcaba un escenario de influencia bastante amplio y lograba que las enseñanzas dadas en las diferentes áreas estuvieran relacionadas con su doctrina. 


\section{CAPÍTULO II ACCIÓN CULTURAL POPULAR Y LA EDUCACIÓN DEL CAMPESINADO COLOMBIANO}

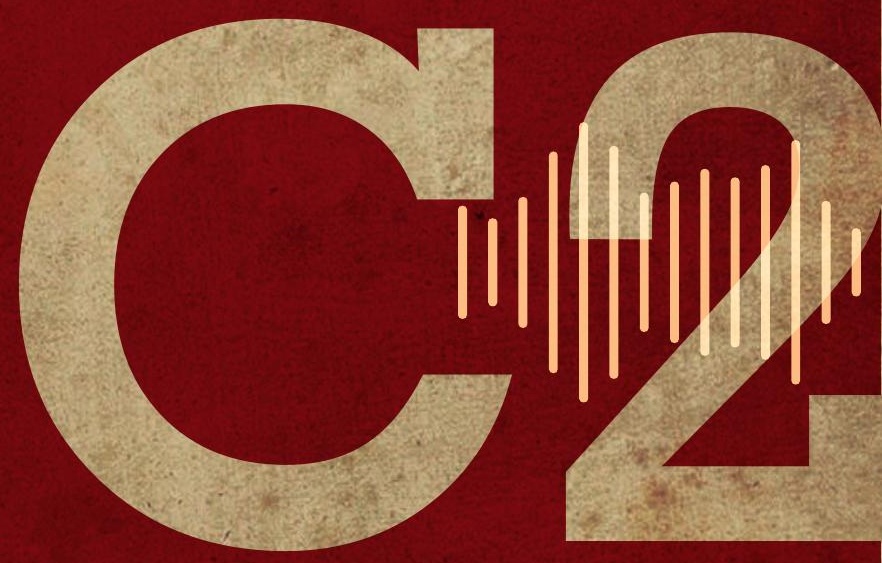



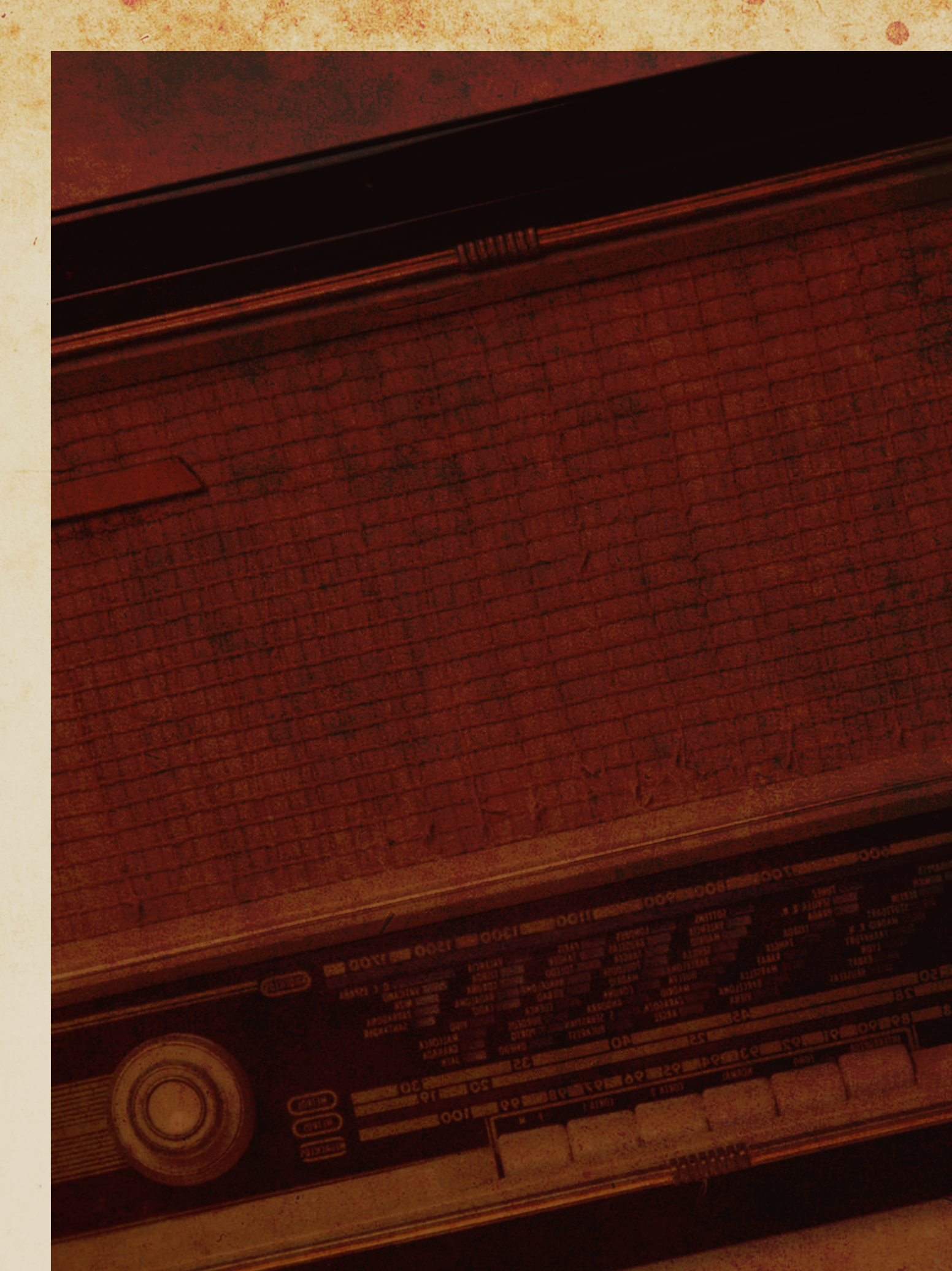


\section{ACCIÓN CULTURAL POPULAR Y LA EDUCACIÓN DEL CAMPESINADO COLOMBIANO}

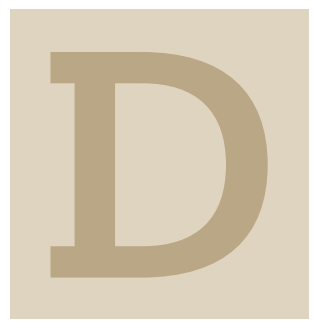

esde su creación en 1947, Radio Sutatenza y la organización Acción Cultural Popular, ACPO, tuvieron un rápido crecimiento tanto en infraestructura como en el cubrimiento de su acción, pues alcanzó a impactar en la mayor parte del país.

Para cumplir con los objetivos propuestos y ante la constante acogida de la obra de Salcedo, Acción Cultural Popular se vio en la constante obligación de ir ajustando su estructura organizativa. A medida que la institución fue creciendo, nuevos retos se presentaron. Diferentes gobiernos como el de Rojas Pinilla, el de Guillermo León Valencia y el de Alberto Lleras Camargo vieron en esta obra la posibilidad de cumplir con el papel educativo del Estado en aquellas regiones apartadas; por eso, mediante la adjudicación de contratos, inyectaron recursos a ACPO. Por ejemplo, se suscribieron contratos para cualificar a maestros rurales mediante clases dadas a través de la radio.

Acción Cultural Popular tuvo un constante apoyo por parte de la Iglesia, lo que permitió que la obra se extendiera a lo largo y ancho de la mayoría del territorio nacional. Es así como una buena cantidad de párrocos, especialmente de la región centro del país, hicieron parte del desarrollo de las escuelas radiales en sus centros de influencia.

Este capítulo analiza la consolidación de Acción Cultural Popular como una institución, cuál fue el camino que se fue trazando a partir de sus principios, los objetivos propuestos y la organización de una estructura administrativa. Además, 
analiza el modelo educativo utilizado en las Escuelas Radiofónicas, denominado Educación Fundamental Integral y los diferentes medios de acción utilizados para lograr el objetivo: educación para el campesinado colombiano.

ACPO, con la educación del campesinado por medio de la radio, logró generar un proceso de formación de líderes, que hicieron parte posteriormente de organizaciones rurales como las juntas veredales. En este último sentido, ACPO fue un promotor de una reforma agraria que le permitiera al campesino colombiano obtener tierras para su cultivo y explotación que lo llevaran a tener condiciones de vida más dignas.

Las fuentes primarias trabajadas en este capítulo son, principalmente, el semanario El Campesino, periódico creado por Acción Cultural Popular en el año de 1958, y los informes entregados por ACPO a la Conferencia Episcopal, desde el año de 1955 hasta 1964 y el de 1967. Igualmente, se hará uso de otras fuentes primarias como las cartillas de apoyo trabajadas por ACPO en sus Escuelas Radiofónicas. Cartillas que contenían información y ejercicios correspondientes a las nociones básicas de aprendizaje establecidas para la formación del campesinado.

Acción Cultural Popular creó una editorial, que le permitió editar una amplia gama de textos como eran las cartillas mencionadas, pero también imprimió los resultados de estudios realizados referentes al trabajo de Radio Sutatenza, las Escuelas Radiofónicas o, en general, de Acción Cultural Popular, como una organización que trabajó con diversos medios de comunicación para cumplir con el objetivo de educar al pueblo campesino.

\section{La estructura organizativa de ACPO}

Acción Cultural Popular fue reconocida como una institución con la aprobación de la personería jurídica 260 del Ministerio de Justicia. Esa decisión se dio el 18 de octubre de 1949, un año después de que Radio Sutatenza iniciara labores en el municipio de Sutatenza en el departamento de Boyacá. Aunque en los primeros años solo estaba la pequeña emisora funcionando, posteriormente hicieron parte de la institución otros proyectos como el periódico El Campesino, que se publicaba semanalmente y estaba dirigido especialmente a la población campesina; la Editorial Andes, que se utilizaba para imprimir todas las cartillas y libros que se utilizaban para acompañar las clases radiales; las bibliotecas campesinas que se implementaron para incentivar el hábito de la lectura y también para fortalecer los temas tratados en las clases; y entre otros, la prensadora de discos, que se utilizaba 
para realizar grabaciones musicales, también apoyaba el proceso de formación así como la grabación de las clases para ser transmitidas por las emisoras.

Desde los primeros años de funcionamiento de Radio Sutatenza y Acción Cultural Popular, la institución tuvo el reconocimiento de personas como el presidente Mariano Ospina Pérez y el Papa Pío XII, quien en 1953 impartió un mensaje y la bendición al campesinado colombiano. En abril 11 de ese mismo año, el cardenal Crisanto Luque ratifica la Fundación de ACPO en compañía del obispo de Tunja, Ángel María Ocampo, de los sacerdotes José Joaquín Salcedo y José Ramón Sabogal, y de un representante de los campesinos. ACPO recibió también el apoyo de la Unesco. Durante cuatro años, hasta 1957, se trabajó en la preparación y validación de las cartillas de lectura y en el diseño de las láminas de lectura, escritura y aritmética utilizadas por los profesores radiales como ayuda complementaria.

A partir de la aprobación de la personería jurídica de ACPO, se constituyó una organización administrativa, que fue conformada inicialmente por medio del trabajo realizado por las Escuelas Radiofónicas. Los primeros indicios que se encuentran de esta organización están plasmados en el texto de Francisco Javier Mejías, S. J. Las Escuelas Radiofónicas, donde se visibiliza la labor realizada por el maestro principal que era el padre Salcedo y por el maestro auxiliar, que era un campesino, pero con nociones de lectura y escritura necesarias para apoyar al resto de estudiantes campesinos. Mejía definiría a este maestro auxiliar como el “último sillar en que descansa la estructura espiritual de las escuelas"95.

A través de los informes que periódicamente debía entregar Acción Cultural Popular a la Conferencia Episcopal, se evidenció la organización administrativa que se estableció para el funcionamiento de la institución. Por ejemplo, en el informe de 1955 a los maestros auxiliares se les denominó Auxiliares Inmediatos, y ya hacían parte de una organización parroquial.

En parroquias donde las Escuelas están organizadas siguiendo las normas indicadas por la institución, los Auxiliares inmediatos se reúnen con su párroco y el Representante Parroquial y forman una milicia de cooperadores abnegados en el apostolado. Ellos reciben las consignas del Párroco y las cumplen; son los apóstoles en su medio 96.

95. Revista Javeriana, No. 160, noviembre de 1949 p. 288

96. Informe al Eminentísimo señor Cardenal y a los Excelentísimos prelados de Colombia reunidos en Conferencia Episcopal en 1955. Acción Cultural Popular. Escuelas Radiofónicas. p.2 
La organización desarrollada correspondió al crecimiento que tuvo ACPO con sus Escuelas Radiofónicas. Al finalizar la década del 40 alcanzó un número de 90 escuelas y alrededor de 7.000 estudiantes ubicados en los municipios cercanos a Sutatenza ${ }^{97}$.

De acuerdo con las fuentes primarias halladas, en 1957 se encuentra el primer organigrama de la institución, cuando se presentó el informe de ACPO a la "Venerable Conferencia Episcopal", correspondiente a los años de 1957 y $1958^{98}$. El crecimiento de la institución permite ver una amplia y compleja organización que había trascendido más allá de las labores realizadas por los párrocos en las Escuelas Radiofónicas.

Según ese organigrama, la estructura organizativa de ACPO respondía a las orientaciones de la Conferencia Episcopal. La institución era dirigida por una junta directiva y por un director general que era el padre José Joaquín Salcedo. El resto de las funciones estaban agrupadas en tres secciones que inicialmente correspondían a la dirección de las Escuelas Radiofónicas, a la gerencia administrativa, y a la gerencia comercial, pero que posteriormente fueron sustituidas por una división comercial, una división cultural y una división administrativa.

En aproximadamente siete años, Acción Cultural Popular, pasó de operar con unas pocas personas en el municipio de Sutatenza, a tener un buen número de empleados que cubrieran los diferentes cargos creados para el funcionamiento de una institución. Ya no se usaba un medio para la educación, como fue la radio, sino que convergían varios medios como las cartillas o los afiches.

El crecimiento de Acción Cultural Popular no se detuvo. En el informe de 1957 se previó trabajar en otras áreas y con otros medios. Uno de ellos fue el semanario El Campesino, que fue el segundo medio en importancia utilizado por Acción Cultural Popular, pues tuvo circulación nacional y se identificaba a sí mismo como el medio del campesinado colombiano. Su primera edición tituló: “Un semanario al servicio y en defensa de los campesinos de Colombia"99.

La estructura administrativa y la organización de Acción Cultural Popular contó con el apoyo expreso de la Iglesia Católica, por ser esta una obra de carácter diocesano, y también contó con la colaboración de personalidades de la vida pública, tanto así que varias de ellas hicieron parte de la Junta Directiva.

97. Revista Javeriana, No. 160, noviembre de 1949 p. 288

98. Informe a la Venerable Conferencia Episcopal, 1957 - 1958, Bogotá. pp. 22

99. El Campesino, Bogotá, 29 de junio de 1958. 
Mediante los diferentes informes entregados a la Conferencia Episcopal, ACPO ratificó su obediencia a las disposiciones de la Conferencia. En el informe que cubre los años de 1961 a 1964 reafirmó que Acción Cultural Popular se encontraba "bajo la orientación de la Venerable Conferencia Episcopal y es gobernada por la Asamblea General, el Consejo de Gobierno, la Junta Directiva y el Director General". ${ }^{100}$

Bajo esta estructura era responsabilidad del Consejo de Gobierno tomar las más altas decisiones y efectuar los nombramientos principales. Entre tanto, la Junta Directiva estaba a cargo de las decisiones “ordinarias". Por esa razón, mientras la primera se reunía de una a tres veces por año, la segunda lo hacía semanalmente. Sin embargo, el peso de la planeación, dirección y control recayó y permaneció sobre la figura de José Joaquín Salcedo.

Paralelo a la definición de los principios que rigieron a ACPO, se fue diseñando la estructura de la institución. Esta se transformó en varias ocasiones, y los diferentes informes enviados a la Conferencia Episcopal dan testimonio de los cambios realizados. El realizado durante el periodo de 1959 a 1960 no fue el último; en la presentación del informe que cubrió tres años, entre 1961 y 1964, se presentó una nueva carta de organización de Acción Cultural Popular.

De esta manera, Acción Cultural Popular se consolidó como una organización de carácter nacional, cubriendo amplios sectores de los departamentos de Antioquia, Atlántico, Bolívar y Boyacá, entre otros, con un total de 238.583 estudiantes. Además, con una circulación anual de El Campesino de 3.388.542 ejemplares en todo el país. El crecimiento en el número de estudiantes y el número de escuelas llevó a crear un sistema que pudiera cumplir con los objetivos propuestos a través del tiempo, pero sobre todo, que pudiera llevar educación a los sectores menos favorecidos.

\section{Principios de ACPO}

Mientras se iba consolidando la organización administrativa de Acción Cultural Popular, se fue trabajando en los principios que regirían a la institución. Hernando Bernal Alarcón, ${ }^{101}$ colaborador y funcionario de ACPO, menciona que la publicación

100. Informe a la Venerable Conferencia Episcopal, 1961 a 1964, Bogotá. p. 7

101. Hernando Bernal Alarcón fue desde el año de 1964 director del departamento de Sociología y de Planeación y Programación de Acción Cultural. Él era un sociólogo de la Universidad Javeriana, con magíster en sociología para el desarrollo de la Universidad de Wisconsin. Bernal Alarcón escribió varias publicaciones relacionadas con Acción Cultural Popular y la Educación Fundamental Integral. Fue uno de los colaboradores más cercanos a monseñor Salcedo. 
de estos principios ${ }^{102}$ se realizó el 5 de septiembre de 1956. Sin embargo, en las fuentes revisadas se encuentran en el informe correspondiente a los años de 1957 y 1958. A lo largo de ocho puntos se demarcaba el camino a seguir por ACPO, sus principios y sus fines. Este primer documento oficial decía así:

\section{PRINCIPIOS IDEOLÓGICOS DE ACCIÓN CULTURAL POPULAR103}

1. ACCIÓN CULTURAL POPULAR es una obra de la Iglesia que tiene como fin ayudar a la dignificación del pueblo y especialmente del campesino adulto, por medio de una educación integral que abarque la cultura básica y la preparación para la vida social y económica con el fundamento de una auténtica formación religiosa.

2. ACCIÓN CULTURAL POPULAR considera que es un deber para toda la sociedad, y de un modo especial para la Iglesia, el colaborar decididamente en el desarrollo de los valores espirituales, culturales, sociales, familiares y aún de perfección individual, que Dios ha puesto en cada uno de los hombres como semilla que habría de fructificar según la naturaleza y el plan del Creador. Por eso facilita al hombre del pueblo los medios que han de ayudarle al cumplimiento de su deber de perfección individual, familiar y social.

3. Para cumplir eficazmente la finalidad que persigue, ACCIÓN CULTURAL POPULAR debe promover una conciencia pública de gran sensibilidad social sobre los problemas del campo, con base en un concepto cristiano de la agricultura y de la vida campesina, frente al concepto puramente técnico y económico.

4. ACCIÓN CULTURAL POPULAR, como institución, es una idea dinámica organizada, con un auténtico sentido jerárquico, que aspira a la integración de sus colaboradores a la obra de la Iglesia, aunando los esfuerzos de todos en una voluntad de apostolado, pero con profundo respeto a su personalidad e iniciativas

5. Las actividades de ACCIÓN CULTURAL POPULAR favorecen la creación de un movimiento desarrollado por unos militantes que encarnen una doctrina de vida en una acción solidaria organizada.

102 BERNAL, Hernando. Acción Cultural Popular, de la realidad a la utopía, Bogotá, Fundación Cultural Javeriana, 2005, p. 118

103 Informe a la Venerable Conferencia Episcopal, 1957 - 1958, Bogotá, p. 3 
6. ACCIÓN CULTURAL POPULAR centra sus actividades en la comunidad parroquial. Al facilitar su colaboración a las parroquias, tiene el criterio de ayudar al mayor número, aunque solo sea con el mínimo de medios y elementos, para despertar en ellos inquietudes e iniciativas.

7. ACCIÓN CULTURAL POPULAR, como parte de la acción de la comunidad parroquial, con espíritu de colaboración y coordinación, crea un ambiente y facilita unos medios que contribuyan al desarrollo de otras obras parroquiales.

8. El párroco, como director del movimiento de Escuelas Radiofónicas en la comunidad parroquial, ocupa en Acción Cultural Popular un puesto activo de orientación y dirección como miembro de la Asamblea General.

Los principios, de una parte, reafirmaron la voluntad de Acción Cultural Popular para ayudarle y colaborarle al campesinado por medio de la educación. Los beneficiarios de esta obra lograban adquirir una preparación que les permitía enfrentarse a la vida social y económica, tal y como Salcedo lo venía promulgando desde el inicio del proyecto. Sin embargo, los principios ponen de manifiesto la necesidad de trascender en esa formación más allá de la vida pública del campesino, más allá de la vida en sociedad, entrando a espacios como el de la familia y a ámbitos de carácter individual. La formación de ACPO trascendía en general a todos los espacios, tanto los públicos como los privados, todos ellos influidos por los valores espirituales inherentes a la Iglesia Católica.

Esta preocupación se manifestó en los informes de la Conferencia Episcopal de 1956 y 1957, cuando Salcedo afirmaba frente a la formación de los Auxiliares Inmediatos que:

Estimamos que es necesaria una acción complementaria que haga más vivo el sentido cristiano del amor, la consideración por la esposa y por los hijos, que ilustre a los padres sobre sus deberes para con la familia en puntos como la educación y la economía del hogar. Nos inquieta profundamente que estos Auxiliares Inmediatos, que ya han cumplido su proceso de formación tanto intelectual como moral, no reciban las sugestiones para irradiar un apostolado católico ${ }^{104}$.

104. Informe al Eminentísimo señor Cardenal y a los Excelentísimos prelados de Colombia reunidos en Conferencia Episcopal en 1955. Acción Cultural Popular. Escuelas Radiofónicas, p.2 
Acción Cultural Popular buscaba que sus principios abarcaran no solo la mayoría sino la totalidad de las acciones del campesinado, pero además que el grupo de personas a las que se les llegaba por medio de las Escuelas Radiofónicas tuvieran la posibilidad de ser, por un lado, multiplicadores de los beneficios recibidos, pero por otro, que como lo indicaban los principios, se convirtieran en verdaderos militantes de un grupo que pudiera organizarse y buscar conjuntamente el desarrollo de sus propias comunidades. Salcedo de esta manera proyectaba a ACPO como una institución capaz de generar identidades colectivas, identidades de grupo para influir activamente en las decisiones que tenían que ver con la calidad de vida del campesinado.

Los principios ideológicos de Acción Cultural Popular, en general, plasmaron el accionar de la Institución, la relación con la Iglesia, la relación con el campesinado, el papel que debían cumplir los párrocos y los estudiantes de las Escuelas Radiofónicas, pero, sobre todo, el carácter católico de la obra y la necesaria obediencia a una organización jerárquica.

La etapa denominada como "el origen" empezó a cerrarse con la publicación de los principios ideológicos. A partir de este momento, Acción Cultural Popular se convirtió en un proyecto maduro y se inició lo que aquí denominamos como la etapa de consolidación. En general, la obra ya contaba con una organización administrativa, con unos principios que la regían y con unos objetivos propuestos.

\section{La Educación Fundamental Integral}

El objetivo principal de ACPO desde su nacimiento fue la capacitación y formación del campesinado colombiano que había carecido de las posibilidades de acceder a la educación formal. Para lograrlo, decidió el padre José Joaquín Salcedo utilizar los medios de comunicación y especialmente la radio. De allí se originó una propuesta de educación para adultos denominada Educación Fundamental Integral que contó, a partir de la experiencia, con un sustento teórico, unas metodologías y unos medios para sus logros. Esta sección del capítulo hace un análisis de los aspectos más importantes de la Educación Fundamental Integral, considerada una propuesta novedosa para la primera mitad del siglo XX por la conformación de las Escuelas Radiofónicas y el apoyo multimedial que tuvieron las diferentes clases radiales. Las fuentes utilizadas principalmente son el periódico El Campesino, medio de Acción Cultural Popular creado en 1958; las cartas de los oyentes de las Escuelas 
Radiofónicas y los informes que ACPO presentó a la Conferencia Episcopal, como lo establecían los estatutos de la organización.

El análisis de la Educación Fundamental Integral, desde las fuentes sugeridas, muestra por una parte una perspectiva institucional, puesto que los informes que se presentan a la Conferencia Episcopal son redactados por la dirigencia de ACPO; de otra parte, la imagen que se proyecta de la institución y de su modelo a través del periódico, como un instrumento de divulgación de los principios y valores de ACPO, pero también como un escenario de diálogo entre los diferentes actores sociales que confluyen en el proyecto de la Educación Fundamental Integral. La relación entre el campesinado y la institución desde la mirada de los propios estudiantes de las Escuelas Radiofónicas se presenta con mayor claridad en las cartas. Allí comentan sobre sus problemas, sus necesidades y sus logros y reconocen sus contextos más cercanos en relación con la Educación Fundamental Integral y las Escuelas Radiofónicas.

Los últimos años de la década del cincuenta son importantes dentro del proyecto de ACPO, pues empieza a emerger el concepto de Educación Fundamental Integral, que se convirtió en el modelo utilizado en las Escuelas Radiofónicas. Se transitó por un camino que había llevado al campesinado exclusivamente, o principalmente, al aprendizaje de la lectura y la escritura, a una educación que afectaba prácticas, mentalidades, hábitos y formas de ser. ACPO incidía por esta vía en los diferentes ámbitos de la vida cultural, afectaba de esta manera "sobre los esquemas de pensamiento y de comportamiento; sobre las formas de realizar papeles sociales; sobre las instituciones; en una palabra, sobre el "way of life", la manera de vivir y de pensar". ${ }^{105}$ Desde esta perspectiva se consignó el concepto de Educación Fundamental Integral en el documento de los Principios y Medios de Acción de ACPO, concepto que parte de la UNESCO en 1955 y que lo define como:

El mínimo de conocimientos generales que tienen por objeto ayudar a los niños y adultos que no disfrutan de las ventajas de la instrucción escolar, a comprender los problemas peculiares del medio en que viven, a formarse una idea exacta de sus derechos y deberes tanto cívicos como individuales, y a participar más eficazmente en el progreso social y económico de la comunidad a que pertenecen. ${ }^{106}$

105. HOUTART, Francisco y PÉREZ, Gustavo. Acción Cultural Popular. Sus principios y medios de acción, consideraciones teológicas y sociológicas. Bogotá. ACPO, 1960. p. 37.

106. Etudes et Documents d'education, No. 15. 1955, p. 12 en CASTRO, Jorge. Acpo y el ideal de una progresión cultural: Génesis de las escuelas radiofónicas. Tunja. Revista Pensamiento y Acción. 2002. p. 56. 
Francisco Houtart y Gustavo Pérez, quienes ya habían trabajado juntos, fueron los dos sacerdotes encargados por ACPO para establecer los principios y los medios de acción necesarios para llevar a cabo el proceso de educación campesino mediante las Escuelas Radiofónicas ${ }^{107}$. El padre Francisco Houtart era sociólogo, director del Centro de Investigaciones Socio-Religiosas de Bélgica, profesor de la Universidad de Lovaina y Secretario General de la Conferencia Internacional de Sociología Religiosa; y el padre Gustavo Pérez también era sociólogo y director del Centro de Investigaciones Sociales de Colombia.

Para Houtart, la Iglesia Católica se encontraba en una crisis frente a los nuevos desafíos que planteaba la creciente urbanización en Europa, pero también en América Latina. En este sentido, las causas de las crisis eran, de una parte, externas, pues la misma urbanización proponía una "nueva sociedad, un nuevo tipo de grupo, nuevas instituciones, nuevas mentalidades, nuevas culturas". ${ }^{108}$

Houtart consideraba que había nuevas maneras de vivir y nuevas maneras de entender las diferentes mentalidades, lo que significaba que existieran también nuevos hombres. De tal manera que la nueva vida social se caracterizaba por poseer una especialización de funciones sociales como eran la vivienda, la escuela o el trabajo. Ya no existía un solo espacio donde el hombre encontrara reunida en su totalidad todas las especializaciones de la vida. Esas especializaciones, para Houtart, se presentaban en instituciones que podían ser escolares, de salud, de vivienda o sindicatos. Instituciones que generaban nuevas interacciones y relaciones sociales que daban origen a ese nuevo mundo social del hombre.

Desde la perspectiva de Houtart, la Iglesia no podía ya ser la única institución que respondiera a todos los problemas de la vida humana, puesto que las relaciones interhumanas no dependían exclusivamente del sitio de residencia de la mayoría de las personas, sino del grado de relaciones funcionales que se establecían. Las relaciones se establecen a partir de las especializaciones, es decir, de los intereses que tenga un grupo de personas. A partir de lo anterior, Houtart afirmaba que los procesos de urbanización y las especializaciones

107. En entrevista realizada por Gabriel Gómez a Hernando Bernal Alarcón, este último comenta que Francisco Houtart fue encargado por monseñor Salcedo para hacer una descripción sistemática de Acción Cultural Popular y de lo que se pensaba que era la institución. Houtart llamó a Gustavo Pérez y Camilo Torres, quienes habían sido estudiantes suyos en Lovaina, para que le colaboraran en dicho trabajo, que posteriormente se vio reflejado en el texto conocido por los miembros de ACPO como el Libro Azul.

108. HOUTART, Abbe. La mentalidad religiosa y su evolución en las ciudades. Bogotá, Universidad Nacional de Colombia, 1959, p. 10. 
hacían que la sociedad fuera más influyente que el individuo. Por último, Houtart planteaba que la creciente urbanización de los territorios llevaba a una mayor movilidad geográfica, un problema, puesto que la Iglesia Católica fue "concebida y organizada hasta ahora como para un sitio geográfico fijo, hasta tal punto que la movilidad de las gentes ha sido considerada como un mal, como un mal social y también como un mal religioso". ${ }^{109}$

Estas eran las causas externas de la crisis religiosa, pero también existieron, según Houtart, unas causas internas de la misma Iglesia que tenían que ver con una institución que mantenía antiguas estructuras que no respondían a los nuevos ambientes y a las nuevas instituciones sociales. Se necesitaba una acción religiosa organizada desde el punto de vista funcional que se acomodara a las nuevas sociedades.

Houtart entendía que para ese momento (1959), se estaba dando un cambio social que exigía una nueva síntesis de la vida religiosa, donde los cambios de las personas modificaban la vida espiritual, y donde se debía continuar con la búsqueda de nuevos medios y de una nueva mentalidad religiosa. ${ }^{110}$

La elección de los dos autores del texto Acción Cultural Popular. Sus principios y medios de acción, consideraciones teológicas y sociológicas, da cuenta del interés de ACPO por lograr un documento ideológicamente consistente y que respondiera al pensamiento contemporáneo. Era un momento en que hacían presencia particularmente las corrientes teológicas y sociológicas distintivas de la Universidad de Lovaina. Tanto Houtart como varios miembros del clero colombiano tenían vinculación con la Universidad de Lovaina, el primero como profesor y los segundos como estudiantes a partir de la colaboración del cardenal Crisanto Luque, quien había apoyado desde los inicios el proyecto de Radio Sutatenza y quien estaba "interesado en mejorar la calidad de su clero" . ${ }^{111}$

Desde la corriente ideológica planteada a través del Libro Azul, ${ }^{112}$ de Houtart y Pérez, para que ACPO actuara en la vida cultural del campesino requería influir en los valores, pues ellos eran la base de la actividad y de la actitud de los hombres; proporcionar mediante una acción pedagógica unos conocimientos y unas

109. HOUTART, Abbe. La mentalidad religiosa y su evolución, op, cit. p. 15.

110. Ibid., p. 20.

111. ARIAS, Ricardo. El Episcopado Colombiano: Intransigencia y Laicidad (1850 - 2000), Bogotá, Ediciones Uniandes, 2003, p.196.

112. Así se conocía institucionalmente el libro escrito por HOUTART, Francisco y PÉREZ, Gustavo. Se le llamó el Libro Azul por el color de su portada. 
técnicas; y generar los ambientes necesarios para que el campesino exigiera una organización más justa y estuviera preparado frente a un cambio cultural.

A partir de lo anterior se apreciaba la relación existente entre la Educación Fundamental Integral y el desarrollo. Esta educación suponía unos conocimientos de carácter teórico - práctico claves para reconfigurar unos esquemas de comportamiento y de pensamiento necesarios para participar activamente en la vida social. “La educación fundamental es por lo tanto educación social por excelencia; es organización y transformación de la comunidad como exigencia de la integración sociocultural. Es capacitación de la persona social y del grupo para que por sí mismos mejoren sus condiciones de vida, mediante esfuerzo propio y ayuda mutua". ${ }^{113}$ Esta organización y transformación solo se podría llevar a cabo por medio del conocimiento de las características fundamentales de la vida social del individuo. Así la acción cultural se haría evidente, en tanto los cambios se dieran en el ámbito individual y en el colectivo a partir de la interacción con los otros, modificando y socializando actitudes, comportamientos y valores sociales.

Para Gustavo Pérez, la labor desarrollada por Acción Cultural Popular en este sentido se estaba planteando una movilización ideológica que tenía que ver con la necesidad de "abrir las mentalidades a la idea del bien común, a los criterios de eficiencia y de productividad. Hay que orientar al colombiano hacia nuevos modos de pensar y de obrar que permitan una integración social y económica"114. Afirmaba que era indispensable una acción integral que estuviera orientada a crear nuevas formas de pensar, de vivir y de obrar para que las transformaciones sociales pudieran ser duraderas en el tiempo y en la sociedad.

Para Pérez, el tema de la instrucción escolar de los niños campesinos debía estar dirigido al papel que desempeñarían estos en su vida y en sus labores cotidianas, por lo tanto era necesaria la "especificidad de la educación rural, no solamente para segurar el acceso de los campesinos a la instrucción superior, sino también para dar a la instrucción su función social, y al trabajo agrícola su calificación propia”. ${ }^{115}$

Las Escuelas Radiofónicas se convirtieron en la célula vital del movimiento radiofónico que relacionó lo teológico, lo sociológico y lo educativo, en un escenario común que era eminentemente pedagógico. A partir de la enseñanza de unos conocimientos básicos se impactaba en los tres ámbitos mencionados.

113. HOUTART, Francisco y PÉREZ, Gustavo. Acción Cultural Popular. Sus principios y medios de acción, op cit., p. 44. 114. PÉREZ, Gustavo. El Campesinado Colombiano...p. 189

115. Ibid., p. 198 
En la Educación Fundamental Integral no se utilizaron términos como asignaturas o materias de estudios para llamar a esos contenidos básicos, sino que se utilizó el concepto de nociones, entendido como una serie de ideas, contenidos y prácticas educativas, que llevaban a la generación de unas pautas de pensamientos, a unas actitudes y a unas formas de comportamiento, que favorecían la generación de unas competencias que permitieran la solución de necesidades. Houtart y Pérez afirmaban que la educación fundamental contribuía eficazmente al desarrollo de la sociedad, porque

...la acción sobre la escala de valores despierta la conciencia de la persona humana y desarrolla el sentimiento de solidaridad, con lo cual sienta las bases para una organización social, en la que tanto las personas como los grupos ocupen su sitio y desempeñen su papel; hace posible una vida cultural por su acción sobre las mentalidades y comportamientos, y culmina finalmente en la integración sociocultural. ${ }^{116}$

Desde esta visión, para asumir un papel en la vida social, el individuo necesitaba las nociones básicas de carácter teórico y técnico que le permitieran desempeñarse en grupo y en la sociedad, ajustándose a los esquemas de pensamiento y de comportamiento de acuerdo con su función social. El aprendizaje de los esquemas y comportamientos lograban una participación constructiva del individuo en la vida social. Se entendía que a partir de estas nociones el campesino lograría mantener su libertad y construir o proyectar su personalidad, sin caer en alienaciones de tipo ideológico o sin que coartaran su voluntad. Las Escuelas Radiofónicas, desde sus primeros años y antes de consolidarse el concepto de Educación Fundamental Integral, ya se habían convertido en un medio para prevenir el ingreso de ideologías no deseadas. En este sentido se expresa el informe de ACPO a la Conferencia Episcopal de 1955:

El fenómeno del crecimiento al que aludíamos arriba también explica la necesidad de prevenir al campesino contra corrientes determinadas, necesidad claramente apreciada por muchos párrocos del país, que han visto en las Escuelas Radiofónicas una barrera contra la infiltración de ideologías extrañas ${ }^{117}$.

116. Ibid., p. 44.

117. Informe al Eminentísimo señor Cardenal y a los Excelentísimos prelados de Colombia reunidos en Conferencia Episcopal en 1955. Acción Cultural Popular. Escuelas Radiofónicas. p. 3. 
La Educación Fundamental era una educación social, pues buscaba la organización y transformación de la comunidad con el interés de lograr una integración sociocultural. La capacitación de la persona social y del grupo llevaba a que se mejorara las condiciones de vida, mediante el esfuerzo propio y la ayuda mutua. La concepción de educación fundamental partía del principio de que el hombre estaba ubicado en un mundo lleno de potencialidades que le permitía transformarlo y utilizarlo para satisfacer las necesidades. ${ }^{118}$

Para Acción Cultural Popular, el desarrollo se lograba a partir de un trabajo organizado, descubriendo las potencialidades de los grupos sociales. Y para ello, la metodología de iniciación para el cambio era por medio de la Educación Fundamental Integral. ACPO consideró que los cambios que se hacían a partir de modelos como el propio eran más racionales, más constructivos y, aunque tal vez más lentos, menos devastadores que los cambios revolucionarios, que implicaban violencia y un presupuesto de que todo lo tradicional debía ser sustituido. Para ese momento ya había llegado al poder Fidel Castro, después del triunfo de la revolución cubana y el derrocamiento de Fulgencio Batista en la Isla. Fidel Castro, por medio de la vía revolucionaria, hizo cambios significativos en temas como la educación, la distribución de la tierra y la salud. También Camilo Torres, el sacerdote colombiano que posteriormente se conoció como el "cura guerrillero", en un estudio que hizo sobre ACPO, criticaba la falta de decisión de la institución para romper con las viejas estructuras establecidas para generar cambios rápidamente y cambios duraderos. Torres afirmaba que el descontento de las poblaciones rurales "podría llevar a un estado revolucionario violento, ya que este se produce cuando las necesidades sentidas no encuentran cauces de solución pacífica". ${ }^{119}$

La Educación Fundamental Integral era entendida como un proceso dinámico que operaba en todas las actividades de la vida humana, puesto que a partir del contenido de las nociones el hombre asumía consciente, libre y responsablemente su tarea en la promoción del desarrollo. Es decir, mediante esta educación fundamental se enseñaba a vivir, a participar en sociedad y a participar en la solución de los problemas. Este tipo de educación buscaba cubrir todos los campos donde se desarrollaba la actividad de la persona, además de incluir todo el espectro de las necesidades tanto materiales como biológicas, entre ellas aspectos como la alimentación, el vestido, la vivienda y la salud, entre otros.

118. BERNAL, Hernando. "Radio educativa para el desarrollo rural: el precursor Radio Sutatenza y Acción Cultural Popular, su influencia en la región", en Radio y democracia en América Latina. IPAL - Instituto para América Latina, 1989. p. 94.

119. TORRES, Camilo y CORREDOR, Bertha. Las Escuelas Radiofónicas de Sutatenza - Colombia, Bogotá, Centro de Investigaciones Sociales. 1961. p. 53. 
Esta educación estaba relacionada con todos los aspectos atinentes a la vida del hombre. Por ser integral no solo reparaba en los aspectos de tipo material, sino que incluía la vida intelectual, la vida social, y en general la globalidad de los problemas humanos. Una educación necesaria para aquellos que por su situación estructural se encontraban aislados de los beneficios y los servicios que producía la sociedad.

Pero la Educación Fundamental Integral se debía caracterizar en hechos concretos. Era necesaria que su efectividad fuera verificable. El aprendizaje de conocimientos y técnicas debía convertirse en hechos de manera consciente mediante su aplicación, creando costumbres y nuevos hábitos sociales. Es decir, se esperaba que el campesino, al aprender a leer, ejercitara su aprendizaje leyendo el periódico que lo vinculaba con la vida nacional, o libros que le permitían acceder a nuevos aprendizajes. 0 si aprendía los números, empezara a llevar con claridad y prontitud su presupuesto familiar, midiendo así sus ingresos y sus gastos. ${ }^{120}$

Por medio de las Escuelas Radiofónicas, la Educación Fundamental Integral llevó al campesinado los conocimientos elementales y los combinó con aprendizajes de asignaturas complementarias. Como la gran mayoría de campesinos no habían tenido la oportunidad de asistir normalmente a la escuela, en ACPO recibieron la educación básica y otros conocimientos que le aportaban a mejorar su calidad de vida. El ingreso del campesino a estos procesos educativos era voluntario, pero debían ser parte de una acción responsable y constante. Los estudiantes podían matricularse en las Escuelas Radiofónicas con absoluta libertad y podían, igualmente, suspender en el momento que lo quisieran, pero debían tener en cuenta que el proceso requería de responsabilidad, entendida esta como el cumplimiento de los compromisos adquiridos a la hora de obtener su radio por medio de créditos para pagarlo por cuotas, y también la responsabilidad con su comunidad a la hora de llevar a cabo obras de mejoramiento.

Pero si la idea era que el campesino mejorara su propio entorno y aportara en la solución de sus propios problemas, surgía un interrogante que consistía en determinar cuáles eran las necesidades de ese campesinado al que se le estaba llegando mediante las clases radiales. ACPO respondió a este interrogante trabajando con aquellas personas que hacían parte de las diferentes Escuelas Radiofónicas. "Por medio de la observación participante, los iniciadores del trabajo de las Escuelas Radiofónicas obtuvieron un conocimiento de primera mano sobre

120 Radio Sutatenza, 60 años de un sueño. Curso básico. Ejercicios para leer de corrido y escribir, Radio Nacional de Colombia. 2008. 
las realidades de la vida de los hombres del campo". ${ }^{121}$ Posteriormente el periódico El Campesino realizó encuestas preguntando a la población campesina cuáles eran los principales problemas que tenían.

El carácter polifacético del hombre incluía necesidades en diferentes ámbitos; estas giraban en torno a valores individuales y sociales que comprendían lo físico y mental, lo sicológico, lo social, lo cultural y lo moral. ${ }^{122}$ De allí surgió la necesidad de suministrar a los campesinos formación en cinco aspectos que constituyeron la Educación Fundamental Integral y que se hicieron visibles con las diferentes nociones: Alfabeto, Número, Salud, Economía y Trabajo (Agricultura), y Espiritualidad. Estas nociones hicieron parte de una propuesta que establecía una relación entre la educación fundamental, el uso de los medios y el énfasis didáctico por medio de las cartillas. A esta propuesta se le denominó Operación Cinco. ${ }^{123}$

\section{Las nociones de la Educación Fundamental Integral}

Las cinco nociones de la Educación Fundamental Integral de ACPO fueron propuestas a partir del análisis de las necesidades de los campesinos. A continuación se explicará cada una de las nociones con sus contenidos generales y los objetivos propuestos.

ACPO, como institución de la Iglesia, consideró de especial importancia la Noción de Espiritualidad, puesto que la acción educativa de las Escuelas Radiofónicas debía girar en torno a la escala de valores del hombre, logrando que este tomara conciencia de los valores fundamentales, de su condición de "ser creado, elevado a un estado sobrenatural, partícipe de la vida misma de Dios y miembro de la comunidad de hermanos". ${ }^{124}$ ACPO pretendía dar una educación al campesinado que le permitiera mediante el ver, el juzgar y el actuar, incidir en su entorno, guiado por la doctrina de Cristo.

A partir de la noción de Espiritualidad se planteó la necesidad de que el hombre luchara por la salvación eterna y por el mejoramiento de las condiciones de

121. BERNAL, Hernando, Educación Fundamental Integral. Teoría y aplicación en el caso de ACPO. Bogotá, Editorial Andes, 1978. p. 132.

122. Informe a la Venerable Conferencia Episcopal, 1961 a 1964, Bogotá. p. 63.

123. Ibid.

124. HOUTART, Francisco y PÉREZ, Gustavo. Acción Cultural Popular. Sus principios y medios de acción, op cit., p. 45. 
vida, porque Dios deseaba el bienestar individual y social del hombre durante su permanencia en la tierra. Igualmente, toda acción del hombre estaba influenciada por la gracia de Dios. Pero la responsabilidad de los actos humanos era individual y por eso a cada persona le correspondía hacer todo lo posible para mejorar sus condiciones de vida, para lo cual debía trabajar y asociarse.

Pero esta noción no solo hacía parte de la vida religiosa, de lo espiritual, sino que iba más allá, ubicándose también en las relaciones sociales y personales del ser humano, en este caso del campesino. Se planteaba de esta manera la idea de que Dios traspasaba todos los límites y deseaba el bienestar del hombre en todos sus ámbitos.

El desarrollo del hombre no era solo una opción personal e individual, sino que para salir del subdesarrollo era necesario utilizar las potencialidades que habían sido dadas por Dios. Alcanzar la gloria y cumplir la misión impuesta por Dios, incluía un deber social y un deber de solidaridad que conjugaba perfectamente con el papel que debían cumplir todas aquellas personas que hacían parte de las Escuelas Radiofónicas. Los deberes de los campesinos, en este caso, estaban en función de lo público y de la misma Iglesia Católica. Cada una de las acciones de carácter individual, llevadas a cabo en las Escuelas Radiofónicas, debía estar al servicio de la comunidad.

En la relación entre la fe y el desarrollo, ACPO sostuvo como principio ideológico el deber de la sociedad y de la Iglesia para colaborar en el desarrollo de los valores espirituales, culturales, sociales y familiares "y aún de perfección individual que Dios ha puesto en cada uno de los hombres como semilla que habrá de fructificar según la naturaleza y el Plan Creador..." ${ }^{125}$ Es así como alfabetizar al pueblo, colaborar en el mejoramiento de la producción agrícola y elevar el nivel de vida de los hombres, respondía a las exigencias fundamentales del Señor y a la indisoluble unión entre acción terrenal y la acción espiritual. De esta manera, ser parte de la obra de ACPO significaba ser parte de la Iglesia. Pero así mismo, para ser parte de la Iglesia se debía ser parte de la obra de Acción Cultural Popular. Esta noción enmarcaba la acción de las personas dentro del ámbito solidario de la acción comunitaria, desarrollando valores de solidaridad necesarios para poder existir en comunidad.

125. HOUTART, Francisco y PÉREZ, Gustavo. Acción Cultural Popular. Sus principios y medios de acción, op cit., p. 14. 
Las clases que hacían parte de esta noción dentro de la programación de las Escuelas Radiofónicas eran de catecismos, de formación, de lo que se debe saber y practicar, y de orientación de la vida familiar y social.

La noción Salud era entendida como la condición para la plena expansión de las facultades físicas e intelectuales del hombre. Esta noción estaba inspirada en los planteamientos de la Organización Mundial de la Salud que afirmaba que "La salud es el estado de completo bienestar físico, mental y social y no solo la ausencia de enfermedad o invalidez". ${ }^{126} \mathrm{El}$ cuidado del cuerpo surgía con esta noción como un deber cristiano, personal y social. Se impartía mediante clases de higiene mental, higiene corporal, de higiene ambiental, de nutrición, de prevención de enfermedades y accidentes, de primeros auxilios y botiquín familiar, de puericultura y de campañas sanitarias. Por medio de ella se desarrollaba una actividad de previsión y conservación del ambiente y de los individuos.

La noción Alfabeto era considerada como la puerta de acceso hacia la cultura, al progreso técnico y el contacto con la sociedad. Mediante el acceso a la lectura y la escritura se le facilitaba al campesino su entrada al mundo intelectual, espiritual, social y económico, y se lograba mejorar el intercambio cultural y social. ACPO consideró que la enseñanza del alfabeto era indispensable como conocimiento básico para mejorar la participación de los estudiantes en sus relaciones sociales, en la organización social y en la vida cultural. La tarea alfabetizadora de ACPO se llevó a cabo desde los inicios de Radio Sutatenza. Adquiriendo este conocimiento los campesinos lograban ampliar los demás conceptos de la educación integral. Era fundamental el leer y escribir para acceder a los diferentes contenidos dados a través de los cursos radiales.

El aprendizaje de la lectura y la escritura llevó a ACPO a la adopción de un método que, en los primeros años, consistió en el uso de otro medio como los afiches para acompañar los programas radiales; ${ }^{127}$ posteriormente se incluyó el acompañamiento de un medio humano, como los auxiliares inmediatos; y por último la elaboración de una cartilla que acompañaba las clases radiales del alfabeto. Las clases eran de lectura y escritura, de orientación para el uso del periódico, de orientación para el uso de la biblioteca, y de campañas de alfabetización. Para fortalecer el aprendizaje de esta noción, ACPO publicó el semanario El Campesino y

126. Ibid., p. 46.

127. La revisión del archivo de Sutatenza permitió ver cómo en las clases que se daban a las primeras Escuelas Radiofónicas se utilizaron los afiches como un medio auxiliar para el aprendizaje. 
organizó la Biblioteca del Campesino, ${ }^{128}$ que contaba con varios títulos y cuyos libros eran enviados a las diferentes Escuelas Radiofónicas. Hasta el 31 de diciembre de 1967, ACPO había impreso 12 títulos diferentes de la Biblioteca del Campesino; entre ellos estaban La buena nueva (el Evangelio según San Lucas), El Evangelio de San Mateo, La madre y el niño, Primeros auxilios, Verduras y frutas, Juegos y diversiones, Cooperativa de ahorro y crédito, Chispa y buen humor o ¡Qué bueno ser colombiano!, entre otros.

Para ACPO existía una gran falla en la cultura del pueblo colombiano, pues el valor del Número no estaba apropiado por las personas y como consecuencia de esa falencia se ignoraba el rigor del cálculo y de la previsión. Dentro del modelo de Educación Fundamental Integral, la noción Número buscaba que el campesino se familiarizara con los conceptos de tiempo y espacio, que le permitirían comprender la relación hora de trabajo con productividad. Además, esta noción buscaba que los campesinos pudieran planear y contabilizar sus gastos y sus ingresos. El conocimiento de las matemáticas también permitía que los campesinos accedieran con mayor tranquilidad a los préstamos y pudieran calcular sus pagos.

Una última noción dentro del modelo de Educación Fundamental Integral tenía que ver con Economía y Trabajo. Esta noción entendía el trabajo del hombre como el desarrollo de las capacidades creativas del mismo con la idea de lograr progreso. ACPO en esta noción realizó un esfuerzo educativo dirigido hacia el trabajo agrícola, pero consideraba que dentro de la propuesta los contenidos de esta enseñanza cambiarían, puesto que la tecnificación de la agricultura llevaría a disminuir la proporción de personas que debían trabajar en el campo. La liberación de la fuerza de trabajo pasaría a otros sectores y necesitaría de unos conocimientos diferentes, por eso ACPO pensó que la formación hacia el futuro debía ser politécnica, con el fin de capacitar al hombre para los nuevos retos.

Esta noción cumplió un papel importante, pues por medio de ella se intentó impactar en las estructuras agrarias, dando a conocer y ayudando a comprender al campesinado los valores fundamentales sobre el problema económico, social y técnico, de la agricultura. Con la perspectiva de cambiar dichas estructuras agrarias, educacionales y sociales, se dieron "al campesino los fundamentos de la economía y de la técnica agrícola, cubriendo todo el ciclo de la producción, del mercadeo y del consumo e insistiendo en las implicaciones sociales y laborales

128. ACPO editaba y distribuía los libros de la Biblioteca del Campesino. Los lectores adquirían el libro a cambio de un huevo. Hasta el año de 1967, según el informe enviado a la Venerable Conferencia Episcopal, se habían impreso 12 títulos diferentes. 

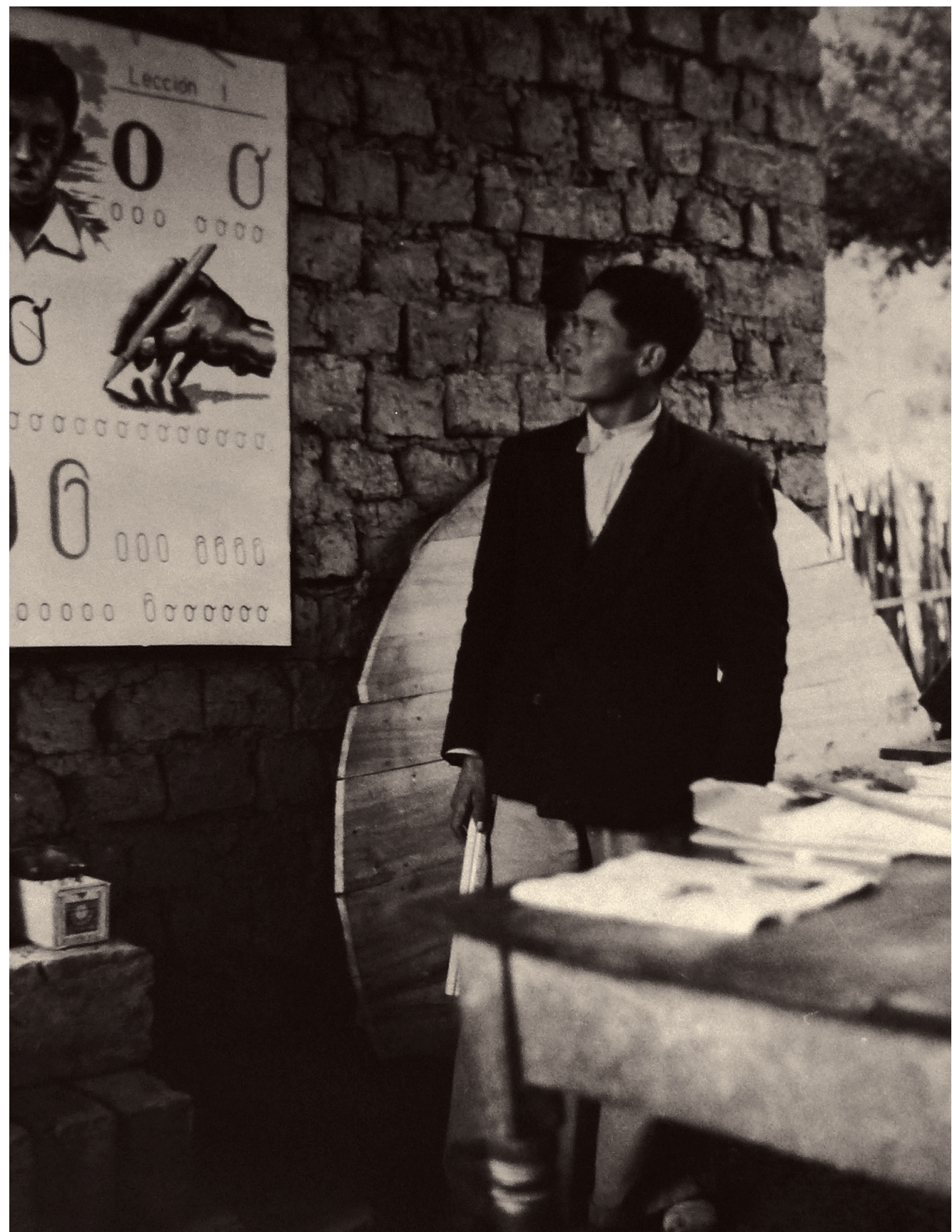
de la agricultura". ${ }^{129}$ Las clases que hicieron parte de esta noción fueron, entre otras: la defensa del suelo, defensa de las plantas, técnica de cultivos, huerta casera, jardinería, industrias animales (vaca de leche, cerdo, gallina, abeja, etc.), y economía doméstica (culinaria, modistería y bordados, etc.).

\section{Los elementos o medios de acción}

A partir de la definición de las nociones había que hacer la conversión de estas a cartillas, pues la Operación Cinco planteaba como propósito “el hacer que en el menor tiempo posible, el mayor número de campesinos posea y ame las cinco cartillas, síntesis de las nociones básicas de educación integral cristiana; que las aprenda y las practique para incorporarse conciente y libremente a su propio mejoramiento y al progreso de la patria". ${ }^{130}$ Esto implicaba un impulso a los denominados elementos de acción como la misma radio, las cartillas, el periódico, la biblioteca, la correspondencia, los institutos campesinos, los cursos de extensión y las grabaciones.

Desde 1960 y durante algunos años fue difundido un diagrama en el periódico El Campesino, de documentos de trabajo y de carteles donde se podía ver los aspectos centrales y distintivos del modelo educativo de ACPO. Este incluía las nociones mencionadas, los medios de acción utilizados y la organización regional y local de ACPO, estrechamente ligada a la formación de líderes y dirigentes campesinos y al posicionamiento de los Auxiliares Inmediatos como sujetos claves en la organización de las Escuelas Radiofónicas y de la institución en general. ${ }^{131}$

Como se observa en el diagrama de la página 80 , el modelo educativo no solo apuntó a llevar unas clases por medio de la radio, sino que se constituyó en un proyecto multimedial, es decir, que utilizó simultáneamente varios instrumentos de comunicación para optimizar el proceso de aprendizaje. Si bien inicialmente se pensó que la labor pedagógica tenía como su medio principal las clases radiales, las Escuelas Radiofónicas con la Educación Fundamental Integral eran mucho más que transmitir contenidos por la radio. Los otros medios no solo fortalecieron el proceso de enseñanza y aprendizaje, sino que se fueron convirtiendo en determinantes. Es así como en el diagrama se observa a la totalidad de los medios en una misma línea horizontal. Se utilizaron diferentes medios con el objetivo de

129. HOUTART, Francisco y PÉREZ, Gustavo. Op cit. p. 50.

130. Informe a la Venerable Conferencia Episcopal, 1961 a 1964, Bogotá. p. 63.

131. El Campesino, Bogotá, 27 de noviembre de 1988, p. 7. 
llegarle al campesinado con una educación que le aportara y le ayudara a mejorar sus condiciones de vida. Mencionaremos algunos de ellos, especialmente los más reconocidos, y analizaremos el papel que cumplieron dentro del sistema de la Educación Fundamental Integral.

Así como los medios se complementaron, la Educación Fundamental Integral no tomaba cada una de las nociones como una respuesta individual a las necesidades, sino que se constituían en un entramado que en su totalidad aportaban a la búsqueda de soluciones del campesino.

De esta manera, mientras que el profesor de la noción Alfabeto utilizaba la palabra leche para enseñar la e o la ch, al mismo tiempo dejaba claro el valor nutritivo de este alimento y motivaba a los estudiantes para que trataran de hacer el esfuerzo de tener una vaca lechera. Así, a partir de varios conceptos que se trabajan en la noción Alfabeto se relacionaban con el resto de las nociones como el Número o la Salud, entre otros. Otro ejemplo se presenta con la noción Número; en esta clase se hacían ejercicios para medir el área de la casa del campesino, pero aparte de practicar la aritmética, se mostraba en las cartillas una organización y distribución de la vivienda campesina, así como la ubicación de los sitios relacionados con la higiene. ${ }^{132}$

Las cartillas como uno de los medios de acción ya habían sido utilizadas en los primeros años de las Escuelas Radiofónicas, pues el Ministerio de Educación del gobierno de Laureano Gómez, realizó una donación de las cartillas que se utilizaban para los niños en las escuelas. ${ }^{133}$ Como dicho material no estaba dirigido al estudiante campesino, ACPO recibió la asistencia de expertos en textos escolares de la Unesco, quienes durante cuatro años trabajaron en la preparación y validación de la primera cartilla de lectura, escritura y aritmética como elementos complementarios de la educación impartida por los profesores radiofónicos.

El 14 de octubre de 1953, la UNESCO inició un programa de asistencia técnica a ACPO. Consistió en la visita de una comisión compuesta por el doctor Adishesha, de nacionalidad hindú, y los hermanos cristianos Idinael y Fulgencio. Idianael, de origen francés, experto en textos escolares, y Fulgencio, español, técnico en ilustraciones de textos. 


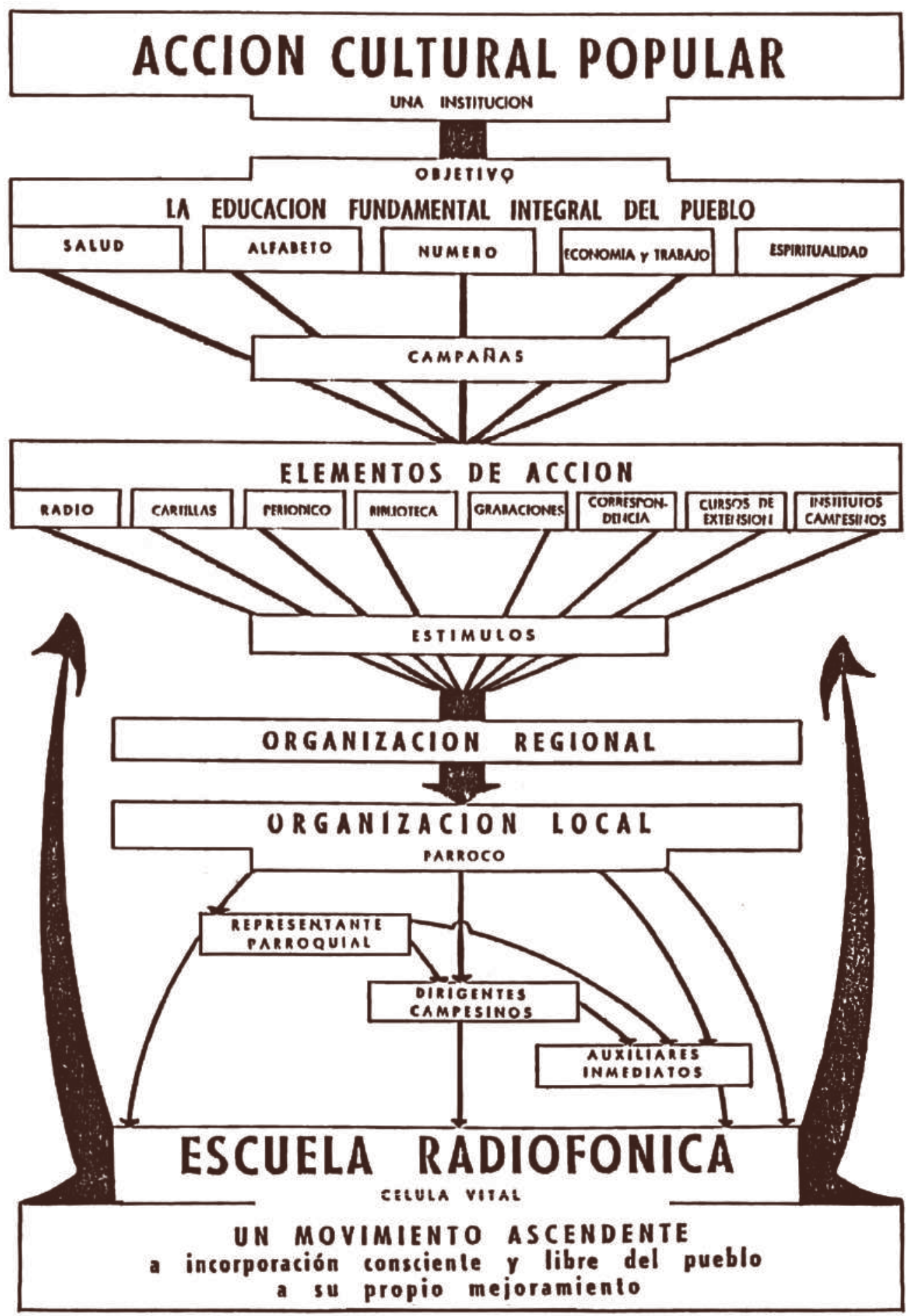


De acuerdo con sus estudios e investigaciones se decidió preparar y experimentar la primera "Cartilla de Lectura" y diseñar las láminas de lectura, escritura y aritmética, en razón de que este tipo de materiales, por ser de índole visual, complementaban la parte meramente auditiva de la radio, que ya había comenzado a actuar en labores culturales Dicha asistencia técnica se prolongó hasta 1957. ${ }^{134}$

En 1955 ya se habían distribuido 82.292 cartillas de una impresión total de doscientos mil, que iban dirigidas a los estudiantes que escuchaban sus clases en los equipos de recepción que tenían 129 parroquias. Para ese año, el padre Salcedo afirmaba contar con la colaboración de 601 parroquias de las 983 existentes en las zonas rurales del país. ${ }^{135}$

La cifra de campesinos alfabetizados en la primera década de funcionamiento de ACPO legitimó el uso de las cartillas como un medio de acción. Desde 1948 hasta 1957, la institución contaba con un total de 21.990 estudiantes alfabetizados en lectura y escritura, y con 62.283 con conocimientos básicos de economía rural, es decir, aprendizaje de la aritmética. El crecimiento de estudiantes fue especialmente significativo a partir de 1955, cuando las Escuelas Radiofónicas pasaron de tener 87.064 estudiantes a 145.114 en $1958 .{ }^{136}$

Ante los hechos, las cartillas se constituyeron en un medio indispensable dentro de la formación de los campesinos que hicieron parte de las Escuelas Radiofónicas y que recibieron la Educación Fundamental Integral. Los campesinos utilizaron las cartillas para realizar los ejercicios prácticos que eran asignados durante la emisión de las clases radiales. ${ }^{137}$

Las clases en las Escuelas Radiofónicas se emitían en diferentes horarios, según la publicación de una programación en el periódico El Campesino; se realizaban emisiones de las clases de lectura y escritura de lunes a jueves con una duración aproximada entre 12 y 16 minutos. Estas clases hacían parte de la educación básica y salían al aire de 6 a.m. a 6:25 a.m., con repetición a las 3 de la tarde. A las 6:44 a.m. hasta las 7:00 a.m. estaban las clases de aritmética y catecismos durante tres días, turnándolas días de por medio. El resto de los cursos que tenían que ver

134. El Campesino, Bogotá, 12 de septiembre de 1976. p. 6.

135. Informe al Eminentísimo señor Cardenal y a los Excelentísimos prelados de Colombia reunidos en Conferencia Episcopal en 1955. Acción Cultural Popular. Escuelas Radiofónicas, p. 3.

136. Informe a la Venerable Conferencia Episcopal, 1957 - 1958, Bogotá, p. 8.

137. Las cartillas correspondientes a las cinco nociones establecidas fueron editadas en 1962. El Campesino del 1 de julio de 1962 reseña dicha información y da a conocer algunas opiniones al respecto. 
con las otras nociones eran dados entre las 6:25 y las 6:42 de la mañana. Estos cursos los realizaban uno o dos locutores, quienes a medida que iban explicando, daban instrucciones para ir guiando al estudiante. Igual que las clases de lectura y escritura, todas las demás se repetían en las horas de la tarde para que el alumno pudiera acceder a ellas en cualquiera de los dos horarios.

La programación hacia finales de los años 50 contaba con 13 contenidos diferentes. Entre ellos estaban los concernientes a las nociones básicas de la Educación Fundamental Integral, y algunos otros programas como eran los boletines informativos, los dramatizados o los programas de música y variedades.

En cada una de las Escuelas radiofónicas había una persona, denominada Auxiliar Inmediata, que ayudaba a los campesinos estudiantes con el aprendizaje de los conocimientos transmitidos a través de la radio. Este auxiliar inmediato se constituyó en pieza fundamental dentro del engranaje, pues era quien debía matricular a los estudiantes de su escuela e informar sobre ella, conseguir los útiles escolares solicitándolos en la parroquia, seguir las clases, cumplir lo que le pedía el profesor por la radio y apoyar a los estudiantes en la adquisición de los conocimientos impartidos. ${ }^{138}$ Este Auxiliar no necesariamente era un profesor, sino que bastaba con que tuviera algún grado de educación formal, preferiblemente que hubiera terminado la escuela primaria y que tuviera el deseo de ayudar a sus familiares o a los miembros de la comunidad. El padre jesuita, Francisco Javier Mejía, lo describe como "un campesino como los demás, pero con algunas nociones rudimentarias de estudio y de conocimientos de lectura y escritura, amén de una buena dosis de abnegación y un chispeante entusiasmo por la obra". ${ }^{139}$

Los Auxiliares Inmediatos no solo contaron con el apoyo de las cartillas, sino que también utilizaron el semanario El Campesino, que empezó a circular desde junio de 1958 como un periódico "al servicio y en defensa de los campesinos". ${ }^{140}$ Los fines de esta publicación, según el mismo semanario, eran básicamente dos:

- Contribuir a la revalorización de la vida rural, por parte de los campesinos en primer término, y de las otras clases sociales, con un concepto cristiano del trabajo del campo;

- Servir de complemento a la obra en que está empeñada la Iglesia con la organización de las Escuelas Radiales.141

138 El Campesino, Bogotá, 4 de febrero de 1968, p. 5.

139 Revista Javeriana, No. 160, noviembre de 1949, p. 288.

140 El Campesino, Bogotá, 29 de junio de 1958.

141 Ibid., p. 2. 


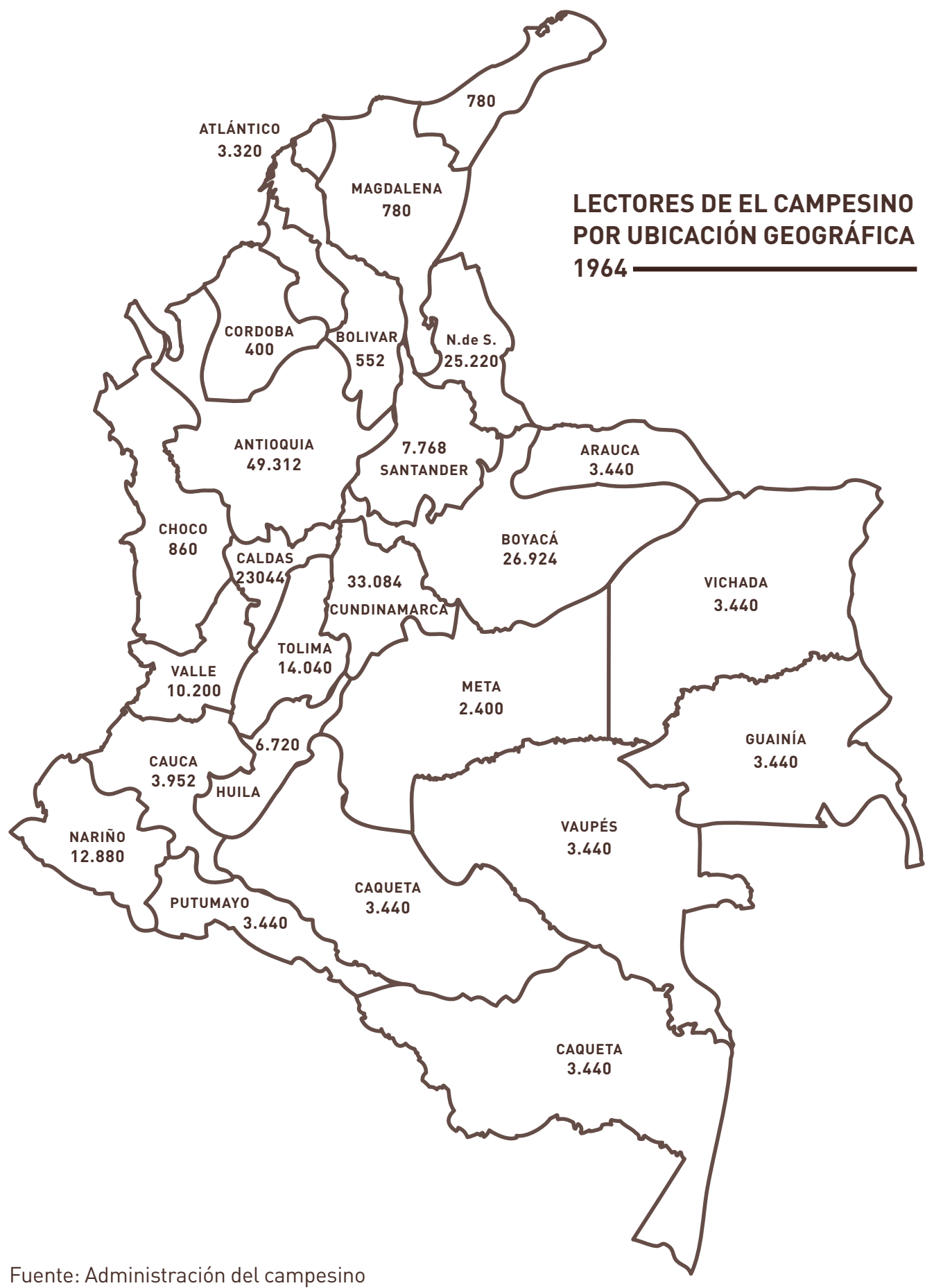


El apoyo prestado por este semanario en el sistema de la Educación Fundamental Integral tomaba dos vías; una, que tenía que ver concretamente con la formación de los conocimientos básicos del campesino, puesto que la adquisición del diario podía fortalecer el aprendizaje de la lectura; y otra, que permitía al campesino relacionarse con el mundo exterior a través de este medio de comunicación. El Campesino era un mediador entre una clase excluida tradicionalmente de las decisiones y las clases dirigentes del país.

Desde sus primeras ediciones, este semanario recogió temas de interés para el campesinado reivindicando el uso racional de la tierra, el derecho a una vida digna, la búsqueda del bien común y la defensa de la vida social, del desarrollo de la parroquia rural y del progreso. La pretensión del periódico era "Transformar al hombre, valorizar todas su posibilidades individuales y colectivas; reestructurar la sociedad en Cristo", considerada como "la amplia empresa que acomete este semanario en un mundo donde los hombres se asfixian de egoísmos". ${ }^{142}$

La vinculación directa del periódico El Campesino con las Escuelas Radiofónicas garantizó en buena medida la adquisición del mismo, por eso el tiraje anual aumentó considerablemente. Lo que empezó en 1958 con una circulación de 29.800 periódicos, alcanzó en 1963 un total de 80.563 periódicos semanales.

El número de páginas de este semanario estuvo entre 16 y 20, y estaba conformado por tres secciones fijas: una, de información general y orientación editorial, es decir, páginas que recogían información de todo el país sobre temas relacionados con la economía, la política, o los hechos internacionales; otra, de servicios y divulgación y conocimiento de nuevas técnicas, que informaba sobre servicios que prestaban organizaciones como el ICA o la Caja de Crédito Agrario, además de publicar las nuevas técnicas para mejorar los cultivos o la cría de ganado; y la tercera, de variedades y desarrollo, que consistía en la divulgación de campañas para el mejoramiento de ambientes familiares. Esta última sección era producida en un $80 \%$ por los propios campesinos, mientras las otras dos eran elaboradas por redactores de planta y colaboradores permanentes. El Campesino llegó a tener corresponsales en 19 ciudades y en 722 poblaciones. ${ }^{143}$ Las secciones que hacían parte del periódico muestran un esfuerzo de este por llegarle a un gran número de personas en diferentes sectores. Aunque el periódico estaba dirigido hacia los campesinos, también, como se mencionó, abordaba temáticas que tenían que ver con las decisiones tomadas en las grandes ciudades del país o los hechos sucedidos a nivel nacional e internacional.

$142 \quad$ Ibid., p. 2 .

143 Informe a la Venerable Conferencia Episcopal, 1961 a 1964, Bogotá. p. 32. 
Durante los primeros años, el periódico tuvo varios cambios tanto en su formato como en sus colores y en el tamaño de letra. Dos años después de su fundación, el periódico amplió su formato de tabloide a universal y empezó a trabajar varias páginas con cuatro colores. La publicidad que hizo presencia en las páginas del periódico, inicialmente tenía que ver con la labor desarrollada por ACPO y muy especialmente por las Escuelas Radiofónicas, pero posteriormente se amplió con la vinculación de empresas como Seguros Bolívar, chocolate Corona o cigarrillos Pielroja, entre otros, quienes pautaban constantemente. Algunos programas de Radio Sutatenza eran patrocinados y por eso aparecían también avisos en el periódico como el publicado en 1960, donde con el logo de Texaco decía: "Radio Sutatenza invita a Uds. a escuchar los siguientes programas patrocinados por Texas Petroleum Company", y a continuación estaban los horarios de los programas culturales. ${ }^{144} \mathrm{~A}$ medida que el periódico alcanzó mayor presencia nacional, la publicidad aumentó. Igualmente, la vinculación de ACPO con instituciones del Estado permitió que ellas pautaran para promocionar o divulgar sus servicios. Ese fue el caso del ICA, del Incora y de la Caja de Crédito Agrario. ${ }^{145}$

El periódico se convirtió, para el campesinado que estaba en las Escuelas Radiofónicas, en una guía que podía ser leída, estudiada, repasada, coleccionada y consultada con frecuencia. Gracias a este medio hacía seguimiento de los aprendizajes con ejercicios adecuados y actualizados, puesto que su circulación semanal le permitía imprimir nuevos contenidos que no estaban en las cartillas, complementando y actualizando los conocimientos del mensaje educativo y las acciones de la Escuela Radiofónica.

El Campesino era un vehículo destinado a promover los cambios de actitudes, mentalidad y comportamiento utilizando mensajes persuasivos, dentro de lo que ACPO consideraba como el desarrollo integral de los individuos. Por ejemplo, el 3 de agosto de 1958, el semanario publicó un aviso donde enunciaba algunas de las virtudes que debía tener un pueblo:

Nuestro pueblo debe tener todas las virtudes cívicas, sociales y religiosas que hacen grande la vida de comunidad, pero de modo especial debe distinguirse por:

- La cultura de todos sus habitantes.

- El interés de todos por su progreso

- La unión de todos sus moradores. 
- La amabilidad, la gentileza y las buenas maneras para con los habitantes.

- El cumplimiento de los deberes cívicos.

- La preocupación por la educación de la niñez.

- El apoyo a las iniciativas provechosas para toda la ciudadanía.

- La colaboración al mejoramiento de los servicios públicos.146

Del mismo modo, continuamente hacía campañas que eran publicadas en el periódico donde invitaban al campesinado para que mejorara sus viviendas, sus huertas, sus gallineros o se implementaran los servicios de acueducto y alcantarillado en sus hogares. Estas campañas se hacían generalmente en homenaje al Papa, como la publicada el 24 de enero de 1960, que se titulaba “En este año, homenaje de las Escuelas Radiofónicas a su Santidad Juan XXIII, las comunidades parroquiales prestarán y ofrecerán sus realizaciones". ${ }^{147}$ De esta manera, el periódico, ante las limitaciones propias de la radio como el tiempo de las grabaciones o la imposibilidad de una interacción directa, complementaba a través de sus páginas con gráficas y con explicaciones detalladas de algunos temas.

El semanario dio cuenta de las informaciones que tenían que ver directamente con el campesino, con sus tierras, con la erosión o con la violencia que se manifestaba en diferentes zonas del país. En varias de las páginas de las diferentes ediciones, El Campesino publicó tanto noticias sobre lo que sucedía en las regiones del país, como información sobre los motivos generadores de violencia. El 20 de marzo de 1960 publicó un texto del obispo de la diócesis de Armenia, Jesús Martínez, donde afirmaba en este sentido que:

Todos estamos convencidos, agrega, de que entre los factores poderosos de la violencia, se cuenta la ignorancia religiosa en los diferentes campos sociales; por este motivo creemos que en la extinción de la violencia, la colaboración más efectiva de las autoridades diocesanas debe ser la de seguir intensificando, dentro de sus posibilidades, la más sólida instrucción religiosa de ricos y pobres, de niños y adultos, en todos los campos del apostolado. ${ }^{148}$

Pero no solo la falta de fe era considerada como generadora de la violencia; continuamente en el semanario se responsabilizaba al comunismo de la situación en la que vivía el país. En distintas ocasiones se escribieron en el semanario sobre el tema, titulares como "El comunismo fomenta la violencia en el Tolima"149 o

\footnotetext{
146 El Campesino, Bogotá, 3 de agosto de 1958.

147 El Campesino, Bogotá, 24 de enero de 1960.

148 El Campesino, Bogotá, 28 de marzo de 1960.

149 El Campesino, Bogotá, 7 de septiembre de 1958.
} 
“El comunismo respalda la violencia"150. Los artículos sobre el tema de violencia en el campo fueron recurrentes y aunque se hacía constante mención al comunismo, continuamente el periódico publicaba los hechos de violencia, la muerte de campesinos y los desplazamientos que se daban en diferentes regiones del país.

A pesar de esa situación social que se vivía en diferentes lugares de Colombia, el periódico mantenía su idea de dignificar al campesino, y por eso publicaba constantemente sobre el valor que tenía ser campesino. Por medio de diferentes artículos, el periódico resaltaba la labor de los campesinos, mostrándolos como unos seres de gran importancia para la economía del país, como hombres productivos, como campesinos cristianos y como hombres fieles al campo.

La imagen de campesino que ACPO buscaba proyectar era la de un ser que mantenía los rasgos de la vida rural, pero que lograba trabajar en comunidad para buscar el desarrollo de los pueblos. Un hombre que mediante la formación en las Escuelas Radiofónicas podía forjar su destino y el de su comunidad, trabajando para que las condiciones de vida mejoraran. La idea de la construcción de una nueva estructura rural estaba fundamentada según El Campesino en que la estructura se "levante" sobre "el respeto a la persona, sobre el respeto a la familia, sobre el respeto a la vida, sobre el respeto a la conciencia, sobre el respeto a la propiedad, sobre el respeto a la autoridad, sobre el desinterés cristiano, sobre la amistad sincera, sobre la confianza mutua". ${ }^{151}$ Es evidente que el concepto de respeto era fundamental en la formación de ACPO, pues por medio de él se podía generar unas condiciones que permitieran que el trabajo en comunidad se concretara con el diálogo y los acuerdos.

Los campesinos constantemente estaban siendo valorados en las páginas del semanario. Se aprecia el interés de ACPO por hacer que el campesino lograra sentir que se constituía en un hombre fundamental en la construcción del país. Uno de los avisos publicados mostraba al campesinado como la población más numerosa del país y la que más divisas producía, también como aquel grupo de hombres que más aportaba al Ejército para la defensa del territorio nacional. ${ }^{152}$

Por medio de sus páginas se difundían los avances y tareas que realizaban los campesinos a favor de su propio mejoramiento. Dentro de la idea de que este medio impreso era en defensa del campesinado, se hizo continua referencia al papel que

150. El Campesino, Bogotá, 17 de agosto de 1958.

151. El Campesino, Bogotá, 6 de julio de 1958.

152. Ibid. 
cumplía el periódico y ACPO a favor de los campesinos y la labor de monseñor José Joaquín Salcedo, dentro del marco de las funciones que tenía como director de la institución. En 1962, el semanario exaltaba la labor del mismo periódico:

En solo cuatro años de vida, EL CAMPESINO ha llegado a constituirse en el PRIMER órgano popular de su género con la MÁS ALTA difusión nacional y como el PRIMER semanario cultural de América Latina. Al educar, orientar el informar al pueblo, EL CAMPESINO está colocando a millones de colombianos en aptitud y capacidad de producir y consumir cada vez más cosas para vivir mejor.

Este triunfo es el resultado del entusiasmo y del sentido de solidaridad social de miles y miles de dirigentes y trabajadores de los pueblos y veredas del país que escriben ELCAMPESINO, que leen ELCAMPESINO, que distribuyen EL CAMPESINO, que difunden EL CAMPESINO y que en este semanario encuentran cada semana un estímulo para trabajar por su propia dignificación y por la grandeza y prosperidad de la nación a la que pertenecen. ${ }^{153}$

También se difundió información relacionada con las actividades de instituciones como el ICA, la Caja Agraria, el Incora y la Federación de Cafeteros, que prestaban servicios directos de créditos, capacitación, organización comunitaria y diferentes apoyos a la promoción de la salud y el mejoramiento de la vivienda. Varias de estas instituciones estatales cumplían papeles complementarios o similares a la acción desarrollado por Acción Cultural Popular, entonces para El Campesino era importante la publicación de las labores que desarrollaban, puesto que ellas intentaban beneficiar al campesinado. De otra parte, a ACPO le servía mantener unas relaciones directas con estas instituciones para, igualmente, contar con el apoyo de ellas en varios de los programas que llevaba a cabo. La Caja Agraria o la Federación de Cafeteros compraban espacios publicitarios en el semanario para promocionarse.

Varias de las publicaciones donde estaban vinculadas las instituciones mencionadas mostraban la relación existente entre sus programas y los proyectos que desarrollaba ACPO. Un ejemplo de ellos fue la financiación que realizó la Caja Agraria para que los campesinos pudieran obtener los radios que les permitían escuchar los programas producidos por la emisora Sutatenza. Bajo el título de 
“Entusiasmo por el nuevo servicio de la Caja Agraria", El Campesino explicaba el programa de financiación:

Han comenzado a llegar a nuestra redacción mensajes de varias comunidades rurales del país en los que se expresa el entusiasmo y reconocimiento por el programa de crédito de la Caja Agraria, mediante el cual los almacenes de Provisión Agrícola de esa entidad han comenzado a distribuir los radio receptores transistorizados que permiten al pueblo rural participar en los programas de Acción Cultural Popular para su mejoramiento.

Particular entusiasmo demuestran en los campos por las facilidades o plan de crédito para la cultura que ofrece ahora la Caja Agraria, mediante el cual se dan facilidades para que los habitantes de los campos puedan adquirir los receptores con una cuota inicial de 45 pesos y con plazo hasta de diez meses para pagar el valor total de este moderno medio de comunicación y educación. ${ }^{154}$

Otra de las secciones era la llamada correo campesino. Esta sección publicaba semanalmente las cartas de los oyentes y lectores del propio periódico. Eran cartas que tenían que ver con los temas tratados en las clases radiales o con aspectos relacionados con el campesinado. Cartas que tenían que ver con los servicios que prestaba la Caja Agraria, como la que escribió un campesino del Huila donde le hacía saber "al gobierno y a la opinión pública que tenemos necesidad de una sucursal de la Caja Agraria con su respectiva sección de ahorros en este pueblo" o las relacionadas, en el mismo periódico, con algunos de los aspectos de la Escuelas Radiofónicas, como el caso de un campesino de Antioquia, quien avisaba que si no había una rebaja en las pilas (baterías) de los transistores, se vería en la obligación de privarse de la Escuela.

Mis circunstancias económicas no me permiten seguir disfrutando de ese gran servicio, pues la pila hasta llegar a mí, me cuesta $\$ 48.00$, con $\$ 4.00$ que me toca pagar de transporte. Y si no tengo que pagar repuestos por daños en el receptor, ¿a cuánto se me eleva el costo de la escuela? Imposible, imposible. Mucho dolor me da tener que privarme de tan sabias enseñanzas, pero no alcanzo. ${ }^{155}$ (sic)

Las cartas de esta manera se convertían en el medio utilizado por el campesino para socializar sus problemas y para evidenciar las necesidades de su entorno. Las cartas 
que llegaban a ACPO, en relación con las Escuelas Radiofónicas eran respondidas de manera personal, pero aún así algunas eran publicadas en el periódico. De esta manera se hacía una socialización de los problemas del campesinado, pero también se destacaban aquellos escritos que tenían que ver con el trabajo desarrollado por las Escuelas Radiofónicas, por El Campesino y por ACPO en general. La publicación de cartas en este sentido era masiva y mayoritaria. Habitantes de todas las regiones del país enviaban estas cartas. Venían de municipios como La Calera, Sibaté o Tausa, cubrían desde el departamento de Boyacá y Cundinamarca hasta el Putumayo o la Guajira. Por ejemplo, del Norte de Santander un campesino enviaba una misiva donde destacaba la labor del periódico:

Respetuosamente me dirijo a ustedes enviándoles mi más efusivo saludo y para felicitarlos por su valiosa labor que han adelantado desde sus columnas a favor de la inmensa masa campesina del pueblo colombiano, con sus lecciones que trae cada semana, instrucciones y consejos, respuestas a sus preguntas y problemas que a diario presentan. ${ }^{156}$

El semanario El Campesino, más allá del papel que jugó en el engranaje de la Educación Fundamental Integral, adquirió importancia por sí solo, pues no solamente llegaba a quienes hacían parte de las Escuelas Radiofónicas, sino que era leído por un buen número de colombianos. Por su circulación nacional, se convirtió en uno de los medios más importantes de la institución. Según ACPO, el periódico recibió "la mejor y más extraordinaria acogida, no solo del pueblo agricultor, sino también de las clases dirigentes, que han visto en el semanario una respuesta a las más urgentes necesidades que el país tenía en ese campo." Para finales de 1960 se editaban normalmente 74.000 ejemplares, y de acuerdo con los propios estimativos, después del diario El Tiempo, era el periódico con mayor circulación en el país. ${ }^{157}$

Si bien el periódico El Campesino empezó a publicar las cartas de sus lectores desde 1958, antes de ese añoya se había creado un Departamento de Correspondencia en ACPO, que tenía como función principal responder todas las cartas recibidas. Desde que se iniciaron oficialmente las Escuelas Radiofónicas en 1949, las cartas se constituyeron en el único medio de comunicación directa entre los alumnos y los profesores de la institución. Estas se convirtieron en un medio práctico para

156. El Campesino, Bogotá, 29 de mayo de 1960.

157. El periódico El Campesino del 29 de abril de 1962 muestra en la página 16 una detallada lista de las poblaciones a donde llega el semanario acompañada del número de ejemplares enviados a cada una de ellas. Igualmente hace un resumen del número de ejemplares por departamentos. Para esta fecha El Campesino distribuye, según el registro publicado, un total de 118.042 ejemplares. 
complementar la enseñanza radial. Era la única posibilidad económica y accesible para tener una retroalimentación o una respuesta de la labor que se desarrollaba en las Escuelas Radiofónicas.

Entre 1953 y 1967, ACPO recibió y contestó un total de 521.519 cartas de campesinos. Estos escritos hacían alusión a situaciones relativas con el funcionamiento de las mismas Escuelas, ya fuera en relación con sus contenidos, con los medios utilizados o con la metodología. También se podía encontrar una variedad de misivas que estaban dirigidas a la institución, agradeciendo la labor prestada y comentando los adelantos que se habían tenido en los diferentes aprendizajes. ${ }^{158}$ María del Carmen Maldonado, en una carta escrita el 10 de junio de 1966 desde el municipio de Carmen de Carupa, en Boyacá, comentaba las mejoras que realizó: "En la casa estoy comenzando con la higiene de la vivienda y la higiene de personas", y manifestaba que desde hacía dos años tenía su radio y estaba trabajando como Auxiliar Inmediato en la escuela donde asistían vecinos y familiares. ${ }^{159}$ De otra parte, las cartas se convertían en un medio de control sobre los problemas que se presentaban en el funcionamiento de las Escuelas Radiofónicas o en las actividades de los líderes. Una de las representantes parroquiales comunicaba a ACPO la necesidad de que le enviaran unos radios para comprarlos a plazos:

Cáqueza, octubre 2 de 1966

Reverendo padre José Ramon Sabogal

Bogotá

R.P. lo saludo con todo respeto deceandole que Dios lo colme de bendiciones.

Padre le contare lo sigiente estuvi esta cemana una santa mision en lavereda y able con el padre misionero del moimiento radiofonico pero un fue posible que le quedara tiempo de acerle propaganda me dijo que esa comunidad tenia varios radios, en la caja se acavaron yo necesito unos 5 radios ojala que fueran a pasos.

158. ACPO cuenta con un archivo de las cartas enviadas por los estudiantes y de las respuestas escritas por los funcionarios de la institución. Este archivo está organizado por años, desde los inicios de ACPO. La revisión y análisis de las cartas se hizo especialmente del año de 1966, periodo al que se tuvo acceso en los archivos de Acción Cultural Popular en el municipio de Sutatenza.

159. Carta de María del Carmen Maldonado dirigida a Acción Cultural Popular el 10 de junio de 1966. 
Padre tenga la vondad de mandarme decir su las comprobaciones de las reuniones de cada mes, a donde tengo que mandarles que he mandado 2 y no se si las abran resividas.

Padre, able con momceñor del asusnto de los radios en Bogotá y dijo que es que ahel no le queda y el padre coadjutor tiene que dar clases en el colegio de varones y ninguno puede hir.

Padre le pido el favor de no pasar ninguna carta al programa de correo. Padre tenga labondad de escusarme que por no escrivirle sino que no me queda tiempo.

Padre medespido pidiendole mede su santa bendicion.

Ana Cecilia Melo T.

Reprecentante parroquial (sic)

Mediante estas cartas, ACPO conocía sobre lo que sucedía en las diferentes Escuelas Radiofónicas y comunidades parroquiales. Los mismos estudiantes se encargaban de informar sobre las necesidades, las carencias y los logros. Esto permitió que los programas de las nociones se fueran actualizando. Con la fundación del periódico El Campesino, algunas de las cartas eran publicadas y dadas a conocer por este medio, lo que permitió la socialización de los problemas del campesinado en diferentes ámbitos.

Los medios mencionados anteriormente tienen relación directa con instrumentos de comunicación; sin embargo, en los elementos de acción se contaba con los Institutos Campesinos, que se crearon para la formación de aquellos que iban a ocupar algún cargo dentro de la estructura local de las Escuelas Radiofónicas. Es decir, en estos institutos se formaban los Auxiliares Inmediatos, los Dirigentes Campesinos o los Auxiliares Parroquiales. ACPO creó en Sutatenza dos institutos para que los campesinos de todo el país recibieran actualizaciones e instrucción durante cuatro meses. Uno de los institutos era para las mujeres y el otro para los hombres.

El instituto de hombres se estableció en 1953, y con la colaboración de los párrocos se hizo una selección del primer grupo de dirigentes campesinos que permanecieron internos durante cuatro meses recibiendo formación en las cinco nociones de la Educación Fundamental y en la adquisición de competencias para la comunicación interpersonal, mediante el aprendizaje de un mayor vocabulario 
y el ejercicio del diálogo y la discusión. De la misma manera, en 1957 se abrió el instituto de mujeres, donde también se capacitó a aquellas mujeres que iban a cumplir un papel de liderazgo en las Escuelas Radiofónicas. Quizás uno de los aspectos más importantes de la experiencia de la Escuelas Radiofónicas fue incorporar a la mujer en este tipo de procesos, de los cuales tradicionalmente se hallaba relegada. A finales de los 50 y principios de la década del 60, las mujeres campesinas relacionadas con ACPO empezaron a ingresar al proyecto asumiendo nuevos roles dentro de la estructura local de la institución.

Los criterios de selección para ingresar a los Institutos Campesinos consistían en tener una edad mínima de 18 años, saber leer y escribir y pertenecer a una familia campesina, honorable, propietaria y solvente. Además, dentro de las condiciones se estableció que "tengan inteligencia suficiente y que tengan capacidad para ser dirigentes", 160 condiciones que evaluaba el cura párroco, quien era el encargado de dar el aval para ingresar al instituto. ${ }^{161}$

El fin principal de los institutos era “la formación apostólica de estos dirigentes, encaminada a la adquisición de conocimientos que les sirvan para colaborar con los señores párrocos y con sus hermanos campesinos para llevar a cabo una auténtica campaña de la revaloración de la vida rural". ${ }^{162}$ Estos institutos sacaban dos promociones de dirigentes al año. Una iba de febrero a junio, y la otra, de agosto a diciembre.

Con la formación de estos dirigentes se logró consolidar un amplio grupo humano que trabajara al lado de los campesinos y que apoyara las labores parroquiales. Su afianzamiento como dirigentes les permitió organizar mejor a las comunidades y hacer parte posteriormente de juntas veredales o juntas comunales que fueron apoyadas en las páginas del periódico El Campesino. ${ }^{163}$ Por eso algunos temas tratados con las nociones tenían que ver con la participación ciudadana, el desarrollo comunitario y el liderazgo. ${ }^{164}$ ACPO intentaba responder así a sus principios, pues en ellos planteaba que las actividades de Acción Cultural Popular favorecían "la creación de un movimiento desarrollado por unos militantes

160. El Campesino, Bogotá, 28 de febrero de 1980, Bogotá, p. 12.

161. Informe a la Venerable Conferencia Episcopal, 1961 a 1964, Bogotá, p. 44

162. El Campesino, Bogotá, 28 de febrero de 1980, Bogotá, p.12

163. El Campesino, Bogotá, 5 de noviembre de 1961, Bogotá, p. 8

164. Un plegable promocional de los Institutos Campesinos de Sutatenza indicaba las clases, los temas y la metodología utilizada en los institutos para la formación de líderes. Este plegable se encontró en los archivos de ACPO en Sutatenza. 
que encarnen una doctrina de vida en una acción solidaria organizada". ${ }^{165}$ Y así lo venían haciendo al capacitar a los campesinos para que lograran ocupar un lugar privilegiado dentro de su comunidad como dirigentes y organizadores de diferentes grupos sociales.

Los medios de acción mencionados se consolidaron como los más importantes dentro de la formación del campesinado, no obstante, después de 1960 se inaugura la prensadora de discos de ACPO que se empleaba para grabar canciones folclóricas y de estilo campesino, música popular, pequeños poemas y mensajes de tipo cultural. ${ }^{166}$ Con la producción magnetofónica, ACPO buscaba que las diferentes emisoras de Radio Sutatenza pudieran pasar las clases en diferentes momentos y pudieran divulgar algunos trabajos musicales que se grababan con el ánimo de promocionar la música popular. La institución tenía en Bogotá los equipos necesarios para la prensa de discos que le permitía realizar las grabaciones. Hasta el año de 1967, el número de discos prensados por ACPO llegó a 16.582, distribuidos en la diferentes Radio Sutatenza del país.

Además, se crean las Bibliotecas del Campesino, medios que aportan significativamente al proceso de lecto-escritura de los estudiantes. Las bibliotecas surgieron como un complemento a las clases radiales y a las cartillas. El material impreso en la Editorial Andes, una de las empresas de ACPO, ampliaba los conceptos y conducía las ideas prácticas para su posterior aplicación. La colección contó con 100 temas, impresos en pequeños libros de bolsillo que fueron vendidos mediante un sistema de canje desarrollado con los tenderos de las veredas, y denominado 'Un libro por un huevo'. ${ }^{167}$ Los libros de la biblioteca trataban temas que tenían que ver con literatura, religión, arte, técnicas para el trabajo, el deporte y el entretenimiento. ${ }^{168}$

El informe de ACPO a la conferencia Episcopal entregado en 1964 registró una impresión de 100.000 libros correspondientes a 10 colecciones, cada una con 10 libros, para un total de 100 títulos. Entre los libros editados hasta ese año, estaban: La buena nueva, La madre y el niño, Qué bueno ser colombiano, La vaca del campesino; y libros que reforzaban los conceptos relacionados con la higiene y la salud como el de Primeros Auxilios; la organización de las comunidades como Cooperativa de

165. HOUTART, Francisco y PÉREZ, Gustavo. Acción Cultural Popular. Sus principios y medios de acción, op cit., p. $40 B$.

166. MARTíNEZ, Emiro. Métodos de periodismo rural en el semanario El Campesino, Editorial Andes, Bogotá, 1978, p. 28.

167. Revista Presencia, octubre de 1960, No. 99, p.44.

168. El Campesino, Bogotá, 14 de enero de 1968. 
ahorro y crédito; o la historia y el civismo en el texto El precursor. Buena parte de estos libros tenían relación con las nociones de la Educación Fundamental Integral y buscaban reforzar los conocimientos impartidos en las Escuelas Radiofónicas.

Los elementos de acción, en general, cumplieron un papel de apoyo a la labor desarrollada desde la radio con las Escuelas Radiofónicas. En medio de las nociones básicas que permitían una formación en áreas consideradas fundamentales por ACPO, se realizaban las Campañas, que eran acciones prácticas pero sustentadas en los principios teóricos que regían la Educación Fundamental Integral. En este sentido, las campañas se concibieron como una adopción de innovaciones resultante de la acción de conocer y de saber. La idea principal a la hora de implementarlas consistió en la necesidad de que el campesino incorporara nuevos elementos a su realidad, se apropiara de ellos y los realizara en su entorno, encontrándoles sentido tanto para su vida como para su comunidad. Por eso se establecieron campañas orientadas en varios frentes.

La campaña Suelo perseguía el desarrollo de las prácticas para la defensa del suelo y de la naturaleza, y buscaba que el campesino aprendiera cómo conservar la tierra. Otra campaña fue la de Vivienda, que pretendía que los campesinos mejoraran sus viviendas y desarrollaran prácticas en torno a ella que tenían que ver con la higiene, el aseo, la distribución de espacios, la implementación de jardines y huertas. Otro aspecto que trabajó ACPO en las campañas estuvo relacionado con la Nutrición, para que los campesinos tuvieran un adecuado y balanceado consumo de alimentos; igualmente la Recreación, que estuvo orientada hacia los deportes, el teatro, la literatura y la música, entre otros; y la Procreación responsable, que fue una campaña que implementó ACPO con el ánimo de que los campesinos tuvieran una orientación dirigida hacia el cuidado de los hijos y el manejo responsable de las relaciones sexuales. ${ }^{169}$ Las áreas que cubrían estas campañas eran aquellas que, de una u otra manera, se trabajaban a partir de las clases que se daban en las Escuelas Radiofónicas. Las campañas eran instrumentos de refuerzo de los aprendizajes obtenidos previamente por la mayoría de los estudiantes.

Estas campañas se realizaron mediante una coordinación sistemática por parte de todos los mensajes difundidos en los diferentes medios, buscando el sentido de la acción misma. En esencia fue la aplicación práctica de un conocimiento, pues se intentaba que los campesinos desarrollaran las acciones recomendadas en sus

169. BERNAL, Hernando. "Radio educativa para el desarrollo rural: El precursor Radio Sutatenza y Acción Cultural Popular, su influencia en la región", en Radio y democracia en América Latina. IPAL - Instituto para América Latina, Lima, 1989, p. 106. 
entornos. El campesino, en la Educación Fundamental Integral, transitaba así de las palabras a los conceptos, de estos a las ideas, y de las ideas a la praxis por medio de las campañas.

Las campañas fueron el instrumento donde se hizo uso sistemático de los medios de acción. Estas campañas se programaban durante varias semanas en las Escuelas Radiofónicas, especialmente los sábados, ${ }^{170}$ y entre tanto en el periódico El Campesino aparecía semanalmente una página dedicada a temas relacionados. ${ }^{171}$ Igualmente, los líderes campesinos divulgaban y promocionaban el tema en los diferentes pueblos.

Habitualmente los medios de acción fueron utilizados en todo el sistema de la Educación Fundamental Integral, y cumplieron papeles de refuerzo de los mensajes de acuerdo con los fines y objetivos propuestos, ya fuera en los cursos, en las cartillas o en las diferentes campañas que se realizaron. Para la institución, las Escuelas Radiofónicas fueron el eje articulador del accionar de cada uno de los medios. Aunque las clases se daban en la radio, perdían sentido sin la existencia de los grupos de estudiantes que conformaban las Escuelas Radiofónicas. La constitución de los grupos familiares o de vecinos en torno a las clases radiales era considerada vital para que los campesinos comprendieran las posibilidades de recibir una educación que los enriqueciera individualmente y que les permitiera forjar proyectos comunes. De acuerdo con el papel que tuvieron las Escuelas Radiofónicas dentro del todo el sistema, fueron consideradas como una célula vital del movimiento de ACPO.

Los medios para los cuales trabaja Acción Cultural Popular para la dignificación del pueblo son varios... Pero la Escuela Radiofónica es la célula vital del movimiento, la Escuela Radiofónica vive en el lugar del campesino, donde transcurre su vida, desarrolla su actividad y ocurren sus preocupaciones, a donde acuden familiares y vecinos. El centro de recepción organizado, la acción del Auxiliar Inmediato, la utilización de los materiales gráficos, la llegada del semanario, la acción permanente de la radio, constituyen el centro, la célula, el origen de una acción que busca la “EDUCACIÓN INTEGRAL CRISTIANA DEL PUEBLO”, con sistemas que abarquen su cultura básica y la preparación para la vida social y económica...

170. De acuerdo con las programaciones publicadas en El Campesino, la transmisión radial de las campañas se realizaba los días sábados.

171. Para observar un ejemplo de las campañas realizadas por ACPO, relacionadas con el tema de la vivienda, se puedo revisar la edición del periódico El Campesino del 5 de julio de 1959. 
El alumno de la escuela radiofónica se educa para sí y para los demás. El Auxiliar Inmediato actúa en beneficio propio, de sus alumnos y de la comunidad. Todos buscan un mismo fin y se mueven por los mismos ideales.

Son parte de una organización familiar len la misma Escuela Radiofónica), veredal, parroquial, diocesana y nacional. TODO ESTO SIGNIFICA EN ACCIÓN CULTURAL POPULAR, LA CÉLULA VITAL DE TODO UN MOVIMIENTO. ${ }^{172}$

En general, el sistema de ACPO poseía tres grandes componentes indispensables para su accionar. Inicialmente una serie de conceptos que constituyeron la ideología de Acción Cultural Popular desde que inició la Emisora Sutatenza hasta el trabajo de reflexión realizado por Houtart y Pérez a finales de los años cincuenta y a principio de los 60. En ese momento se dejó explícita la ideología de la institución en relación con el desarrollo, especialmente de las comunidades campesinas. De otra parte, una serie de procesos que se transformaron en una metodología de la acción educativa y la intervención social, de acuerdo con un orden y funcionamiento de los propios procesos. Y, por último, la puesta en marcha de unos medios o instrumentos de comunicación y de producción que se constituyeron en herramientas que aportaban en el cumplimiento de los objetivos sociales propuestos, pero también a la consecución de recursos externos para el mantenimiento de la institución.

Estos tres componentes que permitieron el funcionamiento de ACPO, durante varias décadas, compartieron un lugar común: el origen y desarrollo a partir de la praxis. Antes que las reflexiones teóricas, la misma práctica fue la que guió el curso de acción de ACPO. Por eso no es extraño que cuando Houtart y Pérez escribieron Los principios y medios de acción de ACPO, un buen número de los medios utilizados ya estaban establecidos con anterioridad. Realmente, el aporte en este sentido fue que al proceso nacido de la práctica se le dio una sustentación teórica, que le permitió a la institución fundamentar y consolidar su accionar durante cuatro décadas más. Se pasó de la etapa de experimentación a la etapa de acción intensiva. ${ }^{173}$

172 El Campesino, Bogotá, 14 de abril de 1963, Bogotá, p. 3.

173 El Libro Azul, hace mención de estas dos etapas en la historia de ACPO. Antes y después de la definición de los principios y medios de acción de la institución. 


\section{ACPO y su apoyo a la reforma agraria}

La carencia de tierras por parte del campesinado colombiano fue una preocupación de Acción Cultural Popular que se hizo evidente incluso antes de que el gobierno de Alberto Lleras Camargo aprobara la Ley de reforma agraria en 1961. Desde años antes, en efecto, ACPO presionó a través de sus diferentes medios, especialmente del periódico El Campesino, para que se tuviera en cuenta el tema de la injusticia de la propiedad agraria y para que se llevaran a cabo algunos cambios que permitieran el acceso de los campesinos a la tierra productiva.

El semanario, desde 1958, hacía alusión en su portada a este tema mediante una frase que rezaba "Los hombres sin tierra tienen derecho a la tierra sin hombres", ${ }^{174}$ recordando la cantidad de extensos terrenos no utilizados para el cultivo y la cantidad de campesinos que carecían de tierras o tenían pequeños minifundios que no lograban producir lo necesario para acceder a los recursos que les permitiera cubrir sus necesidades básicas.

Orlando Fals Borda en su trabajo 'El Hombre y la Tierra en Boyacá', planteaba cambios institucionales para poder realizar una reforma agraria y una organización del mercado de trabajo, y la necesidad de que el país empezara a dotarse de un sistema de transporte que permitiera la movilidad tanto de los productos como de los campesinos. Describía entonces cómo hasta ese momento el transporte de los productos agrícolas "se efectuaba casi todo a espalda o sobre la cabeza de los seres humanos, en carretas de dos ruedas tiradas por bueyes o en pequeños vehículos de cuatro ruedas llamados zorras". ${ }^{175}$

Si bien el problema del acceso a la tierra por parte de amplios sectores campesinos se trató desde gobiernos anteriores, especialmente desde el primer gobierno de la república liberal, a cargo de Alfonso López Pumarejo, no se pudo consolidar una política clara en este sentido durante los siguientes años. El triunfo de la revolución cubana y la violencia existente en el país fueron las causas que llevaron a que la preocupación por los problemas sociales, especialmente del campesinado, cobrara importancia.

La Iglesia, a finales de los años de 1950 y principios de 1960, empezó a hacer “llamados de atención sobre las condiciones de los sectores menos desfavorecidos,

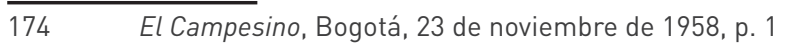

175 FALS Borda, Orlando, El Hombre y la Tierra... pp.191 y 192 
en la creación de comisiones episcopales dedicadas al estudio de asuntos sociales, así como el interés por cuestiones que hasta entonces no habían merecido mayor cuidado, como el problema agrario". ${ }^{176}$ El periódico El Campesino constantemente hizo eco de las palabras de la Iglesia en este sentido, donde no solo denunciaba la penetración del comunismo en el país y su posible influencia en el campesinado, sino que también denunciaba las condiciones en que se encontraban los campesinos por la falta de recursos para cultivar, por la injusta remuneración, por el creciente desempleo o por la falta de tierra. De nuevo el problema de los campesinos empezaba a tomar relevancia y "para ese entonces, la lucha por la tierra y por las condiciones del trabajador rural han vuelto a cobrar gran importancia, por lo que el gobierno, a finales de los sesenta, incluye en su agenda ese delicado problema". ${ }^{177}$

Aunque la política agraria del gobierno no estuvo condicionada a la opinión de Acción Cultural Popular, sí influyó significativamente porque el seguimiento que se realizó en el periódico fue constante. Precisamente desde 1958, año en que se fundó el periódico El Campesino, el tema de la reforma agraria estaba discutiéndose en el escenario político nacional. En ese mismo año, la Conferencia Episcopal había señalado que era el momento para que se realizara una reforma agraria y social que permitiera una riqueza productiva más equitativa. ${ }^{178}$

Ricardo Arias hace mención de las acciones tomadas por la Iglesia sobre el tema agrario en los años siguientes. Destaca cómo en 1959 se realizó el primer Congreso Nacional Católico de la vida rural, donde el clero fijó su posición frente a la problemática campesina, y cómo en 1960 los obispos declararon que la reforma agraria era una de las necesidades más apremiantes del país. Sectores como el de los jesuitas, en la Revista Javeriana criticaron la tenencia de tierras sin una utilización económica plena y destacaron la conveniencia de expropiar las tierras que estuvieran siendo desaprovechadas. ${ }^{179}$

Mientras la Iglesia hacía el planteamiento del tema agrario como una prioridad para el país y este se debatía en los diferentes escenarios, entre ellos los medios de comunicación, en 1959 ya se empezaban a ver algunas respuestas a la situación del campesinado y se evidenciaba en la declaración del gobierno ante la Sociedad

\footnotetext{
176. ARIAS, Ricardo. Episcopado Colombiano: Intransigencia y laicidad (1850 - 2000), Bogotá, Ediciones Uniandes, 2003 p. 195.

177. Ibid.

178. Ibid.

179. Ibid.
} 
Colombiana de Agricultura, donde manifestaba unos avances en el tema de política agraria. Allí se propuso fomentar la industria agropecuaria con un programa de utilización de tierras sin explotar, de entrega de tierras a los campesinos, de facilitación de asistencia técnica, de crédito a largo plazo con intereses reducidos, con el fin de poner en marcha una maquinaria adecuada para impulsar la agricultura y la ganadería. Para ACPO, el programa planteado por el gobierno respondía a las necesidades nacionales y hacía énfasis en lo que ya se venía reclamando desde hacía mucho tiempo.

El programa del gobierno expuesto a la Sociedad Colombiana de Agricultura era la primera iniciativa que se presentaba al país en el marco de la reforma agraria aprobada posteriormente. ACPO valoró, en su medio de comunicación impreso, dicha declaración, puesto que consideraba que la situación actual del campesinado no le permitía disponer de los recursos para "hacerles frente a las múltiples contingencias que lo rodean. Si es propietario de una pequeña parcela, cansada por el intenso laboreo, no encuentra facilidades para abonarla, ni crédito para adquirir herramientas, ni semillas, ni asistencia técnica, ni consejos oportunos para defender sus cultivos de plagas y enfermedades". 180 Pero además, exhortó a la dirigencia del país para que apoyara el programa del gobierno en este sentido, pues no respondía a los intereses políticos de un sector determinado, sino que reflejaba una realidad nacional que era inquietante por la difícil situación de la economía. Para ACPO era importante evitar que por las rencillas, los intereses o las posiciones políticas, se frustrara la posibilidad de que el campesinado accediera a beneficios relacionados con la explotación de la tierra, la asistencia técnica por parte del Estado y la posibilidad de adquirir créditos con facilidades. En su opinión, esas posiciones habían obstinadamente "detenido el progreso del país". ${ }^{181}$

Ante la eventual posibilidad de que se abriera un camino hacia la reforma agraria, Acción Cultural Popular celebró las nuevas decisiones sobre política agraria y se mantuvo a la espera de los resultados que las medidas produjeran hacia el futuro.

Cuando se iniciaron las discusiones de la reforma agraria, ACPO publicó en El Campesino las bases que consideraba como necesarias para una adecuada reforma. Estas eran que fuera económicamente sana, moralmente justa, socialmente democrática y prácticamente moderna. ${ }^{182}$ La coherencia entre lo afirmado por el

180. El Campesino, Bogotá, 1 de febrero de 1959, p. 3

181. El Campesino, Bogotá, 1 de febrero de 1959, p. 3

182. El Campesino, Bogotá, 24 de julio de 1960. p. 1 
semanario y por el episcopado era evidente, pues el segundo reconocía que "la reforma agraria es inevitable, pero agrega que la respuesta a las necesidades del campesino no puede ser solo material, pues en el transfondo de esta crisis aparece el problema moral". 183

El semanario en la edición del 24 de julio de 1960 imprimió una encuesta sobre la reforma agraria para que la contestaran los lectores. Esta constaba de cinco preguntas que tenían que ver con la situación económica actual del pueblo agricultor y se pidió la opinión del campesinado para saber qué consideraban ellos como conveniente para mejorar su situación. Además, se indagó, por medio de selección múltiple, sobre los aspectos donde se esperaban soluciones y mejoramiento; entre las respuestas estaban construir más escuelas, más carreteras, más caminos, más hospitales, abrir más fuentes de trabajo y destinar más préstamos en dinero. También se le preguntó al campesinado por la institución o instancia que consideraban podía hacer algo por ellos. Entre las respuestas para marcar estaban en este orden: el gobierno, la Iglesia, Radio Sutatenza, el periódico El Campesino, el comunismo, el protestantismo, las juntas veredales, los partidos políticos, los sindicatos, los patronos, los hacendados, la masonería y la Caja Agraria.

La idea de la encuesta era dar a conocer las respuestas al gobierno y al Congreso Nacional, e iniciar una campaña a favor de la reforma agraria. ACPO, por medio de la encuesta, propiciaba una participación del campesinado para que se diera la reforma, pero también privilegiaba algunas acciones más que otras. Las posibles respuestas, especialmente las que tenían que ver con las instituciones, mostraban al periódico El Campesino, a Radio Sutatenza o a la misma Iglesia como unas organizaciones que podían sustituir, en algunos aspectos, las actividades que ya se había empezado a discutir en el país.

Durante todo el año de 1960, las páginas de El Campesino y las instalaciones de Acción Cultural Popular fueron escenario de las discusiones y reuniones referentes al tema de la reforma agraria. El 28 agosto de ese año, El Campesino publicó la noticia sobre el envío de un prospecto de reformas de la Federación Agraria Nacional (FANAL ${ }^{184}$ ) a las Cámaras Legislativas, con el ánimo de que el Congreso Nacional las estudiara y las adoptara dentro de las discusiones sobre el tema de la reforma y como una solución a los problemas sociales y económicos del sector campesino ${ }^{185}$.

183. ARIAS, Ricardo. Episcopado Colombiano: Intransigencia..., op cit., p. 196.

184. Fanal fue una federación fundada y apoyada por la Iglesia Católica en 1946, con la intención de realizar acciones que aportaran a los problemas del país, especialmente los relacionados con el sector agrario.

185. El Campesino, Bogotá, 28 de agosto de 1960, p. 1. 
Del mismo modo, el auditorio de Acción Cultural Popular sirvió para que se dieran a conocer y se discutieran informaciones relacionadas con el tema de la reforma agraria. Los estudios realizados para tal fin por un comité coordinado y dirigido por Carlos Lleras Restrepo, a petición del presidente Alberto Lleras Camargo, fueron dados a conocer el 24 de octubre ante 500 personas en el auditorio mencionado. La realización de este evento en ese escenario dejó ver la importancia de ACPO en el marco de las discusiones de la reforma, y lo mostraba como una institución que representaba al campesinado, como un vocero de los intereses del sector agrario del país. Es claro que la posición de ACPO era privilegiada, pues era identificado como un actor principal en las discusiones sobre el tema, lo que le permitía intervenir, explicar y presionar para que los aspectos que consideraba importantes se incluyeran en los proyectos. ${ }^{186}$

El trabajo realizado por Carlos Lleras Restrepo dejó ver una estructura arcaica del factor primario de la producción y un atraso en el régimen de la propiedad rural que no había respondido a las necesidades y exigencias de la demanda de los bienes de consumo. Una de las preocupaciones del comité era la creciente aparición de sectores de personas "desocupadas, analfabetas, ambulatorias y exasperadas que constituyen el caldo de cultivo de los extremismos", ${ }^{187}$ por eso la necesidad de buscar soluciones de equilibrio, como las llamó Lleras Restrepo, para el buen funcionamiento de la economía, pero también para generar una producción que respondiera a las necesidades de los pueblos. La reforma agraria se convertía en la opción para la reestructuración del "sistema que permita modernizar la vida económica colombiana y aliviar las tensiones sociales acumuladas como producto del desajuste actual". ${ }^{188}$

El discurso de Lleras Restrepo mostró una posición común con la que expresó continuamente ACPO en el periódico El Campesino, y que consistía en que la reforma agraria no solo significa la tenencia de la tierra y la distribución de la misma, sino que estas acciones implicaban tomar medidas en relación con la educación, la salubridad y las comunicaciones, temas que venían trabajando las Escuelas Radiofónicas en sus clases radiales.

186. Carlos Lleras Restrepo en su explicación sobre el proyecto de reforma agraria en la revista Semana del 31 de octubre de 1960 confirmó como organismos representativos de los trabajadores rurales a la Iglesia, al Estado y al Ejército, y los denominó "factores reales de poder", por estar en contacto asiduo con los casi 7 millones de trabajadores rurales que sufren una serie de problemas.

187. Semana, 31 de octubre de 1960, p. 22

188. Ibid. 
De acuerdo con los enunciados expuestos en el auditorio de Acción Cultural Popular, el proyecto establecía un organismo que administraría el plan y que lo pondría en marcha. Los objetivos que tenía previstos eran:

a) Modificar las estructuras del sector para extirpar las concentraciones excesivas (latifundios) y evitar el fraccionamiento (minifundio). (sic)

b) Dotar de tierras adecuadas a quienes no las posean y se dediquen a cultivarlas;

c) Poner bajo cultivo las extensiones que hoy no lo estén y que sean susceptibles de explotación de acuerdo con los programas económicos globales;

d) Acrecer el volumen de la producción agropecuaria y aumentar los índices de la productividad (rendimiento hombre-hora);

e) Hacer fácil el acceso a la propiedad de la tierra de los pequeños arrendatarios, parceleros o aparceros (incorporan trabajo y dividen utilidades), y

f) Preservar los cursos naturales y asegurar su empleo adecuado. ${ }^{189}$

El organismo encargado para llevar a cabo ese programa fue el Instituto de la Reforma Agraria - INCORA- creado en el año de 1963, que, además de los objetivos enunciados anteriormente tenía otras funciones específicas como:

- Administrar las tierras baldías de propiedad de la Nación.

- Administrar el Fondo Nacional Agrario (Financiación).

- Orientar el desarrollo económico del sector en cuanto a tenencia, uso de las tierras, distribución de las aguas, recuperación de superficies inundables y lucha contra erosión.

- Fomentar el saneamiento de la titulación y cooperar en la formación de los catastros.

- Promover la construcción de vías y ejecutarlas directamente para los fines provistos.

- Promover y ejecutar las obras de reforestación, drenaje, regadíos, colonizaciones, parcelaciones o concentraciones donde sea necesario cambiar la estructura de la propiedad.190 
Sibien los enunciados del proyecto inicial de la reforma agrariay los objetivos propios del INCORA no daban claridad frente a los aspectos relacionados con la formación del campesinado, Lleras Restrepo sí había hecho mención de la necesidad de actuar con el campesinado analfabeta. Pero además ACPO, en las páginas del semanario El Campesino, fortaleció esa idea con la continua publicación de declaraciones que reforzaron la imperiosa necesidad de educar a la población campesina para que la reforma funcionara. Entre otras, fueron publicadas las palabras de Eduardo Carbonell, gobernador del departamento del Atlántico, quien manifestó estar de acuerdo con la campaña de ACPO en el sentido de que el gobierno debería "incrementar la educación entre las masas campesinas, porque de nada va a servir la reforma agraria si esta no llega a elementos que por su educación puedan hacer buen uso de ellas". ${ }^{191}$ En el marco del debate y discusiones sobre el tema de la reforma, El Campesino titulaba "Sufrimos la tragedia de ignorarlo todo y es tanta nuestra pobreza y nuestra miseria que aunque nos repartieran tierras, no tendríamos cómo trabajarlas ni cómo sostenerlas". 192

De esta manera, ACPO no solo se proyectaba como una institución que velaba por que los campesinos recibieran unas tierras para cultivar los diferentes productos agrícolas, sino también como un organismo dedicado a la educación. Así buscaba que la formación educativa del campesinado se incorporara en el proyecto de una reforma agraria integral, como la denominaría ACPO, haciendo uso del término utilizado dentro de su modelo de Educación Fundamental Integral. Es decir, la reforma agraria no solo debía tocar el tema de tierras y la producción, sino que debía incluir todos los aspectos que estuvieran relacionados con el bienestar del campesinado.

El Campesino, finalizando 1960, hizo circular en sus páginas una segunda encuesta sobre la reforma agraria, donde indagaba sobre lo que se esperaba del plan de tierras, de la forma en que consideraban se podía aplicar la distribución, las clases de tierras que debían ser tenidas en cuenta para incorporarlas a la producción, y las zonas geográficas donde se debía llevar a cabo ese plan de tierras. A partir de las primeras respuestas recibidas, El Campesino publicó artículos desarrollando las propuestas de los lectores. Precisamente en uno de ellos hacía mención de que, debido a que los campesinos cultivarían otro tipo de frutos diferentes a los tradicionales, la repartición de tierras diversificaría la producción. Acompañada de dicha información, el texto mencionaba la necesidad de educar al campesinado en el cultivo de nuevos productos. ${ }^{193}$

191. El Campesino, Bogotá, 6 de noviembre de 1960.

192. El Campesino, Bogotá, 28 de agosto de 1960.

193. El Campesino, Bogotá, 11 de diciembre de 1960 
El discurso de reforma agraria unido a la educación llegó a incidir tanto en la opinión pública y en el gobierno que hasta el mismo ministro de Agricultura, Otto Morales Benítez, se refirió a la necesidad de darle un fuerte impulso a la educación rural popular para no terminar haciendo una reforma a medias. ${ }^{194}$ Estas declaraciones fueron dadas en los primeros días de 1961, año en que se aprobó finalmente la Reforma Social Agraria por parte del Congreso Nacional, mediante la Ley No 135.

El artículo quinto de dicha ley, que rezaba: “Elevar el nivel de vida de la población campesina, como consecuencia de las medidas ya indicadas y también por la coordinación y fomento de los servicios relacionados con la asistencia técnica, el crédito agrícola, la vivienda, la organización de los mercados, la salud y la seguridad social, el almacenamiento y conservación de los productos y el fomento de las cooperativas", contenía varios aspectos de los impulsados por Acción Cultural Popular en el sentido de que la reforma debería ser integral. La Ley incluía la formación mediante la asistencia técnica, pero también la atención al campesinado en materias como la salud y la asociación.

Sin embargo, para poder tener un protagonismo real y para que se llevaran a cabo proyectos en las áreas mencionadas, era necesario que se organizaran los Comités Municipales de Reforma Agraria creados mediante el decreto 3177 de diciembre de 1961. Por eso, luego de aprobada la reforma, ACPO empezó a publicar artículos en el semanario invitando y exhortando a los campesinos para que presionaran para la organización de dichos comités y, por supuesto, para que hicieran parte de los mismos.

Consideramos indispensable hacer un llamamiento muy especial a todos nuestros lectores, en particular a los dirigentes campesinos y a los miembros de las Juntas Veredales, para que procedan sin dilaciones a exigir la pronta constitución en cada uno de los municipios de los Comités Municipales de la Reforma Agraria...

Como podrán haberlo visto en el decreto publicado por nosotros en la edición anterior, en cada municipio funcionará un Comité de la Reforma Agraria, integrado por el Cura Párroco, el Agente de la Caja de Crédito Agrario, si existiere; dos representantes del Concejo Municipal, que pueden ser concejales o no, de filiación política distinta, 
elegidos directamente por dichas corporaciones; y uno designado por las Juntas Locales de Acción Comunal. Los tres últimos tendrán un período de dos años contados a partir del primero de este mismo año de 1962, y dos suplentes numéricos que, en su orden, los reemplacen en caso de falta. Los dos primeros podrán designar delegados suyos que los reemplacen cuando no pudieran concurrir ${ }^{195}$.

Estos Comités cobraban importancia en las diferentes regiones, pues aunque eran órganos consultivos, tenían como objetivo el estudio de los problemas de la tenencia de tierras en la zona y los conflictos que se daban por tal causa, pero así mismo planteaban las posibles soluciones a tener en cuenta entre las que estaban la colonización, la parcelación o las concentraciones parcelarias. Era claro que la participación del cura párroco, sumado a los representantes de los concejales y al representante de la Junta de Acción Comunal, daba un amplio margen de maniobra y amplias posibilidades de incidir en las decisiones por parte de ACPO, si el trabajo se llevaba a cabo en lugares donde tenía presencia la organización.

Desde la aprobación de la Ley en diciembre 13 de 1961 hasta mayo de 1962, El Campesino en sus páginas mantuvo la atención sobre el tema para que se llevaran a cabo las acciones necesarias y para que la ley de reforma agraria empezara a funcionar. Ante la lentitud de las acciones, el semanario empezó a publicar en su primera página un aviso que peguntaba “¿Qué hay de la Reforma Social Agraria?”, para de esta manera presionar a la opinión pública para que pidiera una respuesta rápida. El interrogante iba acompañado de una frase distinta cada vez. En la edición 200 del semanario fue: “Esta es la pregunta que está interpretando la expectativa nacional de los agricultores ante la tan esperada aplicación de la Ley de reforma agraria"; ${ }^{196}$ en la siguiente edición, la pregunta estaba acompañada de la frase: “En todo el país existe gran expectativa", pero también incluía dos interrogantes más ¿cuándo?, y ¿dónde? ${ }^{197}$ En la misma página, ACPO seguía difundiendo su idea de que la reforma debía ir acompañada de la formación educativa. Afirmaba que: "La tierra sin educación no vale". ${ }^{198}$ La campaña realizada por el periódico fue seguida de cartas de los lectores donde reclamaban acciones concretas en torno a la reforma. Una de ellas decía:

195. El Campesino, Bogotá, 21 de enero de 1962.

196. El Campesino, Bogotá, 13 de mayo de 1962

197. El Campesino, Bogotá, 20 de mayo de 1962

198. El Campesino, Bogotá, 20 de mayo de 1962 
Qué pasa con la Reforma Agraria? No sé cómo han transcurrido ya siete meses de su aprobación y sanción y en este Departamento, [Valle] ni siquiera suena y menos truena. Qué pasa? Este Departamento no es de Colombia? 0 aquí no hay pobres? 0 no somos humanos? Yo solicito al señor Director del Incora que se sirva mover los resortes en el Comité o Instituto seccional o como quiera que se llame, que fue organizado en Cali. Se sabe que fue organizado pero no pasó de allí. Ojalá que se den cuenta de que los montañeros de Colombia estamos despertando de ese sueño campesino y sabemos que nuestra patria nos tiene un porvenir reservado. Pero, qué es lo que pasa? Presido una junta veredal y todos sus afiliados son demasiado pobres. Y esperan que la Reforma Agraria se efectúe cuanto antes. Estoy dispuesto a reclamar a diario... ${ }^{199}$ (sic)

La intención de ACPO fue mantener la atención de los campesinos en torno al tema de la reforma agraria y ejercer presión para que la Ley se ejecutara. A pesar de las pocas acciones concretas, ACPO mantuvo un discurso en relación con el tipo de reforma agraria que debía llevarse a cabo dentro de los principios generales de la Ley, por ello publicó también una columna semanal denominada 'reforma agraria integral', donde daba indicaciones sobre la forma en que debían entregarse los créditos a los campesinos y cómo ellos debían estar acompañados de adecuadas políticas en materia económica que llevaran a mejorar los ingresos de los beneficiarios y su poder de compra. ${ }^{200}$ Igualmente, hizo énfasis en la necesidad de que el país fuera de propietarios y no de servidumbre. Su argumento fue que el progreso de la sociedad no podía estar basado en esa servidumbre, puesto que el desarrollo agrario significaría transformaciones de la agricultura del momento y el sobrante de mano de obra que debía ser destinado a la producción de otros bienes. ${ }^{201}$

De esta manera, edición tras edición, se hicieron reflexiones en varias áreas relacionadas con la reforma, para incidir a través de los Comités de Reforma Agraria tanto en las políticas locales como en las nacionales. Esta dinámica se mantuvo desde los primeros años de la aprobación de la reforma agraria, hasta el año de 1968, cuando se empezaron a implementar los proyectos regionales, como el de Nariño. Allí se inició un proceso de titulación de tierras, construcción de vías y vivienda, otorgamiento de crédito y asistencia técnica. Además, se constituyó la Cooperativa Agropecuaria de Nariño para el almacenamiento de

199. El Campesino, Bogotá, 1 de julio de 1962

200. El Campesino, Bogotá, 11 de noviembre de 1962, p. 3

201. El Campesino, Bogotá, 18 de noviembre de 1962, p. 6 
los productos del campesinado de la región. Este proyecto fue destacado en las páginas de El Campesino, por tener los principios básicos de la reforma, pero también por poseer los elementos esenciales que había planteado para que fuera una reforma integral. ${ }^{202}$

La creación de nuevas instituciones como el INCORA, la Caja de Crédito Agrario y el ICA, entre otros, llevó a un replanteamiento de las acciones de ACPO, pues estos prestaban servicios directos de capacitación y extensión agrícola, de organización comunitaria y de promoción de apoyo a la salud y al mejoramiento de la vivienda campesina. Es decir, ACPO perdía terreno frente a estas nuevas instituciones. Como había apoyado la reforma agraria establecida por la Ley $135 \mathrm{de}$ 1961, se empezó un ejercicio de colaboración y apoyo mutuo entre las instituciones y ACPO. Por esta razón, algunos programas de Radio Sutatenza y algunas páginas de El Campesino se utilizaron para informar y difundir materiales escritos o instrucciones de dichas organizaciones. El INCORA, por ejemplo, constantemente hacía anuncios en el semanario y aclaraciones como la publicada bajo el título de “INCORA aclara programa en Risaralda, a los cafeteros", ${ }^{203}$ o la Caja de Crédito Agrario que promocionaba los créditos que ofrecía, utilizando avisos publicitarios donde invitaba a los campesinos a utilizar los servicios con el mensaje de "Haga uso de su crédito. Nosotros le ayudamos a financiar sus necesidades a corto, mediano o largo plazo, con prenda agraria o garantía personal, con garantía hipotecaria... ". 204 Los anuncios en el periódico y en la radio contribuían a dar la impresión de una colaboración activa en la práctica, sin embargo, este concurso se mantuvo en límites estrechos. ${ }^{205}$ La cooperación generalmente se mantuvo en los servicios que prestaban algunas instituciones del Estado y que podían ser aprovechadas por ACPO para cumplir con sus fines. Un ejemplo de esto se vio en la financiación que recibieron los campesinos para acceder a los radios transistores. En esa ocasión, El Campesino publicó el artículo titulado "Circular de la Caja Agraria sobre Crédito Campesino", donde explicaba las decisiones tomadas por las directivas de la institución financiera en el sentido mencionado:

El Gerente General de la Caja Agraria, doctor José Elías del Hierro, ha enviado a todos los gerentes de suscursales, subgerentes de Provisión Agrícola y directores de agencia una circular reglamentaria

202. El Campesino, Bogotá, 11 de agosto de 1968, p. 4

203. El Campesino, Bogotá, 20 de octubre de 1968, p. 3

204. El Campesino, Bogotá, 21 de junio de 1959.

205. MUSTO, Stefan. Los medios de comunicación al servicio del desarrollo rural, Bogotá, Editorial Andes, 1971 p. 138 
en la cual les informa que las directivas de esta entidad accedieron a la solicitud de Acción Cultural Popular para que la Caja Agraria distribuya por intermedio de sus almacenes de Provisión Agrícola, los radiorreceptores transistorizados para la sintonía de las emisiones de Acción Cultural Popular. Dicha circular señala las cinscunstancias y condiciones en que se hará este servicio de venta. ${ }^{206}$

La sustitución de las labores desarrolladas por ACPO a partir de la creación de otros institutos o dependencias manejados por el Estado y con presupuesto propio, ocasionó que los recursos de Acción Cultural Popular se redujeran significativamente y la preocupación de la institución se concentrara en la búsqueda de nuevos recursos. Por esta razón, la atención frente al tema de la reforma agraria en los años siguientes disminuyó, pero además ya se vislumbraba el fracaso de la reforma y cómo una evidencia de eso se declaraba en uno de los documentos de trabajo de ACPO, titulado "Diálogo con líderes", que el país no podía seguir manteniendo indefinidamente "jueguitos democráticos como el de la reforma agraria actual, encaminada hoy solamente a gastar millones de millones de pesos de la economía nacional en comprar y repartir tierras a campesinos llamados a quebrar por no estar en capacidad de lograr una producción adecuada". ${ }^{207} \mathrm{El}$ sueño de una reforma agraria económicamente sana, moralmente justa, socialmente democrática y prácticamente moderna empezaba a derrumbarse.

En definitiva, el apoyo de Acción Cultural Popular al proyecto de reforma agraria de 1961 no logró acabar con las grandes desigualdades existentes en el país, a pesar de que ACPO le apostó a iniciativas que combinaran los aspectos técnicos y las relaciones sociales del hombre dentro de su contexto en la búsqueda de mejorar la calidad de vida y la productividad del campesinado.

Para acabar con la injusticia social, con las desigualdades, y propiciar el desarrollo, para Salcedo era necesario la creación de riqueza en los diferentes ámbitos del ser humano, abordados a partir de las nociones dadas en las clases radiales. Por eso, en uno de sus últimos textos resumió su punto de vista con la frase "Sin producir riqueza, no se acaba con la pobreza". ${ }^{208}$

\footnotetext{
206. El Campesino, Bogotá, 1 de septiembre de 1963.

207. SALCEDO, José. Diálogos con los líderes, documento preparado por el profesor Lázaro Jiménez Acosta, Bogotá, Editorial Andes, abril de 1974, p. 60

208. SALCEDO, José. Sin producir riqueza no se acaba con la pobreza, Publicaciones Violeta, 1994.
} 


\section{Crisis y cierre de ACPO}

La crisis que llevó a ACPO a su desaparición estuvo relacionada con el apoyo que le había dado la Iglesia Católica y críticas de algunos sectores al trabajo realizado por los campesinos para desarrollar las labores de ACPO, con la financiación y sostenimiento de una institución que cubría buena parte del país y con los cuestionamientos recibidos de algunos empresarios colombianos que veían en ella una posible competencia comercial.

La Iglesia Católica que apoyó inicialmente el trabajo desarrollado por el padre José Joaquín Salcedo y avaló la labor de ACPO, trató de tomar el control de la institución durante la década de los años 60 y 70 al considerar que la razón de la misma debía estar enfocada exclusivamente a la evangelización. Salcedo se opuso considerando que si bien era una obra de la Iglesia Católica debía responder también a las necesidades materiales del campesino. "Los jerarcas vieron en ella un elemento muy eficiente de evangelización y quisieron utilizarla y valorarla solo para este fin pastoral; muy claramente quisieron además que ACPO a través de Radio Sutatenza fuera la voz oficial de la Iglesia en Colombia..." 209

Para que las emisoras de Sutatenza funcionaran como la voz de la Iglesia, se necesitaba que ellas dependieran de manera oficial de la Conferencia Episcopal. La jerarquía católica consideró que como ACPO se había definido como una obra de la Iglesia, a partir de allí podía tener un control total de la organización. Hernando Bernal Alarcón muestra de qué manera la Conferencia Episcopal intentó tomar el control:

“La Conferencia Episcopal no dudó en aprobar una reforma de estatutos de la institución que se hizo en el seno de la misma conferencia, contraviniendo las normas estatutarias de ACPO, mediante resolución B778 de la XXXIV Asamblea (Carta remisoria: 8 de octubre de 1978). En la orientación de esos nuevos estatutos, ACPO pasaría a depender en su actividad educativa y programática de las comisiones pertinentes de la Conferencia Episcopal."210

209. BERNAL, Hernando. "Radio educativa para el desarrollo rural: El precursor Radio Sutatenza y Acción Cultural Popular, su influencia en la región", en Radio y Democracia en América Latina. IPAL - Instituto para América Latina, 1989, p. 94

210. BERNAL, Hernando. Acción Cultural Popular, de la realidad a la utopía, Bogotá, Fundación Cultural Javeriana, 2005, p. 86 
Esta decisión fue apelada por ACPO en los tribunales, quienes le restituyeron su autonomía, mediante sentencia del Consejo de Estado dada el 6 de octubre de 1977. Sin embargo, la posición de los directivos de la organización ocasionó una fractura en el apoyo que había mantenido la jerarquía católica. Es así como la Iglesia Católica colombiana decidió pedirle a la Iglesia Católica alemana que retirara el apoyo y el financiamiento que le hacía a ACPO. Esta decisión empezó a limitar las operaciones de ACPO. Se disminuyó así la formación y capacitación de dirigentes y se afectó "el trabajo de promoción y administración de las escuelas radiofónicas, que era realizado en las comunidades rurales por los dirigentes, líderes y supervisores de origen campesino". ${ }^{211}$

Asegura Bernal Alarcón que ante la decisión de la Iglesia Católica de quitar el apoyo a ACPO, el Gobierno nacional, a la cabeza de Alfonso López Michelsen, decidió reducir y terminar los contratos de servicios que venía prestando la institución en lo relacionado con la educación en las escuelas radiofónicas. En este mismo sentido, Luis Zalamea afirma que el ministro de Educación del momento, Hernando Durán Dussán, recibió a miembros de la Iglesia y funcionarios del Estado, quienes le recomendaron tomar la decisión de suspender los vínculos contractuales con ACPO. ${ }^{212}$

La decisión de la Iglesia Católica colombiana de retirar el apoyo se sumó a las críticas que tenía de varios sectores sobre la labor propiamente educativa que venía desarrollando ACPO. Durante la década de los años 60 se realizaron varios estudios sobre el papel desempeñado por ACPO en el mundo rural y campesino. Uno de ellos fue Los medios de comunicación al servicio del desarrollo rural, dirigido por Stefan Musto, quien hizo un balance del trabajo que llevaba a cabo ACPO, y aunque destacó la importancia de la educación campesina por medio de las escuelas radiofónicas, concluyó que ese trabajo no provocaría ninguna revolución, sino que más bien llevaría a que se dieran frustraciones, pues solo corroboraba la pasividad del campesinado. “ACPO no produce actitudes políticas radicales, sino que cumple una función más bien conciliadora. La población rural, por su parte, no ve en ACPO ninguna fuerza revolucionaria, ni espera de ella cambios radicales". ${ }^{213}$

211. BERNAL, Hernando. Acción Cultural Popular, de la realidad a la utopía, Bogotá, Fundación Cultural Javeriana, 2005, p. 88

212. ZALAMEA, Luis. Un Quijote Visionario. Bogotá, Jorge Plazas S. Editor. 1994, p.241

213. MUSTO, Stefan. Los medios de comunicación al servicio del desarrollo rural, Bogotá, Editorial Andes, 1971, p. 150 
En la misma dirección se manifestaron Camilo Torres y Bertha Corredor, quienes hicieron un estudio denominado Las Escuelas Radiofónicas de Sutatenza. Allí expresaban el convencimiento de que la formación educacionalista de ACPO no estaba orientada a "reformar elementos de estructura", 214 una condición necesaria para conseguir cambios sociales. Es decir, había que llevar a cabo una educación "liberadora" como la llamaría posteriormente Paulo Freire. La crítica en estos estudios, entre otros, llevó a que ACPO quedara en la memoria de un sector del país como una institución de carácter conservador y retardatario.

Alarcón considera que el hecho de no tomar una posición contestataria, como lo pedían algunos sectores cercanos a la Teología de la liberación, llevó a que se diera una distancia entre lo que fue la institución con personería jurídica y el movimiento de base conformado por el campesinado. A la postre lo que sucedió fue el desmonte gradual de la organización local de las escuelas radiofónicas, organización que fue fundamental en los inicios del proyecto de Radio Sutatenza. El desmonte se dio por el temor de que esas organizaciones locales pasaran de ser un grupo radiofónico con reconocimiento, a grupos con fines políticos.

Aparte de los enfrentamientos con la misma Iglesia y con académicos, ACPO también tuvo oposición de un sector de los industriales en el país, quienes veían un riesgo en esta institución por su amplio cubrimiento nacional. Las grandes cadenas radiales "vieron en el incremento de la potencia de las emisoras una seria amenaza para la publicidad de sus emisoras". ${ }^{215}$ Así mismo, la exención de impuestos que tenía la institución por ser de la Iglesia y por realizar una obra social, llevó a que sectores como el de los impresores manifestaran su inconformismo, puesto que la posibilidad de competir así les era desfavorable. Tanto las emisoras como parte del sector editorial "consideraban que la cadena Sutatenza era competencia desleal, porque recibía ayuda del exterior, tenía contratos con el gobierno y además no pagaba impuestos. Y lo mismo se decía de la Editorial Andes y del periódico El Campesino". ${ }^{216}$

Debido a las fuertes confrontaciones con la Iglesia Católica, con determinados sectores industriales y con la crítica a la labor desarrollada en el campo de la educación, ACPO redujo significativamente sus ingresos y debió buscar recursos en

214. TORRES, Camilo y CORREDOR, Bertha. Las escuelas radiofónicas de Sutatenza, Bogotá, Centro de Investigaciones Sociales, 1961, p.54

215. BERNAL, Hernando. "Radio educativa para el desarrollo rural: El precursor Radio Sutatenza y Acción Cultural Popular, su influencia en la región", en Radio y Democracia en América Latina. IPAL - Instituto para América Latina, 1989, p. 118

216. ZALAMEA, Luis. Un Quijote Visionario. Bogotá, Jorge Plazas S. Editor. 1994, p.214 
procesos comerciales que lo llevaron a comprometer su patrimonio, a tal punto que se vio en la necesidad de empezar a vender progresivamente su maquinaria, sus instalaciones y a disminuir el personal, liquidando funcionarios y colaboradores. El Campesino, el 27 de noviembre, mostraba claramente la situación de ACPO, en un artículo titulado La realidad de la situación actual de Acción Cultural Popular: “ACPO ha llegado a una situación financiera muy delicada por las circunstancias del país, la suspensión de ayudas, el endeudamiento y la demora de soluciones reales". 217

A pesar de los continuos llamados para apoyar los servicios de ACPO a través del periódico El Campesino, las deudas adquiridas hicieron inviable el proyecto de ACPO y mostraron la incapacidad de adaptarse a los nuevos retos, llevándola al cierre definitivo ${ }^{218}$. Aunque la personería jurídica de ACPO aún existe, de su objetivo inicial de educar al campesino no queda nada. El periódico EL Campesino fue el último de los medios que utilizó ACPO para la educación. En su edición final prometió volver con un nuevo formato.

217. El Campesino, 27 de noviembre de 1988.

218. Durante el año de 1988, el periódico El Campesino publicó artículos donde mostraba las distintas tareas que realizaba ACPO y pedía apoyo para que continuaran, sin embargo, las ayudas en ese sentido no llegaron y cada uno de los beneficios recibidos por los campesinos fueron desapareciendo. 


\section{CONCLUSIONES}

Después de hacer el recorrido desde el origen de Radio Sutatenza, las condiciones que rodearon este proyecto, el papel de la Iglesia Católica y el posterior crecimiento y auge de una institución que llevó educación al campesinado colombiano como fue Acción Cultural Popular, podemos destacar varios aspectos que fueron importantes para que la idea de José Joaquín Salcedo tomara vuelo y se convirtiera en una de las experiencias de educación radial más importantes en América Latina.

Radio Sutatenza, la primera iniciativa que después hizo parte de Acción Cultural Popular, se originó en momentos en que la situación política, social y económica era realmente difícil para la población colombiana. En especial el sector campesino vivió en completa marginalidad y además amenazado por la continua violencia que azotó al país. Las condiciones de privilegio de la Iglesia en las pequeñas poblaciones colombianas, puesto que el cura párroco se veía como una de las autoridades, permitió que donde había vacíos por parte del Estado, estos fueran suplidos por la institución eclesiástica a través del sacerdote, quien cumplía un papel de liderazgo ante la comunidad.

Los altos índices de analfabetismo y la concentración de la mayoría de la población en el campo permitió que se creara el proyecto de educación radial. ACPO encarnó la posibilidad de salir del atraso, mejorar las condiciones en los diferentes ámbitos de la vida y entrar de alguna manera a la modernidad. El vínculo de la Iglesia con Acción Cultural Popular aportó para que el campesinado colaborara en el proyecto, bajo la tutela de los sacerdotes de cada población o municipio. 
Las decisiones tomadas por la Iglesia, en el sentido de que se empezara a hacer un trabajo con las comunidades en busca del desarrollo, pero también con la intención de evitar que las ideas del comunismo se propagaran en la población, generaron un ambiente propicio para que Radio Sutatenza y, tres años más tarde, Acción Cultural Popular, existieran. La Acción Social de la Iglesia fue el marco en donde se movió la idea de José Joaquín Salcedo, por eso recibió el apoyo de un amplio sector de la jerarquía eclesiástica y especialmente del obispo de Tunja, Crisanto Luque. El nombramiento de Luque como Cardenal Primado permitió también el crecimiento del proyecto de Acción Cultural Popular y la posibilidad de que Salcedo lograra relacionarse con diferentes personalidades de la política, con empresarios y con la misma jerarquía eclesiástica, incluyendo las máximas autoridades en Roma. Aunque este trabajo no pretende ser un análisis de la formación del clero en lo que tiene que ver con la Doctrina Social de la Iglesia, es evidente que el sacerdote José Joaquín Salcedo sí había recibido formación en este sentido durante su permanencia en el seminario de Tunja.

La constitución de Acción Cultural Popular como una obra de la Iglesia benefició a la institución, porque logró por medio de ese vínculo alcanzar recursos para su mantenimiento, pero así mismo cedió parte del control administrativo, pues representantes de la Iglesia integraban el Consejo Superior, quedando sometida a las disposiciones de la jerarquía eclesiástica.

Acción Cultural Popular fue una institución coherente y consecuente con la Acción Católica, pues la organización de la misma marcó nuevas relaciones de la Iglesia con los laicos; además utilizó sus medios para divulgar y llamar la atención sobre el tema social. En ese mismo sentido, ACPO fue un motivador de la organización de movimientos sociales para que trabajaran por el desarrollo y la mejora de las condiciones de vida de los hombres y mujeres. Esta institución logró dar el salto de un trabajo exclusivamente asistencialista a un trabajo en comunidad, donde la construcción del desarrollo estaba a cargo de los mismos campesinos.

Otra de las razones que benefició y permitió el crecimiento de Radio Sutatenza fue que se llegó a lugares remotos donde las condiciones topográficas eran difíciles. Veredas y municipios que estaban incomunicados accedieron a programas de alfabetización y formación educativa orientada, sin necesidad de que las personas tuvieran largos desplazamientos.

Acción Cultural Popular suplió la labor del Estado en materia educativa. En muchos lugares donde este no hizo presencia, Sutatenza llevó sus transmisiones 
educativas radiales, organizó grupos para Escuelas Radiofónicas, generó nuevas sociabilidades y acciones colectivas. La relación entre los campesinos estuvo mediada por la institución, visibilizándola como una entidad con criterios participativos y democráticos que promulgaba por el desarrollo de las comunidades campesinas.

Un buen número de intereses confluyeron en el proyecto de Radio Sutatenza. Ligado al proceso educativo que buscaba sacar del analfabetismo a la población, la radio fue un medio de evangelización del campesinado colombiano. Radio Sutatenza contó con la ayuda de los párrocos y estos contaron con la colaboración de la Radio y de ACPO en la divulgación de la información que los sacerdotes de los diferentes municipios consideraban esencial para desarrollar sus actividades religiosas. Entre tanto, ACPO utilizó la organización ya existente de la Iglesia para extender, a través de las parroquias, las actividades desarrolladas con las Escuelas Radiofónicas.

Sin duda, el rápido crecimiento de las Escuelas Radiofónicas a través de Radio Sutatenza originó la creación de Acción Cultural Popular y la consolidación del apoyo de la Iglesia. Los 7.000 estudiantes inscritos en los primeros dos años mostraron que el proyecto, en términos generales, había sido aceptado por los campesinos de la región. Los avances obtenidos en materia de estudiantes, de creación de nuevas Escuelas Radiofónicas y de nuevas estaciones de radio permitieron que la nueva institución se fundara y se convirtiera en la organización que logró consolidar un modelo de educación y una estrategia de medios de comunicación para tal fin.

Acción Cultural Popular, a partir de la adopción de la Educación Fundamental propuesta por la Unesco, creó la Educación Fundamental Integral como un modelo de educación para los campesinos mayores en Colombia a través de los medios de comunicación, especialmente la radio. ACPO no se quedó en su propuesta original del uso de la radio, sino que incluyó los textos, el periódico, las cartillas, las cartas y otros medios para la formación de los estudiantes. La importancia de ese trabajo es que se logró construir un sistema de medios donde cada uno cumplía un papel en el proceso de enseñanza.

La vinculación de diversos temas en el proyecto de Escuelas Radiales, como la escritura, la lectura y las matemáticas, aportaron ampliamente en el desarrollo de los campesinos, pero también en la formación de un ciudadano diferente, conocedor de su entorno y con condiciones más eficientes para exigir sus derechos, cumplir sus deberes y trabajar colectivamente por el bienestar de la comunidad. 
La participación como una condición para el desarrollo es uno de los aprendizajes que deja este proyecto. Acción Cultural Popular reforzó la necesidad de trabajar colectivamente y de participar en lo relacionado con su entorno. Un nuevo esquema de relaciones para el futuro planteó ACPO con su trabajo. Con la organización de los campesinos se reconfiguraban los mapas de poder en las diferentes regiones del país. Pertenecer y hacer parte de las Escuelas Radiofónicas era pertenecer a un grupo que tomaba decisiones frente a su desarrollo.

La combinación o relación de los medios de comunicación interpersonal y de los medios masivos de comunicación con todo su poder, enlazó al campesino, al Estado y a la Iglesia en una red que impulsó nuevas formas de ciudadanía y motivó la participación.

La creación de Radio Sutatenza y Acción Cultural fue una apuesta política, social y comunicativa con el objetivo de sacar al campesinado de la marginalidad y ubicarlo en un mundo moderno, pero con mejores condiciones para vivir dignamente. Una de esas apuestas tuvo que ver con el trabajo desarrollado durante varios años a favor de una reforma agraria que beneficiara al campesino. Este trabajo mostró cómo los medios de comunicación, la organización de ACPO y el funcionamiento de varias organizaciones campesinas, creadas para buscar el mejoramiento de las condiciones de vida de esta población se unieron en una causa común y lograron ejecutar acciones conjuntas.

Por último, uno de los aportes más importantes que dejó el proyecto de Acción Cultural Popular fue sin duda el de establecer unos fundamentos teóricos y metodologías de trabajo con la activa utilización de los medios de comunicación. ACPO, como pionera de la radio educativa, dejó una huella profunda. Su experiencia fue llevada a varios países para ser implementada como un modelo para el desarrollo de los pueblos, especialmente latinoamericanos. A partir de Radio Sutatenza han crecido muchas emisoras que utilizaron diversas estrategias, no solo para llevar algún tipo de formación académica a las comunidades sino para generar procesos colectivos.

El proyecto de Radio Sutatenza y de Acción Cultural Popular aún está lleno de muchos interrogantes que sin duda serán motivo de análisis en otras investigaciones posteriores sobre el tema. Vale la pena aclarar que hasta hoy son muy limitadas las investigaciones relacionadas con los medios de comunicación educativos, participativos o para el desarrollo. Algunos trabajos han indagado sobre la relación de los medios masivos de comunicación y el poder, o sobre 
el periodismo y los medios, pero aún en el campo de interés de este libro falta mucho por hacer.

Serán también motivo de investigaciones futuras el verdadero papel que cumplió Radio Sutatenza en la formación de líderes y en los relevos de cuadros políticos en los municipios, o en las causas que llevaron a que un proyecto de amplias proporciones fuera perdiendo vigencia hasta vender sus activos y cerrar. De igual manera, aún no se ha realizado un trabajo a profundidad que muestre cuáles fueron las fricciones existentes en el seno de la Iglesia colombiana por la realización del proyecto del padre José Joaquín Salcedo. Aún quedan muchas dudas frente a un proceso tan amplio como el de Radio Sutatenza y Acción Cultural Popular, pero eso mismo motiva a seguir trabajando en un tema poco explorado históricamente: los medios de comunicación, la educación y el desarrollo.

Para finalizar, es necesario valorar la encomiable labor de la señorita Hilaria Gutiérrez en Sutatenza, quien durante más de 40 años cuidó lo mejor posible una parte de los archivos de Acción Cultural Popular. Para ella, una campesina del municipio de Gramalote (Norte de Santander), educada por medio de las Escuelas Radiofónicas, lo que inicialmente fue un trabajo, con el pasar del tiempo se le convirtió en una pasión: cuidar el legado del padre Salcedo. Hoy esos archivos están en manos de la biblioteca Luis Ángel Arango; seguramente dentro de algunos meses con la respectiva organización, sistematización y catalogación, se podrán hacer trabajos con mayor rigor.

Radio Sutatenza dejó de existir hace 20 años, pero hoy sigue siendo el principal referente de inspiración de la radio educativa y participativa en varios países del mundo. 


\section{ANEXOS}

\section{Evolución de las parroquias con escuelas radiofónicas por año}

\begin{tabular}{|c|c|c|c|}
\hline Año & Cantidad de parroquias & Escuelas Radiofónicas & Alumnos Radiofónicos \\
\hline 1948 & 1 & 3 & 45 \\
\hline 1949 & 14 & 103 & 1.339 \\
\hline 1950 & 22 & 303 & 3.636 \\
\hline 1951 & 46 & 430 & 5.436 \\
\hline 1952 & 111 & 904 & 10.848 \\
\hline 1953 & 318 & 1.804 & 15.648 \\
\hline 1954 & 412 & 6.492 & 20.409 \\
\hline 1955 & 553 & 7.512 & 42.319 \\
\hline 1956 & 602 & 12.221 & 109.989 \\
\hline 1957 & 740 & 15.221 & 136.385 \\
\hline 1958 & 792 & 17.162 & 145.248 \\
\hline 1959 & 805 & 14.490 & 112.576 \\
\hline 1960 & 861 & 14.504 & 114.186 \\
\hline 1961 & 892 & 15.924 & 129.681 \\
\hline 1962 & 899 & 22.145 & 215.309 \\
\hline 1963 & 905 & 24.059 & 227.735 \\
\hline 1964 & 911 & 28.535 & 240.915 \\
\hline 1965 & 916 & 26.101 & 238.563 \\
\hline 1966 & 909 & 22.129 & 200.161 \\
\hline 1967 & 849 & 22.781 & 179.685 \\
\hline 1968 & 1054 & 21.094 & 127.072 \\
\hline
\end{tabular}

Fuente: Musto, p.94. Basado en ACPO, Informe anual 1967, p.47y material del Departamento de estadística para el año 1968. 
Servicios prestados por ACPO entre 1947 a 1988

\begin{tabular}{|c|c|c|c|c|}
\hline Servicios básicos & Área Educativa & $\begin{array}{l}\text { Cantidad } \\
\text { Servicios }\end{array}$ & $\begin{array}{l}\text { Tiempo } \\
\text { Año Servicios }\end{array}$ & Municipios \\
\hline Cartillas & $\begin{array}{l}\text { Básica } \\
\text { Educación Fundamental } \\
\text { Integral } 5 \text { títulos }\end{array}$ & 6.404 .902 & 34 & 950 \\
\hline Libros & 99 títulos - 10 colecciones & 4.393 .961 & 24 & 870 \\
\hline $\begin{array}{l}\text { Periódico } \\
\text { El Campesino }\end{array}$ & $\begin{array}{l}\text { Información, recreación, } \\
\text { enseñanza. }\end{array}$ & $\begin{array}{l}74.262 .859 \\
1.542 \text { edic. }\end{array}$ & 40 & 1.000 \\
\hline Becas & $\begin{array}{l}\text { Formación de dirigentes } \\
\text { campesinos }\end{array}$ & 22.250 & 34 & 968 \\
\hline Líderes & Promoción capacitación rural & 3.896 & 22 & 687 \\
\hline Cursos extensión & $\begin{array}{l}\text { Estudio de soluciones } \\
\text { a problemas locales }\end{array}$ & 4.350 & 38 & 568 \\
\hline Radio Sutatenza & $\begin{array}{l}\text { Instrucción, } \\
\text { recreación, noticias, } \\
\text { primaria, bachillerato. }\end{array}$ & 1.485 .000 & 40 & 770 \\
\hline Emisoras locales & Cursos radiales & 68 emisoras & 10 & 60 \\
\hline Disco estudio & $\begin{array}{l}\text { Alfabetización: } \\
\text { discos cartillas. }\end{array}$ & $\begin{array}{l}690.000 \\
170.000\end{array}$ & 10 & 687 \\
\hline
\end{tabular}

Fuente: El Campesino, 30 de octubre de 1988 p. 3

\section{Dirigentes campesinos formados en los Institutos Campesinos}

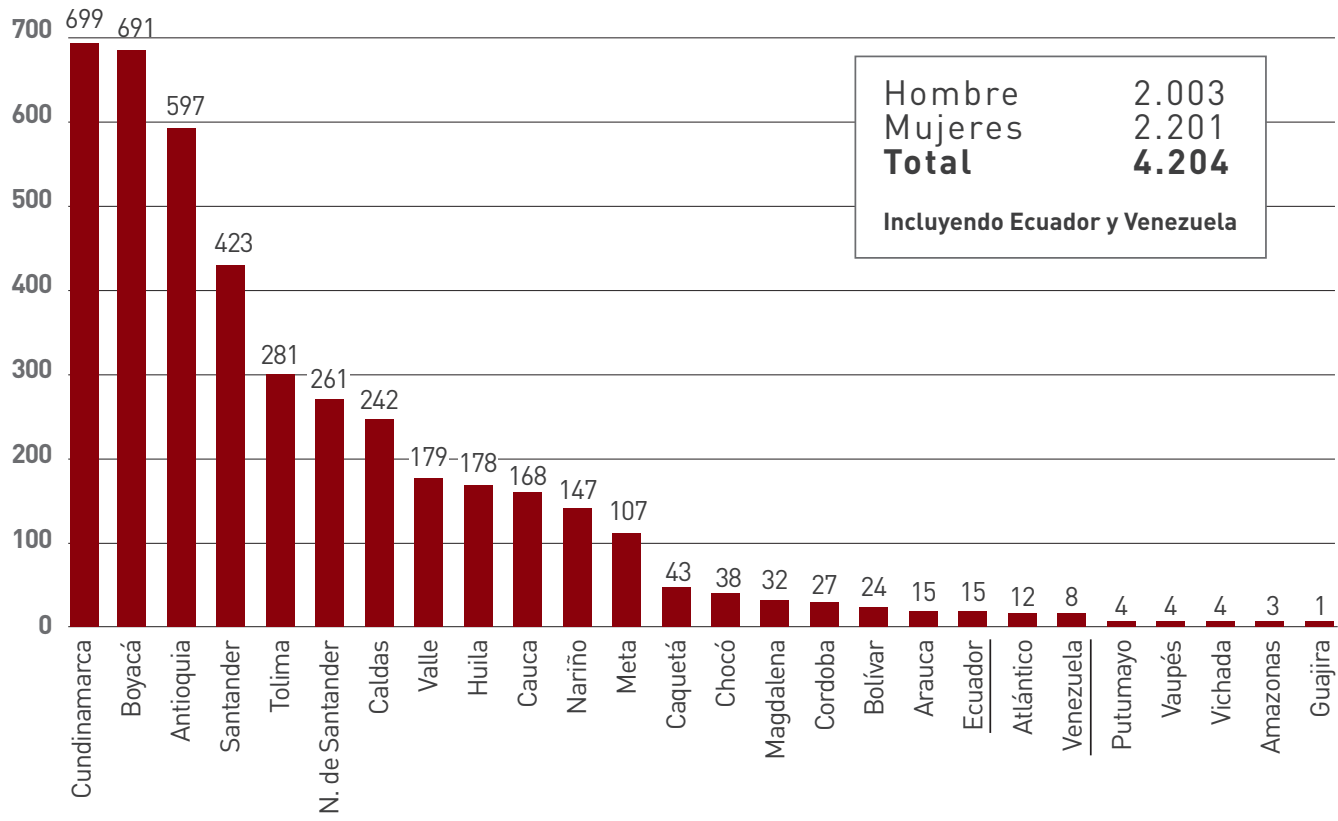

Fuente: Informe de Acción Cultural Popular a la Venerable Conferencia Episcopal 1961 a 1964. 


\section{Radio de influencia de las emisiones de onda corta}

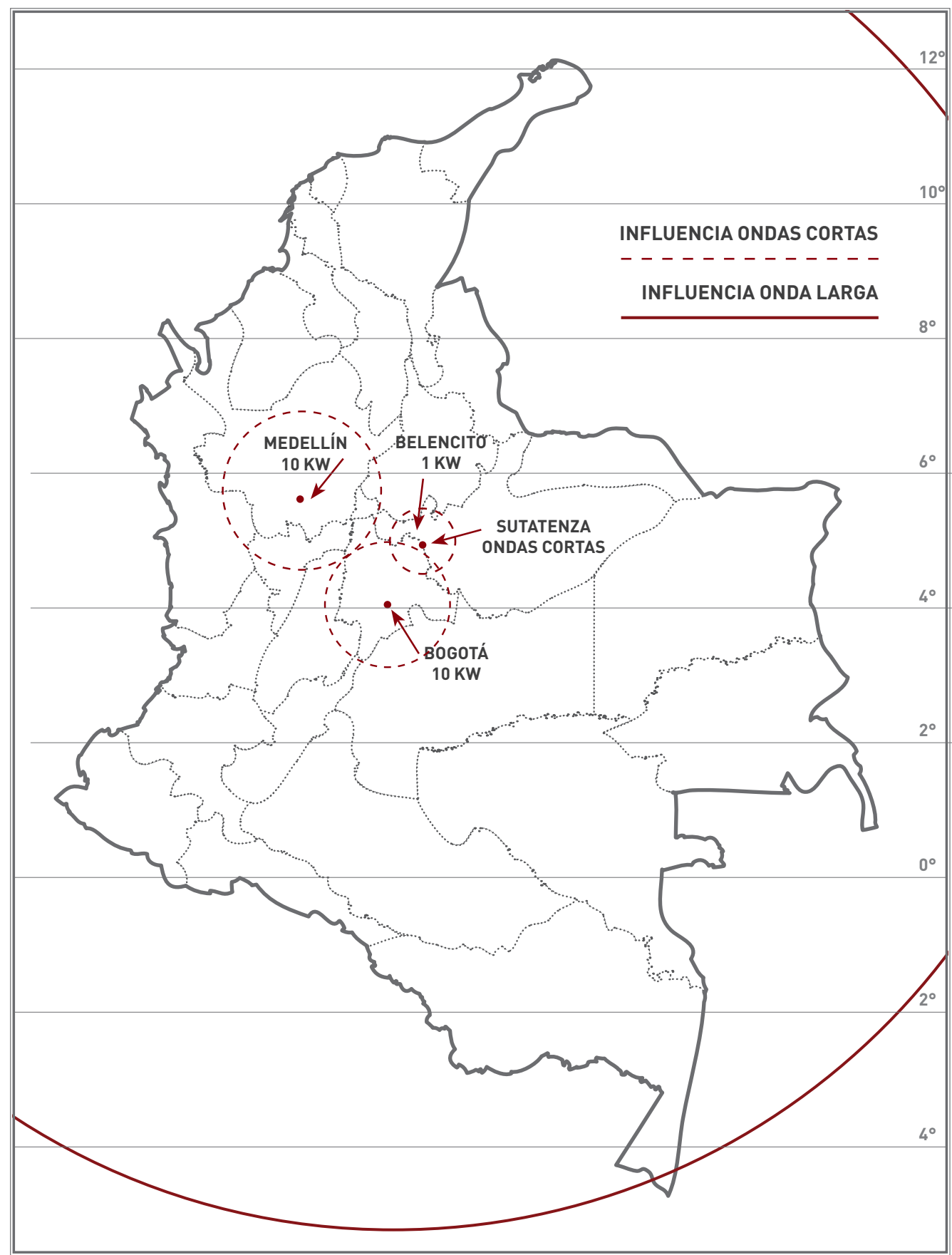

Fuente: Informe de Acción Cultural Popular a la Venerable Conferencia Episcopal 1961 a 1964 


\section{Entrega de equipos General Electric}

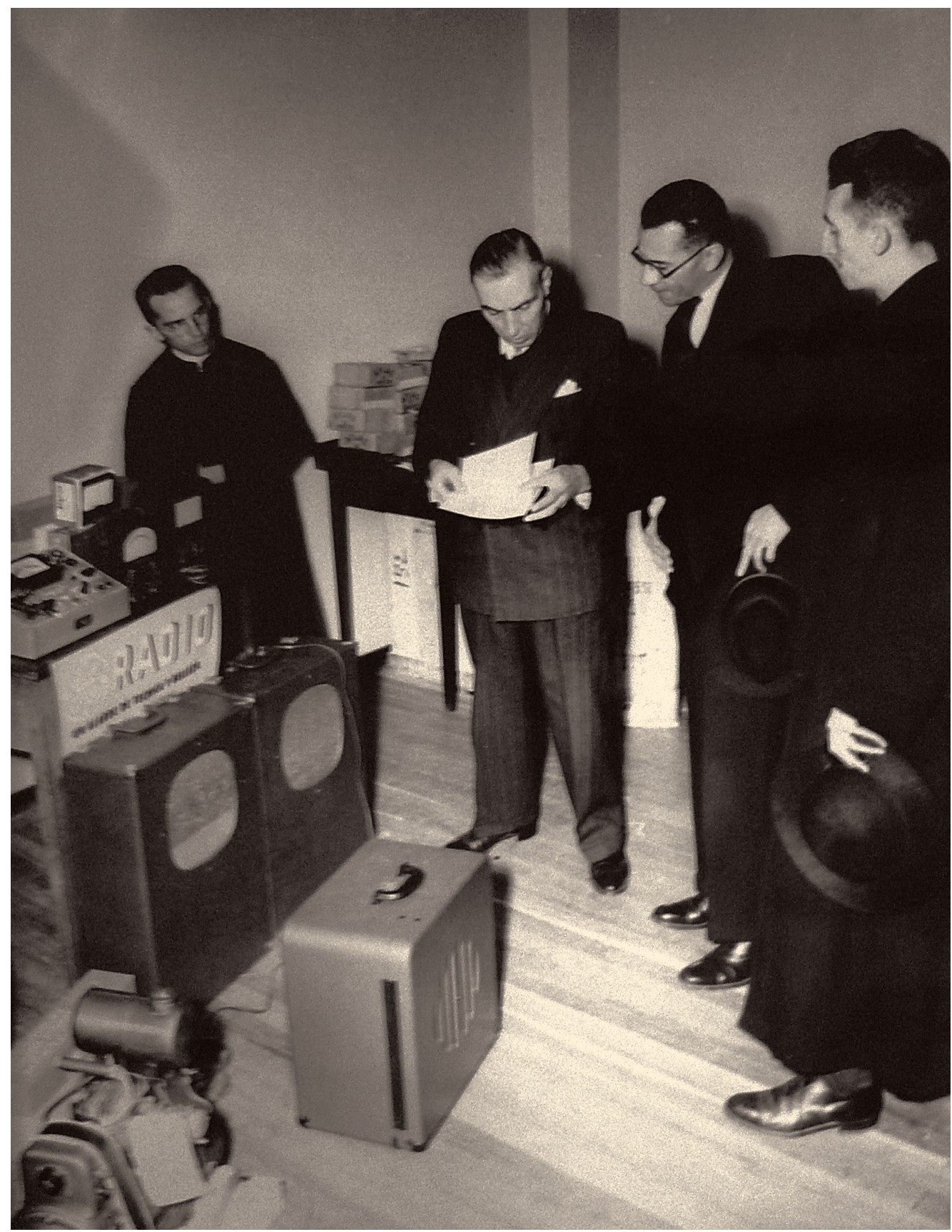

Fuente: Archivo de Acción Cultural Popular en Sutatenza, Boyacá 
Cabina de grabación de Radio Sutatenza

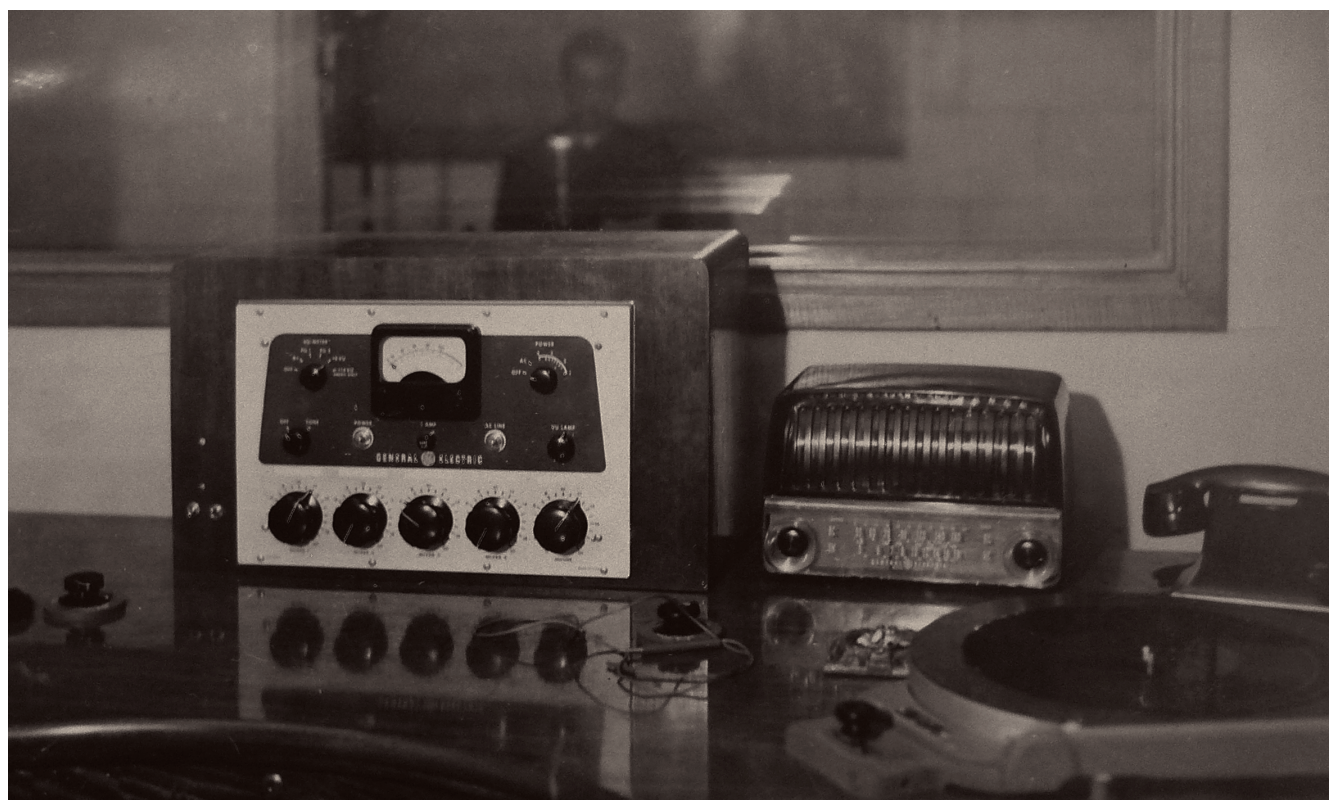

Fuente: Archivo de Acción Cultural Popular en Sutatenza, Boyacá

Clases a los soldados pertenecientes a las Escuelas Radiofónicas

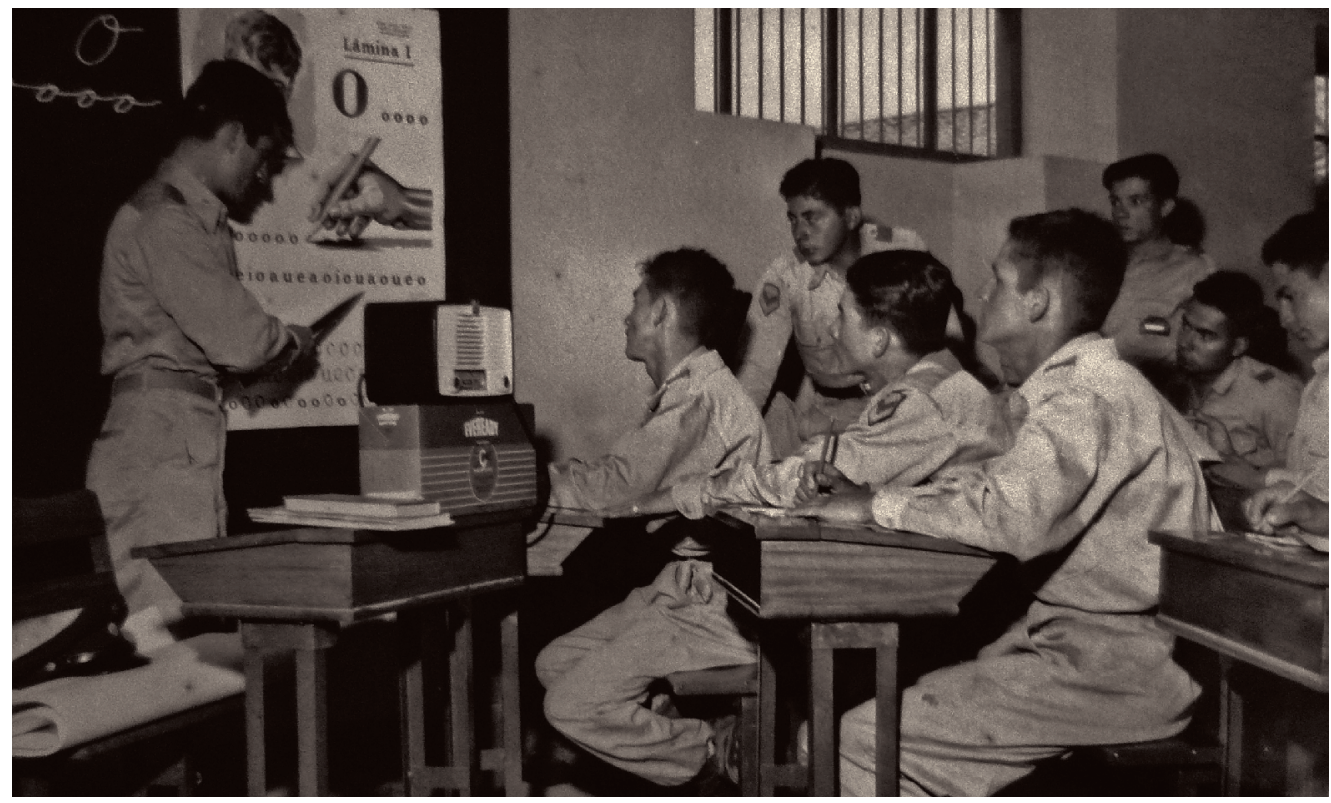

Fuente: Archivo de Acción Cultural Popular en Sutatenza, Boyacá 
Campesinos estudiantes de las Escuelas Radiofónicas en las veredas de Boyacá

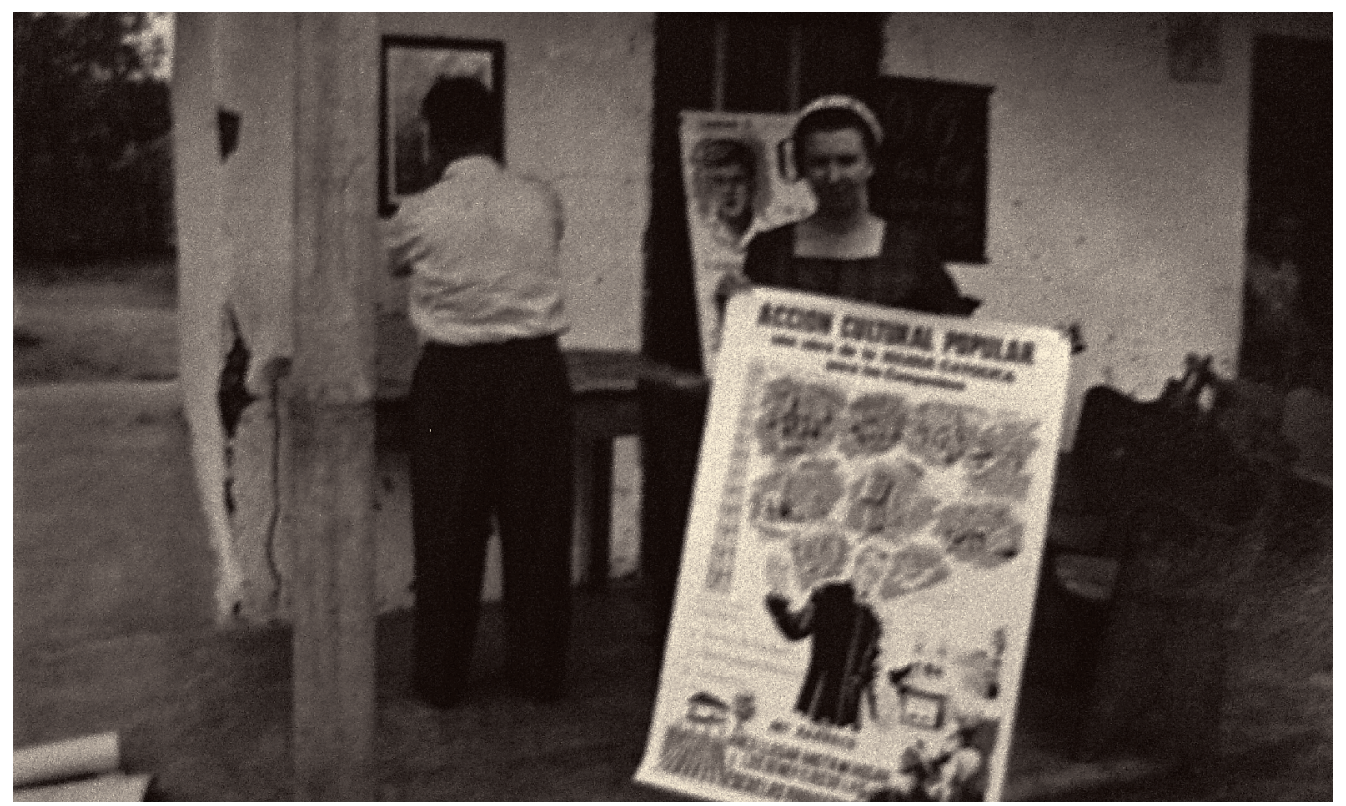

Fuente: Archivo de Acción Cultural Popular en Sutatenza, Boyacá

\section{Estudio de Radio Sutatenza en Bogotá}

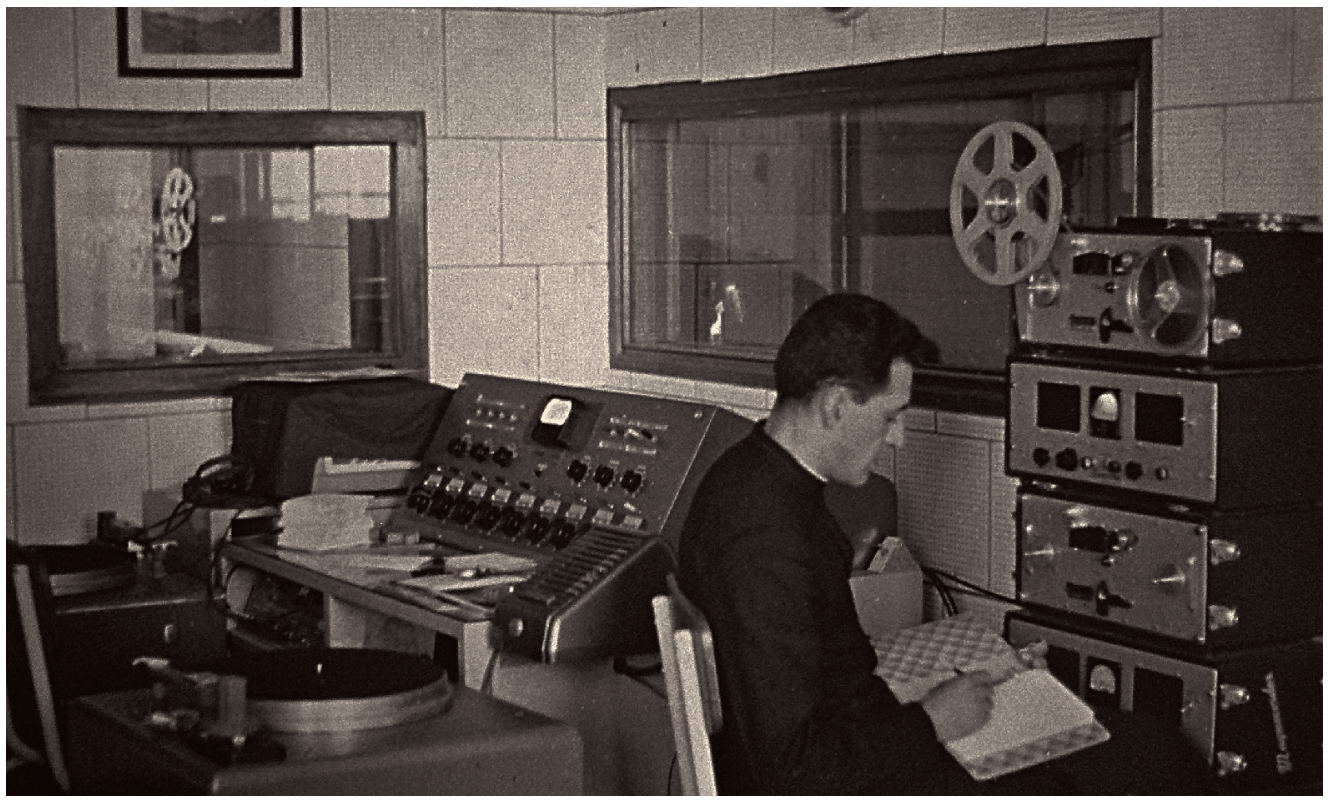

Fuente: Archivo de Acción Cultural Popular en Sutatenza, Boyacá 


\section{Primeras radios utilizadas por los campesinos}

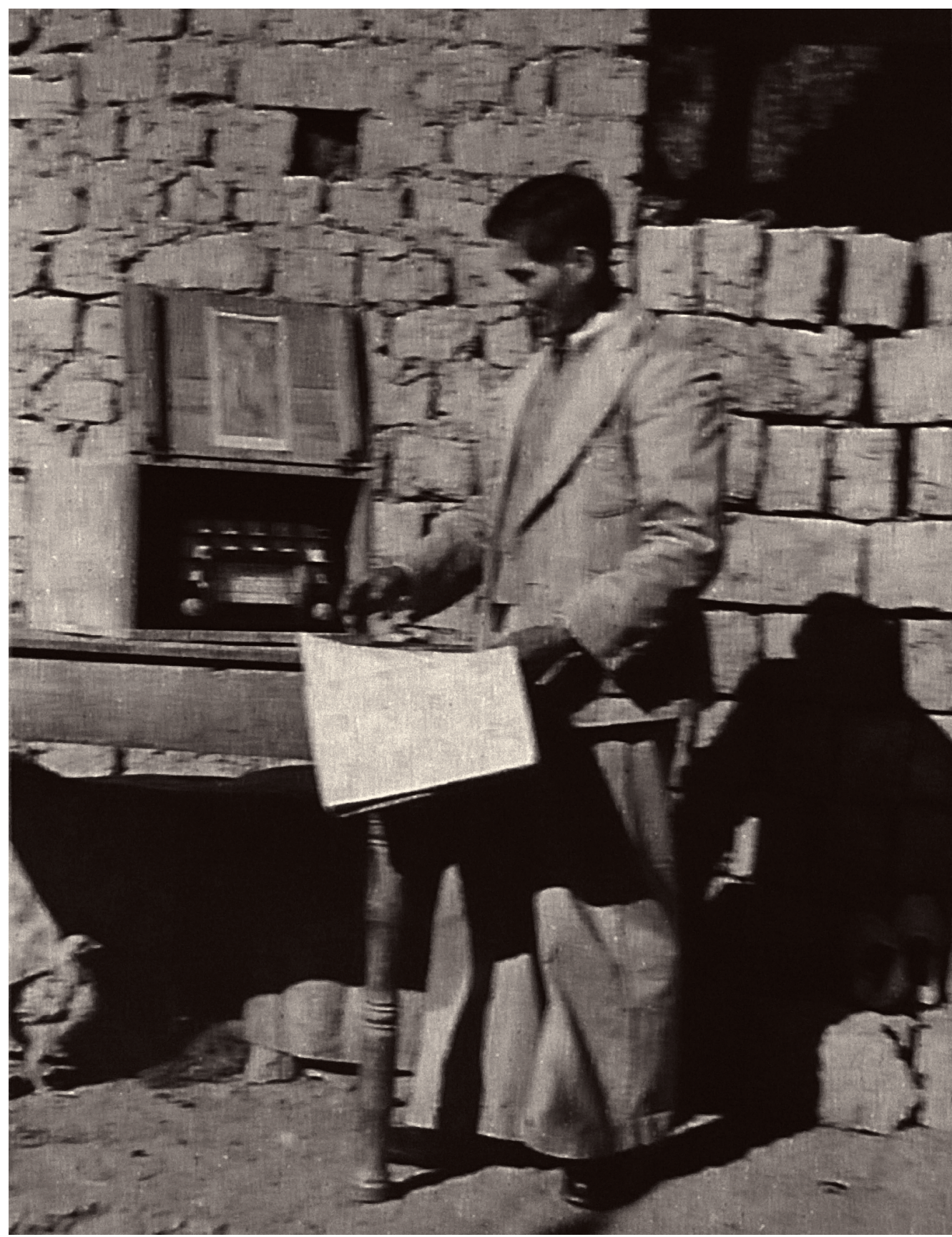

Fuente: Archivo de Acción Cultural Popular en Sutatenza, Boyacá 


\section{B I B L I O G R A F Í A}

\section{Fuentes primarias}

Acción Cultural Popular. (1960). Informe a la venerable Conferencia Episcopal, 1959 - 1960.

Acción Cultural Popular. (1964). Informe a la venerable Conferencia Episcopal, 1961 - 1964.

Acción Cultural Popular. (1967). Informe a la venerable Conferencia Episcopal.

Acción Cultural Popular. (1956). Informe Acción Cultural Popular.

Acción Cultural Popular. (1955). Informe al eminentísimo señor Cardenal y a los excelenísimos prelados de Colombia reunidos en la Conferencia Episcopal.

Acción Cultural Popular. (1987). Cartilla Comunidad Cristiana, Noción Espiritualidad. Bogotá:

Editorial Andes.

Acción Cultural Popular. (1987). Cartilla Cuentas Claras, Noción Número. Bogotá: Editorial Presencia.

Acción Cultural Popular. (1985). Cartilla estudiamos letras y números, Cartilla Básica de Educación Fundamental Integral. Bogotá: Editorial Andes.

Acción Cultural Popular. (1987). Cartilla hablemos bien, Noción alfabeto. Bogotá: Editorial Andes.

Acción Cultural Popular. (1987). Cartilla Nuestro Bienestar, Noción Salud. Bogotá: Editorial Presencia.

Acción Cultural Popular. (1987). Cartilla Suelo Productivo, Noción de Economía y Trabajo. Bogotá: Editorial Presencia.

Acción Cultural Popular. (1968). Correspondencia. (Cartas de estudiantes y respuestas), (1965 1966 - 1968).

Acción Cultural Popular. (1958). Informe a la venerable Conferencia Episcopal, 1957 - 1958. 
Acción Cultural Popular. (1969). Radio Sutatenza, Programación. Bogotá: Editorial Andes.

El CAMPesino, 1958 - 1989

EL TIEMPO, 1947 - 1949.

Houtart, Francisco, y Pérez, Gustavo. (1960). Acción Cultural Popular. Sus principios y medios de acción, consideraciones teológicas y sociológicas. Bogotá: ACPO.

REVISTA JAVERIANA, 1947 - 1948 - 1949.

Revista Presencia. (1960). No. 99.

Revista Semana. (1959). Bogotá, 24 de febrero.

\section{Fuentes secundarias}

ARIAS, Ricardo. (2007). Los Leopardos, una historia intelectual de los años 1920, Bogota: Uniandes.

ARIAS, Ricardo. (2003). El Episcopado Colombiano: Intransigencia y Laicidad 1850-2000. Bogotá: Ed. Uniandes.

BERNAL, Hernando. (2005). ACPO - Radio Sutatenza: de la realidad a la utopía. Bogotá: Ed. Fundación Cultural Javeriana, 2005.

BERNAL, Hernando. (1978). Educación Fundamental Integral. Teoría y Aplicación en el caso de ACPO. Bogotá: Editorial Andes.

BERNAL, Hernando. (1971). Educación Fundamental Integral y Medios de Comunicación Social. Bogotá: Editorial Andes.

BIDEgAín, Ana. (1985). Iglesia, Pueblo y Política: un estudio de conflictos de intereses 1930 - 1955. Bogotá: Pontificia universidad Javeriana.

DE LANNOY, Juan, y PÉREZ, Gustavo (1961). Estructuras demográficas y sociales en Colombia. Bogotá: Centro de Investigaciones Sociales.

DE ROUX, Rodolfo. (1981). “La Iglesia Colombiana en el período 1930 - 1962” En: Historia general de la Iglesia Católica en América Latina. tomo. VII. CEHILA, Salamanca: Ediciones Sígueme.

FALS, Orlando. (2006). El hombre y la tierra en Boyacá. 4ta. Ed. Tunja: Uptc.

GONZÁLEZ, Fernán. (1997). Para leer la política. Bogotá: Cinep, tomo 1.

GONZÁLEZ, Fernán. (1977). Partidos políticos y poder eclesiástico, Bogotá: Cinep.

GONZÁLEZ, Fernán. Poderes Enfrentados, Iglesia y Estado en Colombia, Bogota: Cinep, 1997.

GUERRERO, Javier. Los años del olvido. Bogotá: Tercer Mundo Editores, 1991.

GUMUCIO, Alfonso. (2001). Haciendo Olas. Historias de comunicación participativa para el cambio social. La Paz: Plural Editores.

HOUTART, Francisco. (1959). La mentalidad religiosa y su evolución en las ciudades. Bogotá:

Universidad Nacional de Colombia.

JIMÉNEZ, Gustavo. (1967). Sacerdote y cambio social. Bogotá: Tercer Mundo.

MUSTO, Stefan y colaboradores. (1971). Los medios de comunicación Social al servicio del 
desarrollo rural. Análisis de la eficiencia de Acción Cultural popular. Radio Sutatenza (Colombia) Prólogo y Glosas de Acción Cultural Popular ACPO. Bogotá: Editorial Andes.

PÉREZ, Gustavo. (1959). El Campesino Colombiano: un problema de estructura. Bogotá: Editorial Iqueima.

Radio Sutatenza, 60 años de un sueño. Bogotá, Radio Nacional de Colombia, 2008.

SALCEDO, José. (1974). Diálogos con los líderes. Bogotá: Editorial Andes.

SALCEDO, José. (1994). Sin producir riqueza no se acaba con la pobreza. Bogotá: Publicaciones Violeta.

SILVA, Renán. (2005). República liberal, intelectuales y cultura popular. Medellín: La Carreta Histórica.

TELADO, Ana. (Ed.) (1989). Radio y Democracia en América Latina. Lima: IPAL Instituto para América Latina.

TÉLLEZ, Hernando. (1974). Cincuenta años de radiodifusión en Colombia. Bogotá: Editorial Bedout S. A.

TORRES, Camilo, y CORREDOR, Berta. (1961). Las escuelas radiofónicas de Sutatenza - Colombia. Bogotá: Centro de Investigaciones Sociales.

ZALAMEA, Luis. (1994). El Quijote Visionario. Bogotá: Ed. Jorge Plazas 
